\title{
The Spectrum of Singly Ionized Atomic Iodine (I II)
}

\author{
William C. Martin and Charles H. Corliss
}

\author{
(July 11, 1960)
}

\begin{abstract}
The III spectrum has been excited in electrodeless lamps and photographed from $655 \mathrm{~A}$ to $11084 \mathrm{~A}$. Wavelengths and estimated intensities are given for almost 2,400 lines. A revision and extension of the earlier analyses of this spectrum has increased the number of known even levels from 43 to 124 , and the number of odd levels from 55 to 190 . New $g_{J}$ factors are given for 46 levels, and the previous designations of 40 levels are changed. Improved measurements in the vacuum ultraviolet region give a correction of $7.4 \mathrm{~cm}^{-1}$ to be subtracted from the values listed in Atomic Energy Levels, Vol. 3 (1958), for all levels above the ground configuration. The approximately 1,800 classified lines now include all of the strongest lines. The ${ }^{1} \mathrm{~S}_{0}$ of the ground configuration $5 s^{2} 5 p^{4}$ has been found, and this configuration has been fitted to intermediate coupling theory. Magnetic dipole transitions between levels of the ground configuration, ${ }^{3} \mathrm{P}_{2}-{ }^{1} \mathrm{D}_{2}(7282 \mathrm{~A})$ and ${ }^{3} \mathrm{P}_{1}-{ }^{1} \mathrm{~S}_{0}(4460 \mathrm{~A})$, have been observed and their nature confirmed by the Zeeman effect. The line $5 p^{4}{ }^{3} \mathrm{P}_{2}-{ }^{1} \mathrm{D}_{2}$ shows hyperfine structure which is in approximate agreement with a theoretical calculation of the expected structure. New levels have been found for almost all higher configurations. All previously known series have been extended and new ones found. From one of the new series, $5 p^{3}\left({ }^{4} \mathrm{~S}^{\circ}\right) 5-12 g^{5} \mathrm{G}_{6}^{\circ}$, the principal ionization energy for I II $\left(154304 \pm 1 \mathrm{~cm}^{-1}\right)$ has been derived. The results of the analysis are compared with theoretical expectations in a number of eases.
\end{abstract}

\section{Introduction}

One of the purposes served by the systematic compilation of Atomic Energy Levels [1] ${ }^{1}$ being carried out at NBS is to point out inadequacies in the existing analyses of atomic spectra. The work reported here was partly stimulated by the need revealed under the scrutiny of this program for new observations and analyses of the iodine and bromine spectra. Another reason for our interest in these particular spectra is that iodine and bromine are the halogens most frequently used in the electrodeless metal-halide lamps [2] developed in this laboratory. These lamps have proved to be excellent sources of metallic spectra. We have also found that the electrodeless lamp gives a strong pure iodine spectrum when used as described below. Since the spectrum of the halogen contained in a metal-halide lamp appears along with that of the metal, the user of these lamps needs a complete and accurate knowledge of the iodine and bromine spectra. The present or recently completed work of this laboratory includes new descriptions and analyses of the first and second spectra of both iodine and bromine.

The spectrum of singly ionized iodine has previously been analyzed by P. Lacroute [3] and by K. Murakawa [4]. The results of their work, together with some preliminary revisions and extensions made possible by the new observations reported here, are given in Atomic Energy Levels (AEL), Vol. III. Our observations are superior to earlier measurements in being more complete (particularly in the vacuum ultraviolet region) and more accurate. Also important is our ability to distinguish better between the first and second spectrum.

${ }_{1}^{1}$ Figures in brackets indicate the literature references on page 452 .

\section{Observations}

The sources for the spectrum in the region 2000 to $11000 \mathrm{~A}$ were electrodeless lamps made from 5-mm i.d. quartz or vycor tubing about $10 \mathrm{~cm}$ long with a hemispherical window blown at one end and a side arm attached. These were thoroughly evacuated and outgassed. and a few crystals of iodine distilled into them before sealing off. The discharge was excited with the Raytheon Microtherm microwave generator which operates at 2,450 Mc with 125 -w output. We made all observations with the lamp end-on except when Zeeman patterns were photographed. The spectra were dispersed with gratings having $30,000,15,000$, and 7,500 lines per inch, each mounted in parallel light to give stigmatic images. From 2000 to $2400 \mathrm{~A}$ the plate factor was $2.2 \mathrm{~A} / \mathrm{mm}$; from 2400 to $4400 \mathrm{~A}, 1.0 \mathrm{~A} / \mathrm{mm}$; from 4400 to 9000 $\mathrm{A}, 2.0 \mathrm{~A} / \mathrm{mm}$; from 9000 to $10400 \mathrm{~A}, 5 \mathrm{~A} / \mathrm{mm}$; and from 10400 to $11100 \mathrm{~A}, 10 \mathrm{~A} / \mathrm{mm}$.

Most of the wavelength values given in table 10.1, the line list (sec. 10, Appendix), are averages of measurements made on more than one plate. The intensities are visual estimates, meaningful only for lines in the same spectral region. Almost all of the stronger I II lines show hyperfine structure under high resolution. Where the structures were completely or partially resolved, we measured the individual components. With few exceptions, however, only the weighted average of the component wavelengths is given in table 10.1. The intensity given for such a line is the sum of the estimated component intensities. Murakawa [4, 5] has observed interferometrically the hyperfine structure of a number of I II lines.

Because of the line-broadening due to structure, the wavelength measurements here are not as 
accurate as one might wish. However, the disagreement between the observed wavenumbers and the corresponding differences of the "best" values for the relevant energy levels is usually less than 0.1 $\mathrm{cm}^{-1}$ for lines in the region above $2500 \mathrm{~A}$.

When the iodine in the side arm of the discharge tube was kept at $30^{\circ} \mathrm{C}$, corresponding to about $1-\mathrm{mm}$ vapor pressure, most lines of the first spectrum appeared in the discharge, with only the strongest lines of III showing. As the temperature was lowered, the second spectrum increased in intensity until it became stronger than the first spectrum. The discharge ceased at about $-28^{\circ} \mathrm{C}$, when the pressure was between $10^{-2}$ and $10^{-3} \mathrm{~mm} \mathrm{Hg}$. We were able to assign most lines to the proper spectrum by including on every spectrogram these four spectra in juxtaposition: iron arc, "high" temperature $\left(20\right.$ to $30^{\circ}$ C) iodine spectrum, "low" temperature $\left(\approx-25{ }^{\circ} \mathrm{C}\right)$ iodine spectrum, and iron are.

This procedure leaves the origin of some of the weaker lines doubtful for two reasons: the weaker I I lines appear in the low pressure discharge but not at the higher pressure, while the I III spectrum is also faintly excited at low pressures. The latter observation was surprising, but a comparison of the intensities in our list with those given by observers $[3,6,7]$ of rather high energy discharges in iodine vapor leaves no doubt that our low pressure source gives the strongest IIII lines weakly. However, we believe that by this comparison we have eliminated the I III lines from the list. Those unclassified lines above $5000 \mathrm{~A}$ which have intensity less than $50 \mathrm{com}-$ prise practically all the remaining lines of doubtful origin. These lines may belong to either the first or second spectrum.

We have observed the Zeeman effect in a field of about 37000 gauss for most of the strong I II lines in the region 4000 to $9000 \mathrm{~A}$. The technique is described by Kiess and Corliss [8]. Zeeman patterns obtained from these observations are given in table 10.2 .

The spectrum was dispersed in the region 584 to $2000 \mathrm{~A}$ by a $2-\mathrm{m}$ radius concave grating of 30,000 lines per inch ruled directly on pyrex. This grating, which was ruled under the direction of R. W. Wood at Johns Hopkins, was originally mounted in a vacuum spectrograph by K. T. Compton and J. C. Boyce [9]. W. R. Bozman has designed a new housing for the grating and plateholder of the old instrument. It consists primarily of a cylindrical section of steel pipe $75 \mathrm{~cm}$ in diameter and $210 \mathrm{~cm}$ long fitted with aluminum end covers which are sealed to the main tube by means of O-ring flanges. The slit is contained in a side tube. The optical arrangement is essentially that of Compton and Boyce except that the angle of incidence has been decreased slightly to about $13.1^{\circ}$ to give the normal spectrum at $1920 \mathrm{~A}$. The plate factor is $4.26 \mathrm{~A} / \mathrm{mm}$ at the normal and the plateholder covers the range 0 to $2570 \mathrm{~A}$ in the first order. The height of the plateholder is adjustable externally so that several different exposures may be made on one plate.
We mounted a glass discharge tube end-on to the slit housing by means of an O-ring seal. After a side tube was charged with iodine, the lamp was evacuated and excited as described above. The slit of the evacuated spectrograph was open directly to the light from the discharge. We used Eastman SWR plates below $1400 \mathrm{~A}$ and Ilford Q-2 plates in the region above $1400 \mathrm{~A}$. The first order spectrum was measured from 500 to $2500 \mathrm{~A}$; and from 800 to $1200 \mathrm{~A}$ all but the weaker lines were measured in the second order. Most lines were measured three or four times. Calculated wavelengths of lines in the I I spectrum [8] served as the principal standards in the region 1200 to $2060 \mathrm{~A}$. Lines of helium, oxygen, nitrogen, and carbon also were used for standards. Some bands, due principally to carbon monoxide, appeared on the spectrograms.

Lines of bromine were found on all our vacuum region plates. The existing measurements of the bromine spectra were not complete enough for the elimination of these lines from our list. We have excited, photographed, and measured the Bri and $\mathrm{Br}$ II spectra in the vacuum ultraviolet. Analyses of these spectra are underway in this laboratory and will be reported later.

We have obtained averaged values of the I II $5 p^{4}$ ground-configuration energy levels relative to the lower odd levels by using the measurements of lines from 1100 to $1300 \mathrm{~A}$. These odd levels are known relative to each other with good accuracy from measurements above $2000 \mathrm{~A}$. We then calculated the wavelengths of all singly-classified lines observed in the vacuum ultraviolet. Since these wavelengths are on a consistent scale and the I II spectrum is fairly rich below the I I limit $(1200 \mathrm{~A})$, we have thought it worthwhile to give these calculated wavelengths in table 10.1. Together with the I I wavelengths above 1200 A they comprise a consistent set of wavelengths over a large part of the vacuum region and should prove useful in reducing low- and medium-dispersion plates obtained with metal iodide lamp sources. An estimated uncertainty in the calculated I II wavelengths of $\pm 0.005 \mathrm{~A}$ at $1100 \mathrm{~A}$ gives $\pm 0.002 \mathrm{~A}$ at $665 \mathrm{~A}$, where the first calculated lines occur. The new I II wavelengths in the vacuum ultraviolet region yield, for the energy levels above those of the ground configuration, values which are $7.4 \mathrm{~cm}^{-1}$ less than the correspondirg values given in AEL.

\section{Ground Configuration}

The $5 s^{2} 5 p^{4}$ ground configuration of singly ionized iodine gives the Russell-Saunders terms ${ }^{3} \mathrm{P},{ }^{1} \mathrm{D}$, and ${ }^{1} \mathrm{~S}$, as shown in table 1 . The energy levels for these terms are listed in table 10.3, which includes all presently known even levels for I II. Lacroute's values for ${ }^{3} \mathrm{P}_{1},{ }^{3} \mathrm{P}_{0}$, and ${ }^{1} \mathrm{D}_{2}$ are about $3 \mathrm{~cm}^{-1}$ too high relative to the ground state ${ }^{3} \mathrm{P}_{2}$. The level he designated ${ }^{1} \mathrm{~S}_{0}$ is not real. In the three atoms for which the configuration $5 p^{4}$ is known (Te I, I II, and Xe III) one finds good agreement with intermediate 
TABLE 1. Predicted terms of I II

\begin{tabular}{|c|c|c|c|c|c|}
\hline Configuration & \multicolumn{5}{|c|}{ Predicted terms } \\
\hline \multirow{2}{*}{$\begin{array}{l}5 s^{2} 5 p^{4} \\
5 s 5 p^{5}\end{array}$} & \multicolumn{2}{|c|}{3} & ${ }^{3} \mathrm{P}^{\circ}$ & is & \\
\hline & $\begin{array}{c}n s \\
n \geq 6\end{array}$ & $\begin{array}{c}n p \\
n \geq 6\end{array}$ & $\begin{array}{l}n d \\
n \geq 5\end{array}$ & $\stackrel{n f}{n \geq 4}$ & $\stackrel{n g}{n \geq 5}$ \\
\hline $5 s^{2} 5 p^{3}\left({ }^{4} \mathrm{~S}^{\circ}\right) n x$ & $\left\{\begin{array}{l}{ }^{5} \mathrm{~S}^{\circ} \\
{ }^{3} \mathrm{~S}^{\circ}\end{array}\right.$ & ${ }^{5} \mathrm{P}$ & $\begin{array}{l}{ }^{5} \mathrm{D}^{\circ} \\
{ }^{3} \mathrm{D}^{\circ}\end{array}$ & ${ }^{5} \mathrm{~F}$ & $\begin{array}{l}{ }^{5} \mathrm{G}^{\circ} \\
{ }^{3} \mathrm{G}^{\circ}\end{array}$ \\
\hline $5 s^{2} 5 p^{3}\left({ }^{2} \mathrm{D}^{\circ}\right) n x^{\prime}$ & $\left\{\begin{array}{l}3 \mathrm{D}^{\circ} \\
{ }^{1} \mathrm{D}^{\circ}\end{array}\right.$ & $\begin{array}{l}3(\mathrm{PDF}) \\
1(\mathrm{PDF})\end{array}$ & $\begin{array}{l}{ }^{3}(\mathrm{SPDFG})^{\circ} \\
{ }^{1}(\mathrm{SPDFG})^{\circ}\end{array}$ & $\begin{array}{l}3(\mathrm{PDFGH}) \\
{ }^{1}(\mathrm{PDFGH})\end{array}$ & $\begin{array}{l}{ }^{3}(\mathrm{DFGHI})^{\circ} \\
{ }^{1}(\mathrm{DFGHI})^{\circ}\end{array}$ \\
\hline $5 s^{2} 5 p^{3}\left({ }^{2} \mathrm{P}^{\circ}\right) n x^{\prime \prime}$ & $\left\{\begin{array}{l}{ }^{3} \mathrm{P}^{\circ} \\
{ }^{1} \mathrm{P}^{\circ}\end{array}\right.$ & $\begin{array}{l}3(\mathrm{SPD}) \\
1(\mathrm{SPD})\end{array}$ & $\begin{array}{l}{ }^{3}(\mathrm{PDF})^{\circ} \\
{ }^{1}(\mathrm{PDF})^{\circ}\end{array}$ & $\begin{array}{l}3(\mathrm{DFG}) \\
1(\mathrm{DFG})\end{array}$ & $\begin{array}{l}3(\mathrm{FGH}) \\
1(\mathrm{FGH})\end{array}$ \\
\hline
\end{tabular}

coupling theory. Robinson and Shortley [10] have calculated the coupling parameters for $5 p^{4}$ in these atoms by making ${ }^{3} \mathrm{P}_{1},{ }^{3} \mathrm{P}_{2}$, and ${ }^{1} \mathrm{D}-{ }^{3} \mathrm{P}_{c}$ exactly fit the theoretical curves given in Condon and Shortley [11], p. 301, and reproduced in figure 1. This method gives a good fit for all levels except ${ }^{1} \mathrm{~S}_{0}$ which lies too high in all three cases. (The position for I II $5 p^{4}{ }^{1} \mathrm{~S}_{0}$ in figure 1 of reference [10] must be corrected since only the incorrect value of Lacroute was available to Robinson and Shortley-this reduces the disagreement to about one third of its former value.) As Robinson and Shortley point out, this does not mean that ${ }^{1} \mathbf{S}_{0}$ is perturbed-an interaction would push the term down. We have

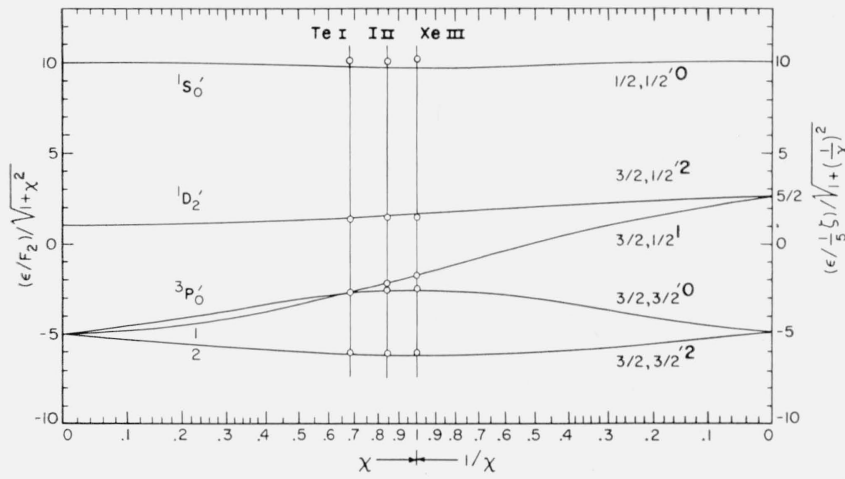

Figure 1. The levels of $5 \mathrm{p}^{4}$ for three atoms fitted to theoretical intermediate-coupling curves.

calculated the parameters by the method Condon and Shortley originally used for Te I, i.e., by making ${ }^{3} \mathrm{P}_{1}$, the mean of ${ }^{1} \mathrm{D}_{2}$ and ${ }^{3} \mathrm{P}_{2}$, and the mean of ${ }^{1} \mathrm{~S}_{0}$ and ${ }^{3} \mathrm{P}_{0}$ fit exactly. This brings ${ }^{1} \mathrm{~S}_{0}$ down to excellent agreement while leaving the value of $\chi=\frac{1}{5} \zeta_{p} / \mathrm{F}_{2}$ (see Condon and Shortley for notation) essentially unchanged in all cases, but the agreement of the $\mathbf{J}=2$ levels is not as good as in Robinson and Shortley. As a compromise we have averaged the values of the parameters obtained by these two methods. The results are given in table 2 and the corresponding values of the observed energy levels are plotted in figure 1 , again making ${ }^{3} \mathrm{P}_{1}$ fit exactly. Since the Landé, Slater, and coupling ratios all are functions only of the parameter $\chi$ the good agreement obtained for them by Robinson and Shortley is retained here. The new ${ }^{1} \mathrm{~S}$ term makes the agreement of the observed Slater ratio $\left({ }^{1} \mathrm{~S}-{ }^{1} \mathrm{D}\right) /$
TABLE 2. Intermediate-coupling parameters and predicted level positions for the $5 \mathrm{p}^{4}$ configuration in Te I, I II, and Xe III

\begin{tabular}{|c|c|c|c|}
\hline & Te I & I II & Xe III \\
\hline $\begin{array}{c}\chi=1 / 5 \zeta_{p} / \mathrm{F}_{2} \\
\zeta(5 p) \\
\mathrm{F}_{2}(5 p, 5 p)\end{array}$ & $\begin{array}{r}0.684 \\
\mathrm{~cm}^{-1} \\
4090 \\
1195\end{array}$ & $\begin{array}{r}0.844 \\
\mathrm{~cm}^{-1} \\
5930 \\
1405\end{array}$ & $\begin{array}{r}\text { 1. } 004 \\
\mathrm{~cm}^{-1} \\
8180 \\
1630\end{array}$ \\
\hline${ }^{3} \mathrm{P}_{2}\left\{\begin{array}{l}\text { pred. } \\
\text { obs. }\end{array}\right.$ & $\begin{array}{r}-171 \\
0\end{array}$ & $\begin{array}{r}-220 \\
0\end{array}$ & $\begin{array}{r}-480 \\
0\end{array}$ \\
\hline${ }^{3} \mathrm{P}_{1}\left\{\begin{array}{l}\text { pred. } \\
\text { obs. }\end{array}\right.$ & $\begin{array}{c}(4751) \\
4751\end{array}$ & $\begin{array}{l}(7087) \\
7087\end{array}$ & $\begin{array}{c}(9795) \\
9795\end{array}$ \\
\hline${ }^{3} \mathrm{P}_{0}\left\{\begin{array}{l}\text { pred. } \\
\text { obs. }\end{array}\right.$ & $\begin{array}{l}4697 \\
4707\end{array}$ & $\begin{array}{l}6325 \\
6448\end{array}$ & $\begin{array}{l}7878 \\
8131\end{array}$ \\
\hline${ }^{1} \mathrm{D}_{2}\left\{\begin{array}{l}\text { pred. } \\
\text { obs. }\end{array}\right.$ & $\begin{array}{l}10708 \\
10559\end{array}$ & $\begin{array}{l}13929 \\
13727\end{array}$ & $\begin{array}{l}17580 \\
17100\end{array}$ \\
\hline${ }^{1} \mathbf{S}_{0}\left\{\begin{array}{l}\text { pred. } \\
\text { obs. }\end{array}\right.$ & $\begin{array}{l}22731 \\
23199\end{array}$ & $\begin{array}{l}28924 \\
29501\end{array}$ & $\begin{array}{l}36162 \\
37398\end{array}$ \\
\hline
\end{tabular}

$\left({ }^{1} \mathrm{D}-{ }^{3} \mathrm{P}_{c}\right)$ in I II (1.481) with the theoretical value (1.365 for $\chi=0.844$ ) about the same as in Te I and better than in Xe III.

The eigenvectors of the two second-order energy matrices for $p^{4}$ in intermediate coupling, for $\mathrm{J}=0$ and $J=2$, respectively, are functions of $\chi$ only. By calculating these eigenvectors and squaring the elements of each, one obtains the percentage composition of each level of a given $J$ in terms of the pure Russell-Saunders levels of that J. The results of this calculation for $\chi=0.844$ (I II $5 p^{4}$ ) are that ${ }^{1} \mathrm{D}_{2}$ and ${ }^{3} \mathrm{P}_{2}$ have 90.3 percent Russell-Saunders purity (i.e., they are $9.7 \%$ mixed), while the purity for ${ }^{1} \mathrm{~S}_{0}$ and ${ }^{3} \mathrm{P}_{0}$ is 83.5 percent. Hence the $L S$ designations assigned these levels are not without some meaning.

\section{Magnetic Dipole Transitions}

"Forbidden" transitions between pairs of levels belonging to the $p^{4}$ configuration have been observed in laboratory sources of the spectra $\mathrm{O}_{\mathrm{I}}$ (the aurora line at $5577 \mathrm{~A},{ }^{1} \mathrm{~S}_{0}{ }^{1} \mathrm{D}_{2}$ ), Se I [12], Te I [13], Xe III [14], and Po I [15]. We have found two such transitions in I II: $5 p^{4}{ }^{3} \mathrm{P}_{1}-{ }^{1} \mathrm{~S}_{0}(4460.185 \mathrm{~A})$ and $5 p^{4}{ }^{3} \mathrm{P}_{2}$ ${ }^{1} \mathrm{D}_{2}(7282.83 \mathrm{~A})$. A diagram of the ground configuration levels showing these transitions is given in figure 2. The observed wavenumber of each line is that predicted by the separation of the relevant levels as determined from lines in the vacuum ultraviolet. The transition probabilities as derived from magnetic dipole strengths tabulated against $\chi$ by Shortley et al. [16] are $99 \mathrm{sec}^{-1}$ for the line at 4460 $\mathrm{A}$, and $9.1 \mathrm{sec}^{-1}$ for the line $7282 \mathrm{~A}(\chi=0.844$; both lines have zero transition probability in pure RussellSaunders coupling, where $\chi=0$ ). Of course the observed intensities in table 10.1 have no absolute meaning, and for these two lines in different spectral regions do not give even relative experimental intensities. Both transitions appear much stronger 


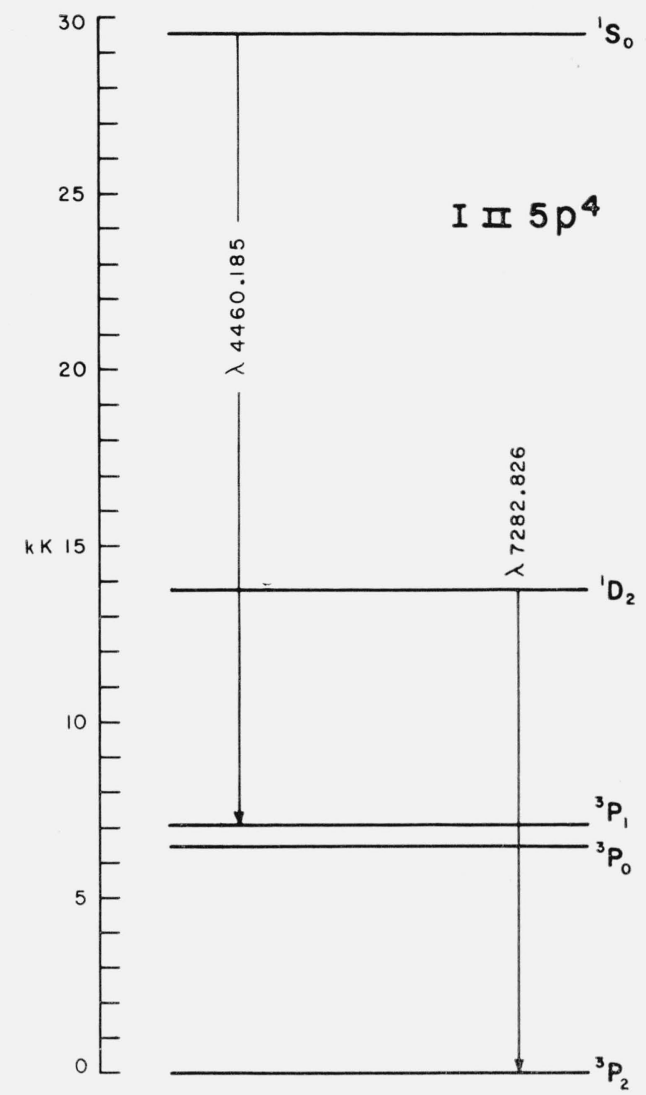

FIGURE 2. Two magnetic dipole transitions observed in I II.

in the high pressure (I I) discharge than with low pressure (I II) excitation. This first spectrum character is not surprising since these transitions occur between levels which are series limits for the I I spectrum. The levels lie about $100,000 \mathrm{~cm}^{-1}$ above the I I ground state, while the excitation energy for any $I$ II line in this region is almost twice that amount. In his note on the xenon spectra, Edlén [14] mentioned that such lines were at first experimentally referred to the next lower ionization than that to which they actually belonged.

The line at $4460 \mathrm{~A}$ is pure magnetic dipole radiation, and its classification was made certain by the transverse Zeeman effect observation shown in figure 3. Aiter the line had been classified, a search through the Zeeman data of Kiess and Corliss yielded this pattern. In a field of about 37,000 gauss the line splits into a triplet with separation of 1.51 Lorentz units (L.U.). But the unshifted perpendicularly polarized component and the symmetrically displaced parallel components form a pattern that is the inverse of the other triplets appearing in the figure, and can arise only îrom a magnetic dipole transition. The derived $g_{J}$-value for $5 p^{4}{ }^{3} P_{1}$ is, of course, 1.51. By observing the Zeeman effect for the analogous transition in $\mathrm{Pb} \mathrm{I}, 6 p^{2}{ }^{3} \mathrm{P}_{1}-{ }^{1} \mathrm{~S}_{0}$ at $4618 \mathrm{~A}$, H. Niewodniczanski [17] gave the first definite experimental proof ior the occurrence of magnetic dipole radiation in atomic spectra.

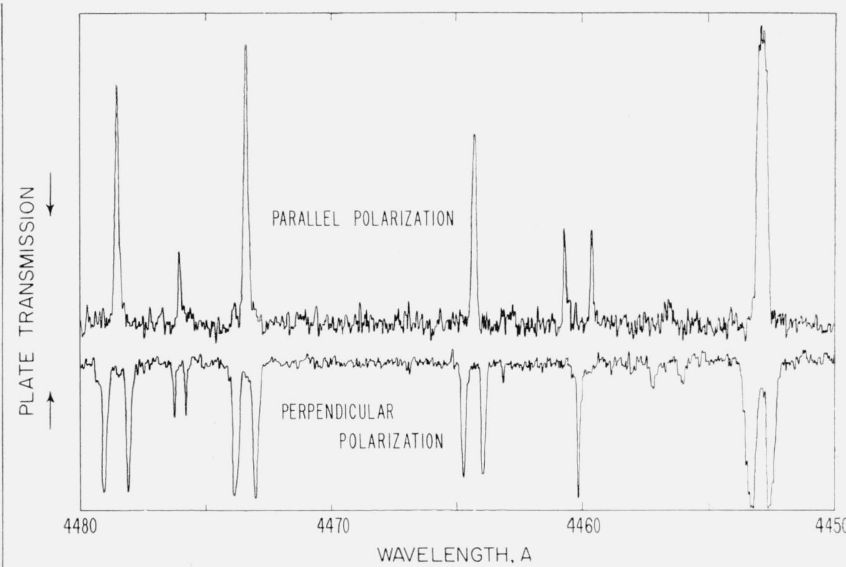

FiguRE 3. Microphotometer traces of an iodine spectrogram showing the transverse Zeeman effect in the region near $4460 \mathrm{~A}$.

The "upside-down" Lorentz triplet observed for the I II line at $4460.185 \mathrm{~A}$ is definite proof of its magnetic-dipole character.

The resolution obtained in the first order spectrum with a grating of 30,000 lines per inch was sufficient to resolve partly the hyperfine structure of the line $5 p^{4}{ }^{3} \mathrm{P}_{2}-{ }^{1} \mathrm{D}_{2}(7282 \mathrm{~A})$, as shown in figure 4 . There seem to be three or four components on our plates, though only one is well resolved irom the rest. In order to compare the observed structure of this line with theory, we have calculated the hyperfine splittings of the $5 p^{4}{ }^{3} \mathrm{P}_{2}$ and $5 p^{4}{ }^{1} \mathrm{D}_{2}$ levels in $\mathrm{I}^{127} \mathrm{II}$. The required constants were taken as follows: nuclear $\operatorname{spin}=5 / 2$, nuclear magnetic moment $=2.81$ n.m., nuclear electric quadrupole moment $=-0.62 \times$ $10^{-24} \mathrm{~cm}^{2}$ [18]. The formulas of Goudsmit [19] and Casimir [20] give the magnetic splitting iactors, $\mathrm{A}(\boldsymbol{J})$, and the electric quadrupole factors, $\mathrm{B}(\boldsymbol{J})$, respectively. Trees [21] has published convenient general expressions for evaluating these iormulas. We have also taken the effects of intermediats coupling into account. The calculated splittings are $\mathrm{A}\left({ }^{3} \mathrm{P}_{2}\right)=0.033 \mathrm{~cm}^{-1}, \mathrm{~B}\left({ }^{3} \mathrm{P}_{2}\right)=-0.00017 \mathrm{~cm}^{-1}, \mathrm{~A}\left({ }^{1} \mathrm{D}_{2}\right)$

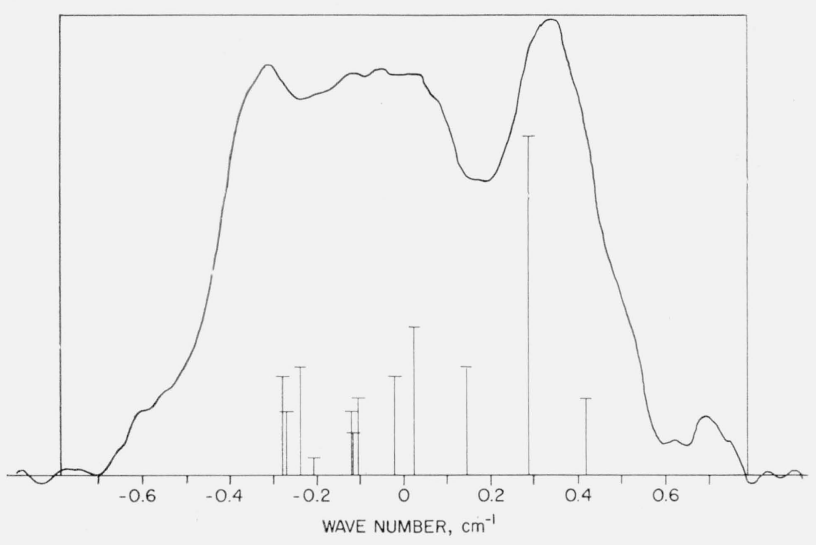

Figure 4. Microphotometer trace showing the hyperfine structure of the forbidden line $5 \mathrm{p}^{4}{ }^{3} \mathrm{P}_{2}-{ }^{1} \mathrm{D}_{2}$ at $7282 \mathrm{~A}$.

The theoretical relative intensities and calculated positions of the components of this pattern are also indicated. The position of the trace with respect to the zero of the wavenumber scale is arbitrary. 
$=0.078 \mathrm{~cm}^{-1}, \mathrm{~B}\left({ }^{1} \mathrm{D}_{2}\right)=0.00042 \mathrm{~cm}^{-1}$. If it is assumed that $5 p^{4}{ }^{3} \mathrm{P}_{2}-{ }^{1} \mathrm{D}_{2}$ is predominately a magnetic dipole transition, the same intensity ratios as for electric dipole radiation should apply to the hyperfine components $[22,23]$. The "theoretical" hyperfine pattern in figure 4 is based on this assumption and the calculated splittings. In view of the approximations made in the theory, the agreement of the calculated and observed patterns seems satisfactory and may be regarded as a confirmation of the suggested origin of this line.

Since the Zeeman effect for a forbidden line showing hyperfine structure has rarely been observed, three separate several-hour exposures were made especially to obtain the magnetic splitting of the line $7282 \mathrm{~A}$ in a field of 35,500 gauss. A microphotometer tracing of one of the Zeeman patterns obtained is shown in figure 5. Assuming the calculated intermediate coupling $g_{J}$-values of 1.451 for $5 p^{4}{ }^{3} \mathrm{P}_{2}$ and 1.049 for $5 p^{4}{ }^{1} \mathrm{D}_{2}$, one obtains the calculated Zeeman-component positions given in table 3. The observed values, which are averages for

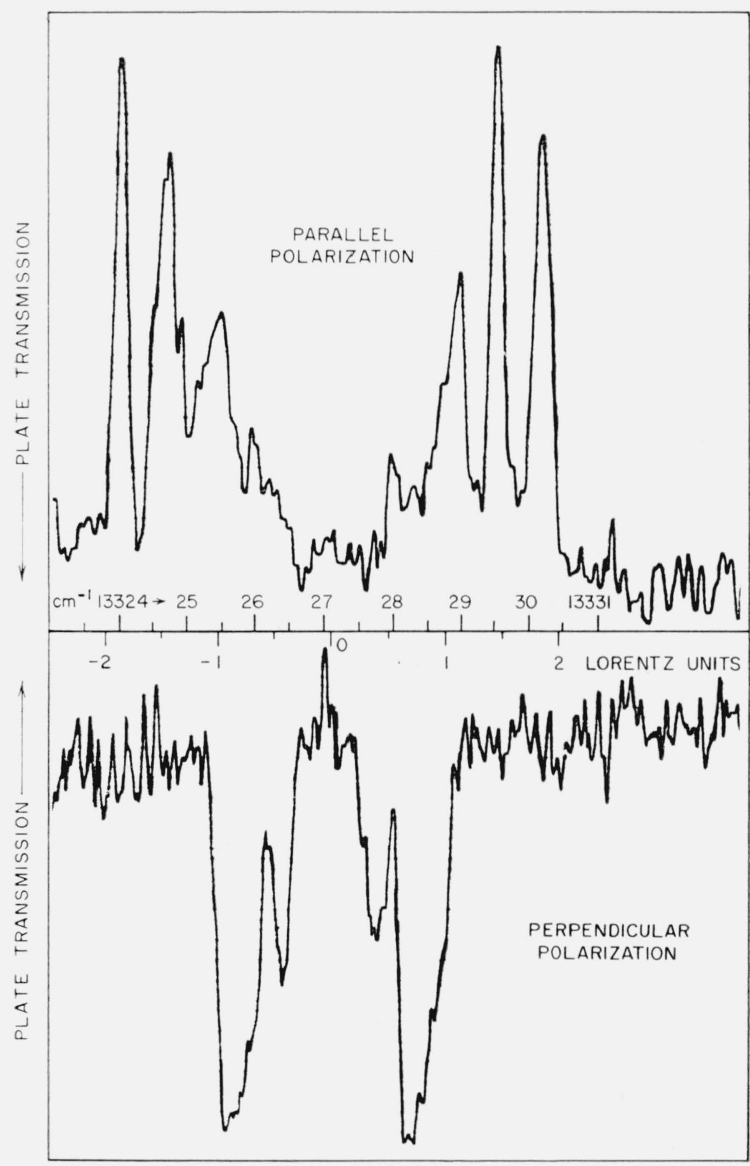

Figure 5. Microphotometer traces of the transverse Zeeman pattern for the line at $7282 \mathrm{~A}$.

The spectrogram from which these traces have been made was obtained with the source in a field of 35,500 gauss. In order to locate the Zeeman components with respect to the undisplaced hyperfine pattern, an exposure with the source in zero respect to the undisplaced hyperfine pattern, an exposure with the source in zero
magnetic field was also made on this spectrogram (not shown). The zero of the above Lorent $z$ unit scale is taken at the same position, relative to the observed hyperfine pattern of figure 4 , as the zero of the wavenumber scale in figure 4 .
TABLE 3. Zeeman effect for the forbitden line at $7282 \mathrm{~A}$

The observed component positions are average values from 3 patterns obtained with a magnetir field of about 35,500 gauss. Only half the pattern is given since the centers of gravity of any two corresponding components were, within the errors of observation, located symmetrically with respect to the zero of the magnetic displacement scale in figure 5.

\begin{tabular}{|c|c|c|c|c|}
\hline $\begin{array}{c}\pi \text {-compo- } \\
\text { nents } \\
\mathrm{M}_{\mathrm{J}}\left({ }^{1} \mathrm{D}_{2}\right) \rightarrow \\
\mathrm{M}_{\mathrm{J}}^{\prime}\left({ }^{3} \mathrm{P}_{2}\right)\end{array} \rightarrow$ & $\begin{array}{l}\text { Theo- } \\
\text { retical } \\
\text { relative } \\
\text { inten- } \\
\text { sity }\end{array}$ & $\begin{array}{l}\text { Calculated } \\
\text { position }\end{array}$ & $\begin{array}{l}\text { Observed } \\
\text { position }\end{array}$ & $\begin{array}{c}\text { Calculated } \\
\text { total } \\
\text { width }\end{array}$ \\
\hline $\begin{array}{l}2 \rightarrow 1 \\
1 \rightarrow 0 \\
0 \rightarrow 1 \\
1 \rightarrow 2\end{array}$ & $\begin{array}{l}2 \\
3 \\
3 \\
2\end{array}$ & $\begin{array}{l}\text { 0. } 647 \text { L.U. } \\
\text { 1. } 049 \\
\text { 1. } 451 \\
\text { 1. } 853\end{array}$ & $\begin{array}{l}\text { 1. } 042 \text { L.U. } \\
\text { 1. } 459 \\
\text { 1. } 860\end{array}$ & $\begin{array}{l}0.615 \mathrm{~cm}^{-1} \\
.390 \\
.165 \\
.069\end{array}$ \\
\hline $\begin{array}{c}\sigma \text {-compo- } \\
\text { nents }\end{array}$ & & & & \\
\hline $\begin{array}{l}1 \rightarrow 1 \\
2 \rightarrow 2\end{array}$ & $\begin{array}{l}2 \\
8\end{array}$ & $\begin{array}{r}\text { 0. } 402 \text { L.U. } \\
.804\end{array}$ & $\begin{array}{l}\text { 0. } 393 \text { L.U. } \\
.808\end{array}$ & $\begin{aligned} 0 . & 225 \mathrm{~cm}^{-1} \\
& .450\end{aligned}$ \\
\hline
\end{tabular}

measurements of the three patterns, are also given. The agreement of calculated and observed positions and the reversal of the respective polarizations from those expected for an electric dipole transition are definite proof of the origin of this line. The average values of the $g_{J}$-factors derived from the measured patterns are 1.457 for ${ }^{3} \mathrm{P}_{2}$ and 1.046 for ${ }^{1} \mathrm{D}_{2}$.

A broadening due to unresolved hyperfine structure is apparent for most of the components in figure 5. Since the splitting of either level by the external magnetic field is here several times larger than the zero-field hyperfine splitting, the formula for the Back-Goudsmit case [24] should give a fair approximation for the total energy of each magnetichyperfine state. This formula predicts a splitting of each Zeeman component into $2 \mathrm{I}+1=6$ equally spaced hyperfine components. The expected overall width of a given Zeeman component due to this structure can be obtained from the previously calculated values of the hyperfine splitting factors for the two levels (see above) and the standard formula for the Back-Goudsmit effect [24]. These calculated widths are given in table 3 . Neglecting for a moment the observed asymmetries, one can see that the general features of the pattern are in accord with these widths. In particular, what might at first be taken as large deviations from the predicted relative intensities of table 3 can probably for the most part be explained as effects due to the different widths. For example, the appearance of the distinct and relatively narrow $\pi$-components at \pm 1.85 L.U., as contrasted with the barely observable structures at \pm 0.65 L.U. - where components with the same total intensities as those at \pm 1.85 L.U. should occur - is, no doubt, due principally to the fact that the predicted overall width of the innermost components is 10 times that of the outermost conponents. Since the additional broadening of all components due to Doppler and instrumental effects has not been considered, the calculated widths of 
table 3 should be taken only as indicative. Previous experience with uncooled electrodeless lamps exited as described above indicates effective gas temperatures of 4,000 to $8,000{ }^{\circ} \mathrm{C}$ when the lamp is in a strong magnetic field. At these temperatures the Doppler width of each transition contributing to one of the Zeeman components of $7282 \mathrm{~A}$ is comparable to the "total width" of table 3 for the narrowest components $\left(0.06 \mathrm{~cm}^{-1}\right)$.

The asymmetries, with respect to total width and peak intensity, observed between members of the symmetrically positioned pairs of components in figure 5 are confirmed on the other two Zeeman spectrograms of this pattern. The complete BackGoudsmit effect would divide each Zeeman component into six equally intense components without altering the overall symmetry of the usual Zeeman pattern. It seems likely that the asymmetries are caused more by deviations from the intensity rule for the Back-Goudsmit case than by the remaining asymmetries in the level positions. With the present resolution, no significant asymmetries in the positions of the centers-of-gravity of corresponding components are observed.

The line ${ }^{3} \mathrm{P}_{2}-{ }^{1} \mathrm{D}_{2}$ is allowed in electric quadrupole radiation as well as in magnetic dipole radiation. Although it is certain that $7282 \mathrm{~A}$ is almost pure magnetic dipole in character, it might be possible to deduce from a symmetric Zeeman pattern a slight admixture of electric quadrupole radiation in the line. This was done for a similar transition, $6 p^{2}$ ${ }^{3} \mathrm{P}_{1}-{ }^{1} \mathrm{D}_{2}$ in $\mathrm{Pb}$, by Jenkins and Mrozowski [25]. These investigators also were able to confirm an interesting "interference" effect [23] between the magnetic dipole and electric quadrupole radiation in this line. An application of this type of analysis to the pattern in figure 5 does not appear feasible because of the asymmetries due to hyperfine structure. It is possible that a detailed calculation of this pattern by use of the formulas for the "intermediate field" case would be worthwhile.

\section{Higher Even Terms}

The higher terms of I II are of three types, according to whether the parent term in I III is $5 p^{3}$ ${ }^{4} \mathrm{~S}^{\circ},{ }^{2} \mathrm{D}^{\circ}$, or ${ }^{2} \mathrm{P}^{\circ}$. As shown in table 1 , these are denoted by affixing to the valence electron no prime, one prime, or two primes, respectively. No meaningful analysis exists for I III, but one can estimate the positions of $5 p^{3}{ }^{2} \mathrm{D}$ and $5 p^{3}{ }^{2} \mathrm{P}$ from their positions in $\mathrm{Sb} I$ and $\mathrm{Te}$ II. The result is that the ${ }^{2} \mathbf{D}_{1 \frac{1}{2}, 21 / 2}$ levels should lie about 12,000 and 15,000 $\mathrm{cm}^{-1}$, respectively, above ${ }^{4} \mathrm{~S}$, and the ${ }^{2} \mathrm{P}_{1 / 2,11 / 2}$ at approximately 25,000 and $30,000 \mathrm{~cm}^{-1}$, respectively.

We have indicated in our discussion of $5 p^{4}$ the extent to which Russell-Saunders designations are meaningful for that configuration. For many of the higher levels such designations have considerably less meaning. The overlapping of the "terms", belonging to a given configuration and parentage signifies the usual heavy-atom departure from Russell-Saunders coupling, and makes the L-S naming of some of these higher levels little more than a convenient accounting system. With the reader thus warned we shall, however, use this notation.

Earlier investigators found the levels of the even groups $\left({ }^{4} \mathrm{~S}^{\circ}\right) 6 p,\left({ }^{2} \mathrm{D}^{\circ}\right) 6 p^{\prime}$, and $\left({ }^{4} \mathrm{~S}^{\circ}\right) 4 f$. Transitions from these levels to lower odd levels are responsible for the strongest I II lines in the air region. The intensities of the $5 d-4 f$ transitions indicate that the strong line at $2993.866 \mathrm{~A}$ is due to $5 d^{3} \mathrm{D}_{1}^{\circ}-4 f^{3} \mathrm{~F}_{2}$. This requires that the designations of the levels previously called $5 d^{3} \mathrm{D}_{1}^{\circ}$ and $6 s^{\prime}{ }^{3} \mathrm{D}_{1}^{\circ}$ be interchanged, as well as those of $4 f^{3} \mathrm{~F}_{2}$ and $6 p^{\prime \prime}{ }^{3} \mathrm{D}_{2}$. Murakawa [4] noted that the ${ }^{3} \mathrm{D}_{1}^{\circ}$ levels were almost indistinguishable, and Lacroute [3] mentioned "l'analogie" of the $J=2$ levels involved. Neither of these authors had available a complete line list with a uniform intensity scale. We unfortunately did not notice Murakawa's incorrect designation of the $4 f$ levels as $5 f$-an error retained by Lacroute - until after the publication of AEL, Vol. III. Our measurement of these strong multiplets has resulted in some designation changes. While some configuration mixing undoubtedly takes place for each of these pairs, the intensities of most of the other combinations of these levels confirm our changes. In the next section it will be shown that the present choice of $6 s^{\prime}{ }^{3} \mathrm{D}_{1}^{\circ}$ is supported by theory. The relative position of the level here designated $4 f^{3} \mathrm{~F}_{2}$ is supported by the position of ${ }^{3} \mathrm{~F}_{2}$ in the newly-found $5 f$ configuration. Also on the basis of our intensities and $g$-values, we have reversed Murakawa's designations of the pairs $6 p^{\prime}{ }^{3} \mathrm{~F}_{3},{ }^{3} \mathrm{D}_{3}$ and $6 p^{\prime}{ }^{1} \mathrm{P}_{1},{ }^{3} \mathrm{D}_{1}$.

The $7 p^{5,3} \mathrm{P}$ levels, all of which have been found, overlap the $4 f$ levels but do not make as strong combinations. The level $7 p^{5} \mathrm{P}_{2}$ was previously known.

The terms of $\left({ }^{2} \mathrm{P}^{\circ}\right) 6 p^{\prime \prime}$ are now complete. Lacroute gave five of these levels correctly, although the level he designated $6 p^{\prime \prime} y_{1}$ has a J-value of 2 . As noted above, his $6 p^{\prime \prime}{ }^{3} \mathrm{D}_{2}$ fits better in the $4 f$ configuration. We assign his $6 p^{\prime \prime}{ }^{3} \mathrm{P}_{2}$ to $6 p^{\prime \prime}{ }^{1} \mathrm{D}_{2}$. The $6 p^{\prime \prime}$ group overlaps both the $4 f$ and $7 p$ levels. From the line intensities it appears that the $4 f$ levels and $7 p{ }^{5} \mathrm{P}_{3}$ are relatively pure, while most of the remaining levels of $7 p$ and $6 p^{\prime \prime}$ are configuration-mixed.

The analysis has yielded all but two of the levels arising from $4 f^{\prime}$ and $7 p^{\prime}$. Since these groups overlap and mix, any individual assignment to configuration and Russell-Saunders designation at best represents only the principal contribution to a complete description of a given level. Lacroute found five of these levels, assigning them to $7 p^{\prime}$. We have assigned all but one of these to $4 f^{\prime}$. 'Four other levels listed by Lacroute for $7 p^{\prime}$ are not real.

All the levels of the complete $5 f$ configuration are new except ${ }^{3} \mathrm{~F}_{3}$, which was given by Lacroute as $7 p^{\prime}{ }^{1} \mathrm{P}_{1}$. Most of the levels of $n f$ are now known through $n=8$. Four levels are assigned to $9 f$ - three of them tentatively - on the basis of series regularity.

The level given in table 10.3 as $8 p^{3} \mathrm{P}_{2}$ was erroneously assigned a J-value of 3 in the AEL table, while $8 p{ }^{3} \mathrm{P}_{1}$ was given by Lacroute as $7 p^{\prime}{ }^{3} \mathrm{D}_{2}$. The $8 p$ levels fall amongst those of $4 f^{\prime}$ and $7 p^{\prime}$, but the 
present designations seem most likely on the basis of combination intensities and series considerations.

A group of 13 higher even levels which may belong to any of four configurations, as shown in table 10.3, have been given only numerical designations.

\section{Odd-Parity Configurations}

Table 10.4 is a complete list of the presently known odd levels in I II. The terms of $5 s 5 p^{5}, 5 p^{3}\left({ }^{4} \mathrm{~S}^{\circ}\right) 6 s$, $\left({ }^{4} \mathrm{~S}^{\circ}\right) 5 d$, and $\left({ }^{2} \mathrm{D}^{\circ}\right) 6 s^{\prime}$ were previously known. The $5 p^{5}, 6 s$, and $5 d$ configurations are probably mixed, but the new intensities leave no doubt that Lacroute's designations for $5 p^{5}{ }^{3} \mathrm{P}_{0}^{\circ}$ and $5 d^{5} \mathrm{D}_{0}^{\circ}$ must be reversed. The resulting new position of $5 d^{5} \mathrm{D}_{0}^{\circ}$ is confirmed in the $6 d$ configuration.

A comparison of the predictions of intermediate coupling theory for $p^{5} s$ with the experimental results for a number of rare-gas type atoms is made in the book of Condon and Shortley ([11], p. 304). It seems of interest to make this comparison for the known examples of $s p^{5}$ which exhibit intermediate coupling to a significant extent. There are only three of these, and the results for them are shown in table 4 and figure 6 . The levels for $\mathrm{Kr}$ III $4 s 4 p^{5}$ and Xe III $5 s 5 p^{5}$ were fitted to the intermediate coupling formulas in Condon and Shortley by the method used

$\mathrm{T}_{\mathrm{ABLE}} 4$. Intermediate-coupling parameters and predicted level positions for the configuration $\mathrm{sp}^{5}$ in three atoms

\begin{tabular}{|c|c|c|c|}
\hline & $\mathrm{Kr}$ III $4 \diamond 4 p^{5}$ & I II $5 s 5 p^{5}$ & Xe III $5 s 5 p^{5}$ \\
\hline $\begin{array}{c}\chi=3 / 4 \zeta_{p} / \mathrm{G}_{1} \\
\zeta(n p) \\
\mathrm{G}_{1}(n s, n p)\end{array}$ & $\begin{array}{l}0.236 \\
3741 \mathrm{~cm}^{-1} \\
11890\end{array}$ & $\begin{array}{l}\text { 1. } 000 \\
5900 \mathrm{~cm}^{-1} \\
4425\end{array}$ & $\begin{array}{l}\text { 1. } 240 \\
9621 \mathrm{~cm}^{-1} \\
5819\end{array}$ \\
\hline${ }^{3} \mathrm{P}_{2}^{o}\left\{\begin{array}{l}\text { pred. } \\
\text { obs. }\end{array}\right.$ & $\begin{array}{l}(115932) \mathrm{cm}^{-1} \\
115932\end{array}$ & $\begin{array}{l}81555 \mathrm{~cm}^{-1} \\
81908\end{array}$ & $\begin{array}{l}(98263) \mathrm{cm}^{-1} \\
98263\end{array}$ \\
\hline${ }^{3} \mathrm{P}_{1}^{\circ}\left\{\begin{array}{l}\text { pred. } \\
\text { obs. }\end{array}\right.$ & $\begin{array}{l}119358 \\
119381\end{array}$ & $\begin{array}{l}85296 \\
84222\end{array}$ & $\begin{array}{l}103686 \\
103569\end{array}$ \\
\hline${ }^{3} \mathrm{P}_{0}^{\mathrm{o}}\left\{\begin{array}{l}\text { pred. } \\
\text { obs. }\end{array}\right.$ & $\begin{array}{l}(121544) \\
121544\end{array}$ & $\begin{array}{l}(90405) \\
90405\end{array}$ & $\begin{array}{c}(112694) \\
112694\end{array}$ \\
\hline${ }^{1} \mathrm{P}_{1}^{\mathrm{o}}\left\{\begin{array}{l}\text { pred. } \\
\text { obs. }\end{array}\right.$ & $\begin{array}{l}141899 \\
141876\end{array}$ & $\begin{array}{l}95514 \\
95956\end{array}$ & $\begin{array}{l}118909 \\
119026\end{array}$ \\
\hline
\end{tabular}

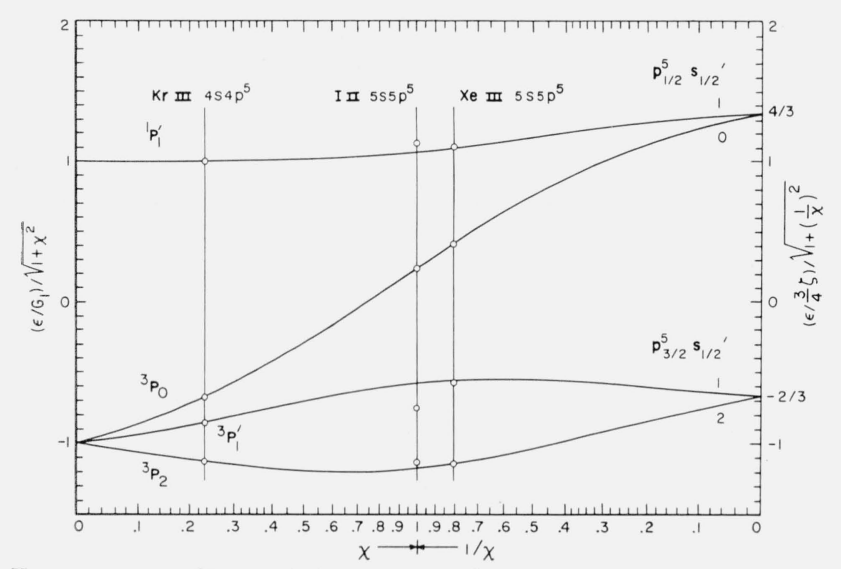

Figure 6. Observed levels of $\mathrm{sp}^{5}$ for three atoms fitted to intermediate-coupling curves. there: the parameter $\chi$ is chosen so that the levels $J=0,2$, and the mean of the two levels of $J=1$, fit the theory exactly. The value of $\chi$ chosen for I II $5 s 5 p^{5}$ gives a somewhat better fit than is obtained by the Condon and Shortley method. Still, the fit for I II is not as good as for the other two atoms. Interaction with either $5 d{ }^{3} \mathrm{D}_{1}^{\circ}$ or $6 s^{\prime}{ }^{3} \mathrm{D}_{1}^{\circ}$, or with both, probably causes the apparent depression of $5 p^{5}{ }^{3} \mathrm{P}_{1}^{\circ}$ in I II. In any case this calculation definitely supports the designation change for $5 d{ }^{5} \mathrm{D}_{0}^{\circ}$ and $5 p^{5}{ }^{3} \mathrm{P}_{0}^{\circ}$ mentioned above. The other known cases of $s p^{5}$, in $\mathrm{Cl}$ II through $\mathrm{Sc}$ vi of the $\mathrm{S}$ I isoelectronic sequence, are quite close to $\mathrm{L}-\mathrm{S}$ coupling $(\chi<0.1)$.

The level adopted here for $5 p^{5}{ }^{3} \mathrm{P}_{0}^{\circ}$ in Xe III is listed as $5 d{ }^{5} \mathrm{D}_{0}^{\circ}$ in AEL, Vol. III. The analogy with I II and $\mathrm{Kr}$ III leaves little doubt that our change should be made. The three combinations [26] on which the level is based were not sufficient to determine its configuration unambiguously. Humphreys' [26] level for $5 p^{5}{ }^{3} \mathrm{P}_{0}^{\circ}$ in Xe III would seem questionable; it is far lower than the expected position of $5 d^{5} \mathrm{D}_{0}^{\circ}$, the only other possible designation. The known levels $5 d{ }^{5} \mathrm{D}_{3,2,1}^{\circ}$ of $\mathrm{Xe}$ III agree with the order found in I II.

A diagonalization of the energy matrix in intermediate coupling for the configuration $5 p^{3} 6 s$ in I II has increased our confidence in the configuration and parentage assignments made here for all the known odd levels based on $5 p^{3}{ }^{2} \mathrm{D}^{\circ}$ and $5 p^{3}{ }^{2} \mathrm{P}^{\circ}$ parents. The matrices of the electrostatic and spin-orbit interactions for $s p^{3}$ are given on pages 199 and 268, respectively, of Condon and Shortley [11]. The value of $\mathrm{F}_{2}(5 p, 5 p)$ used in our calculation, $1425 \mathrm{~cm}^{-1}$, was obtained from the relation $6 \mathrm{~F}_{2}={ }^{3} \mathrm{P}_{0}^{\circ}-$ ${ }^{3} \mathrm{D}_{3}^{\circ}$ for $s p^{3}$. It is supported by the value of $\mathrm{F}_{2}$ for the $5 p^{4}$ configuration given above, $1405 \mathrm{~cm}^{-1}$. If one knows $\mathrm{F}_{2}$ and the levels of either $\mathrm{J}=2$ or $\mathrm{J}=1$, the value of $\mathrm{G}_{1}(6 s, 5 p)$ may be obtained from the diagonal-sum rule. At the time the value of $\mathrm{G}_{1}$ adopted here $\left(1000 \mathrm{~cm}^{-1}\right)$ was chosen, however, it was based on values obtained from the equation $5 p^{3}\left({ }^{4} \mathrm{~S}^{\circ}\right) 6 s \quad\left({ }^{3} \mathrm{~S}_{1}^{\circ}-{ }^{5} \mathrm{~S}_{2}^{\circ}\right)=4 \mathrm{G}_{1}$. This gives $\mathrm{G}_{1}=952$ $\mathrm{cm}^{-1}$ for III and $\mathrm{G}_{1}=1035 \mathrm{~cm}^{-1}$ for XeiII. By carrying out the calculation for $\mathrm{G}_{1}=500,1000$, and $1500 \mathrm{~cm}^{-1}$ we have assured ourselves that the intermediate value is very close to the "best" value for fitting the observed levels. The other parameter needed for the calculation, $\zeta_{p}$, was taken to be $5930 \mathrm{~cm}^{-1}$, as in the $5 p^{4}$ configuration.

The calculated energies and $g_{J}$-values for the levels of $5 p^{3} 6 s$ are given in table 5 , together with the observed values. An exact fit is assumed for the ${ }^{3} \mathrm{D}_{0}^{\circ}$ and ${ }^{3} \mathrm{P}_{0}^{\circ}$ levels. The average deviation of the predicted and observed values, $322 \mathrm{~cm}^{-1}$, seems reasonable for a calculation neglecting configuration mixing. Table 6 gives the calculated composition of the levels of $J=1$ and $J=2$ in terms of pure Russel-Saunders states.

It will be seen that the aforementioned designation of the level at $94825 \mathrm{~cm}^{-1}$ as $6 s^{\prime}{ }^{3} \mathrm{D}_{1}^{\circ}$, instead of the level at $92133 \mathrm{~cm}^{-1}$, is supported by this calculation. The indicated perturbation of $6 s^{\prime}{ }^{3} \mathrm{D}_{1}^{\circ}$ is in the direction to be expected if it is caused mainly by inter- 
TABLE 5. Predictions of intermediate-coupling calculation for I II $5 \mathrm{p}^{3} 6$ s compared with observation

The parameters were taken as follows: $\zeta(E p)=5930 \mathrm{~cm}^{-1}, \mathrm{~F}_{2}(5 p, 5 p)=1425 \mathrm{~cm}^{-1}$ and $\mathrm{G}_{1}(6 \mathrm{~s}, 5 \mathrm{p})=1000 \mathrm{~cm}^{-1}$.

\begin{tabular}{|c|c|c|c|c|c|}
\hline Designation & $\begin{array}{l}\text { Predicted } \\
\text { position }\end{array}$ & $\begin{array}{l}\text { Observed } \\
\text { position }\end{array}$ & Difference & $\underset{g_{J}}{\text { Predicted }}$ & $\begin{array}{c}\text { Observed } \\
g_{J}\end{array}$ \\
\hline $\begin{array}{ll}6 s & { }^{5} \mathrm{~S}_{2}^{\circ} \\
6 s & { }^{3} \mathrm{~S}_{1}^{\circ} \\
6 s^{\prime} & { }^{3} \mathrm{D}_{1}^{\circ} \\
6 s^{\prime} & { }^{3} \mathrm{D}_{2}^{\circ} \\
6 s^{\prime} & { }^{3} \mathrm{D}^{\circ} \\
6 s^{\prime} & { }^{1} \mathrm{D}_{2}^{\circ} \\
6 s^{\prime \prime} & { }^{3} \mathrm{P}_{0}^{\circ} \\
6 s^{\prime \prime} & { }^{3} \mathrm{P}_{1}^{0} \\
6 s^{\prime \prime} & { }^{3} \mathrm{P}_{2}^{\circ} \\
6 s^{\prime \prime} & { }^{3} \mathrm{P}_{1}^{\circ}\end{array}$ & $\begin{array}{c}81176 \mathrm{~cm}^{-1} \\
84862 \\
94096 \\
94103 \\
(96651) \\
98035 \\
(105201) \\
105749 \\
110015 \\
111173\end{array}$ & $\begin{array}{l}81033 \mathrm{~cm}^{-1} \\
84843 \\
94825 \\
93691 \\
96651 \\
97701 \\
105201 \\
106103 \\
110459 \\
111962\end{array}$ & $\begin{array}{r}143 \mathrm{~cm}^{-1} \\
19 \\
-729 \\
412 \\
0 \\
334 \\
0 \\
-354 \\
-444 \\
-789\end{array}$ & $\begin{array}{l}1.954 \\
1.877 \\
0.703 \\
1.235 \\
1.333 \\
1.048 \\
1.383 \\
1.430 \\
1.037\end{array}$ & $\begin{array}{l}1.95 \\
1.753 \\
0.653 \\
1.16 \\
1.36 \\
0.996\end{array}$ \\
\hline
\end{tabular}

TABLE 6. Calculated percentage compositions for the levels of I II $5 p^{3} 6 \mathrm{~s}$ tion

The composition of each level is given in the column under its assigned designa-

\begin{tabular}{|c|c|c|c|c|}
\hline & $6 s^{5} \mathbf{S}_{2}^{\circ}$ & $6 s^{\prime}{ }^{3} \mathrm{D}_{2}^{\circ}$ & $6 s^{\prime}{ }^{1} \mathrm{D}_{2}^{\circ}$ & $6 s^{\prime \prime}{ }^{3} \mathrm{P}_{2}^{\circ}$ \\
\hline $\begin{array}{ll}6 s & 5 \mathrm{~S}_{2}^{\circ} \\
6 s^{\prime} & 3 \mathrm{D}_{2}^{\circ} \\
6 s^{\prime} & 1 \mathrm{D}_{2}^{\circ} \\
6 s^{\prime \prime} & 3 \mathrm{P}_{2}^{\circ}\end{array}$ & $\begin{array}{r}\% \\
91.7 \\
0.8 \\
0.4 \\
7.1\end{array}$ & $\begin{array}{r}\% \\
4.5 \\
65.6 \\
13.7 \\
16.2\end{array}$ & $\begin{array}{r}\% \\
0.3 \\
22.5 \\
75.6 \\
1.6\end{array}$ & $\begin{array}{r}\% \\
3.6 \\
11.1 \\
10.2 \\
75.1\end{array}$ \\
\hline & $6 s^{3} \mathrm{~S}_{\mathrm{i}}$ & $6 s^{\prime}{ }^{3} \mathrm{D}_{\mathrm{i}}^{\circ}$ & $6 s^{\prime \prime}{ }^{3} \mathrm{P}_{1}^{\circ}$ & $6 s^{\prime \prime}{ }^{1} \mathrm{P}_{1}^{\circ}$ \\
\hline $\begin{array}{ll}6 s & { }^{3} \mathrm{~S}_{1} \\
6 s^{\prime} & { }^{3} \mathrm{D}_{1}^{\circ} \\
6 s^{\prime \prime} & 3 \mathrm{P}_{1} \\
6 s^{\prime \prime} & 1 \mathrm{P}_{1}\end{array}$ & $\begin{array}{r}\% \\
87.4 \\
3.0 \\
3.6 \\
6.0\end{array}$ & $\begin{array}{r}\text { 7. } 9 \\
80.1 \\
\text { 4. } 9 \\
\text { 7. } 1\end{array}$ & $\begin{array}{r}\% \\
0.2 \\
0.8 \\
77.1 \\
21.9\end{array}$ & $\begin{array}{r}\% \\
4.6 \\
16.0 \\
14.4 \\
65.0\end{array}$ \\
\hline
\end{tabular}

action with $5 d^{3} \mathrm{D}_{1}^{\circ}$. The other ambiguities resolved by this calculation were between the $5 d^{\prime}$ and $5 d^{\prime \prime}$ levels on the one hand and those belonging to $6 s^{\prime \prime}$ on the other. As between the $5 d^{\prime}$ and $6 s^{\prime \prime}$ groups, the present assignments are in general supported by the relative intensities of combinations of levels belonging to these configurations with levels of the distinct $6 p^{\prime}$ and $6 p^{\prime \prime}$ groups.

The intensities would not have served, however, to distinguish the $6 s^{\prime \prime}$ levels from those of $5 d^{\prime \prime}$. The assignments of the two levels $5 d^{\prime \prime}{ }^{1} \mathrm{D}_{2}^{\circ}$ and $5 d^{\prime \prime}{ }^{3} \mathrm{D}_{3}^{\circ}$ may be considered questionable, since the former is well below a level of $\mathrm{J}=2$ assigned to $5 d^{\prime}$ and the latter is near the level designated $5 d^{\prime}{ }^{1} \mathrm{~F}_{3}^{\circ}$. However, these assignements fit in with the other levels of $J=2$ and $\mathbf{J}=3$ within each parentage group better than any other arrangement. The $5 d^{\prime}$ group is now known except for one level of $\mathrm{J}=5$, and only ${ }^{3} \mathrm{~F}_{4}^{\circ}$ is lacking in the $5 d^{\prime \prime}$ group.

The sorting-out of these lower odd levels, together with an approximate knowledge of the various series limit positions which they approach, have enabled us to assign definite configuration and parentage designations to the complex group of 91 odd levels between $118074 \mathrm{~cm}^{-1}\left(5 d^{\prime}{ }^{3} \mathrm{P}_{1}^{\circ}\right)$ and $145837 \mathrm{~cm}^{-1}$ $\left(20_{2}^{\circ}\right)$. Only eight of the levels expected in this region are missing, four of them from $9 d^{5,3} \mathrm{D}^{\circ}$. The levels of $6 d^{5,3} \mathrm{D}^{\circ}$ and $7 s^{5,3} \mathrm{~S}^{\circ}$ were previously known and correctly identified. About 15 other previously listed higher odd levels are included in this analysis, usually with a changed designation or a new assignment to a definite configuration.

It is interesting to note that the smallness of the ${ }^{3} \mathrm{D}_{1}^{\circ}-{ }^{3} \mathrm{D}_{2}^{\circ}$ intervals in the $7 s^{\prime}$ and $8 s^{\prime}$ terms (2.37 and $36.12 \mathrm{~cm}^{-1}$, respectively) is in accord with the theoretical predictions for the corresponding levels of $6 s^{\prime}$. In table 5 the predicted positions of $6 s^{\prime}{ }^{3} \mathrm{D}_{1}^{\circ}$ and ${ }^{3} \mathrm{D}_{2}^{\circ}$ are both very near $94100 \mathrm{~cm}^{-1}$. The large observed separation of these levels, $1134 \mathrm{~cm}^{-1}$, is apparently due to perturbations in opposite directions for the two levels.

We have assigned 15 levels to the $6 d^{\prime}$ group, but there is really no good basis for giving them term designations; hence they are listed numerically. The Russell-Saunders designations given the $5 d^{\prime}$ and $5 d^{\prime \prime}$ levels probably should not be taken as more than suggestive, but the names given here fit the observed combinations better than any other arrangement.

The levels of the newly-found $\left({ }^{4} \mathrm{~S}^{\circ}\right) n g{ }^{5,3} \mathrm{G}^{\circ}$ terms in table 10.4 are based on combinations with $4 f^{5,3} \mathrm{~F}$ and, in the case of the higher series members, with $5 f^{5,3} \mathrm{~F}$. Although we have assigned multiplicities to the $n g$ levels on the basis of these transitions -intercombinations are definitely weaker than intrasystem transitions - it is clear from figure 7 that these levels

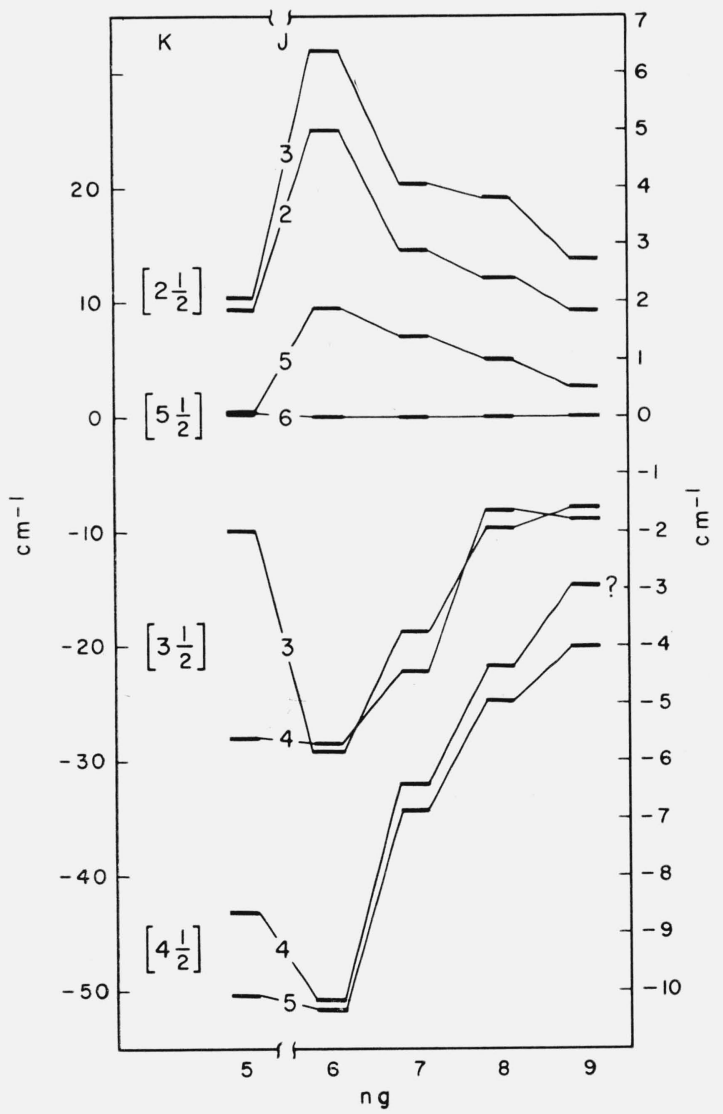

FIGURE 7. Levels of the $\left({ }^{4} \mathrm{~S}^{\circ}\right) \mathrm{ng}$ groups.

The ordinate scale on the left applies to the $5 g$ levels, the higher levels being plotted according to the scale on the right. The Russell-Saunders designations for these levels may be obtained by comparing this figure with the level values given in table 10.4 . 
do not fall into the triplet-quintet pattern of RussellSaunders coupling. "The numbers under " $\mathrm{K}$ " in this figure refer to pair-coupling [27]; they are the four possible results of adding the orbital angular momentum of a $g$-electron to the $J$ of the parent ${ }^{4} \mathrm{~S}_{1 \frac{1}{2}}^{\circ}$ level. While these levels certainly do not show good pair-coupling, it seems probable that this notation describes the observed structures better than the L-S scheme in table 10.4.

Each $n g$ triplet level is paired with a quintet level in the three higher "pairs" of figure 7. In the known I II terms of the type $\left({ }^{4} \mathrm{~S}^{\circ}\right) n l^{5} \mathrm{~L},{ }^{3} \mathrm{~L}$, where $l=$ $p, d, f$, or $g$, a characteristic partial inversion of levels occurs except in $n p{ }^{5} \mathrm{P}$. (Both of the known terms $6 p, 7 p,{ }^{5} \mathrm{P}$ show large deviations from the Landé interval rule in the direction of partial inversion.) However, this deviation from Russell-Saunders structure is compounded by overlapping of the triplet and quintent terms only in the $\left({ }^{4} \mathrm{~S}^{\circ}\right) n g$ groups. Even the $\left({ }^{4} \mathrm{~S}^{\circ}\right) n f{ }^{3} \mathrm{~F}$ terms are well above the corresponding quintets.

It would seem from figure 7 that some of the $n g$ levels are perturbed by amounts comparable to the (small) level separations. The position of the $5 g$ $\left[5 \frac{1}{2}\right]_{5}$ level and the crossing-over behavior of the $\left[3 \frac{1}{2}\right]_{3,4}$ pair with each increase in $n$ are probably the most obvious examples. Perhaps the best overall description of the grouping observed for these $n g$ levels would be "frustrated pair-coupling."

In addition to the identified series members based on the $5 p^{3}\left({ }^{4} \mathrm{~S}^{\circ}\right)$ parent, the higher group of odd levels beginning with $20_{1,2}^{\circ}$ at $145837.7 \mathrm{~cm}^{-1}$ probably contains levels belonging to each of the designations $6 d^{\prime \prime}$, $7 d^{\prime}, 7 s^{\prime \prime}, 8 s^{\prime}$, and $5 g^{\prime}$. We have given only numerical designations to these levels, no attempt having been made to assign them to definite parents and configurations.

\section{Series and the Ionization Energy}

In a singly-ionized atom, the Rydberg denominator $n *$ for a series member is defined by the equation $4 \mathrm{~T}=$ $\mathrm{R} /\left(n^{*}\right)^{2}$; where $4 \mathrm{~T}$ is the position of the level measured from the series limit, and $R$ is the Rydberg constant. (The quantity $\mathrm{T}$ is the "reduced" absolute term value. For convenience in using the Rydberg Interpolation Table [28], the value of $R$ was taken as $109737.4 \mathrm{~cm}^{-1}$ in the series calculations reported here.) Many unperturbed series obey quite closely the Ritz formula $n^{*}=n+\mu+\alpha$ T, where $n$ runs through the successive integers for the series and $\mu$ and $\alpha$ are constants for a given series. Since the fraction by which $n^{*}$ exceeds an integer is a linear function of ' $\mathrm{T}$ ' for such a series, the position of the series limit is taken as that value which gives the "best" straight line when these successive fractions are plotted against the corresponding values of T.

Figure 8 shows two such plots for the new $\left({ }^{4} \mathrm{~S}^{\circ}\right) n g$ ${ }^{5} \mathrm{G}_{6}^{\circ}$ series, $n=5$ through 12 . The approximately straight line is obtained by taking the $5 p^{3}{ }^{4} \mathrm{~S}^{\circ}$ limit, the ground state of I III, to lie $154304 \mathrm{~cm}^{-1}$ above the $5 p^{4}{ }^{3} \mathrm{P}_{2}$ ground level of $\mathrm{I}$ II. The curved line, representing a very unlikely behavior for this series, results from assuming the limit to be only $4 \mathrm{~cm}^{-1}$ above the straight-line value. It is seen that the Rydberg denominator fractions for the higher series members become increasingly sensitive to the limit chosen or, equivalently, to the series level values as $n$ increases. The last point on the left in the straightline plot, for $n=12$, would fall on the straight line if the position of $12 g^{5} \mathrm{G}_{6}^{\circ}$ were raised by $0.2 \mathrm{~cm}^{-1}$. Since this level is based on two weak lines-transitions to $4 f^{5} \mathrm{~F}_{5}$ and $5 f{ }^{5} \mathrm{~F}_{5}$ the observational uncertainty in its position is about $0.1 \mathrm{~cm}^{-1}$. In any case a series of this regularity leaves small doubt about the reality of any of its members.

Another example of a fairly regular series, $n s^{5} \mathrm{~S}^{\circ}$, is shown in figure 9, along with the perturbed $n s^{3} \mathrm{~S}^{\circ}$

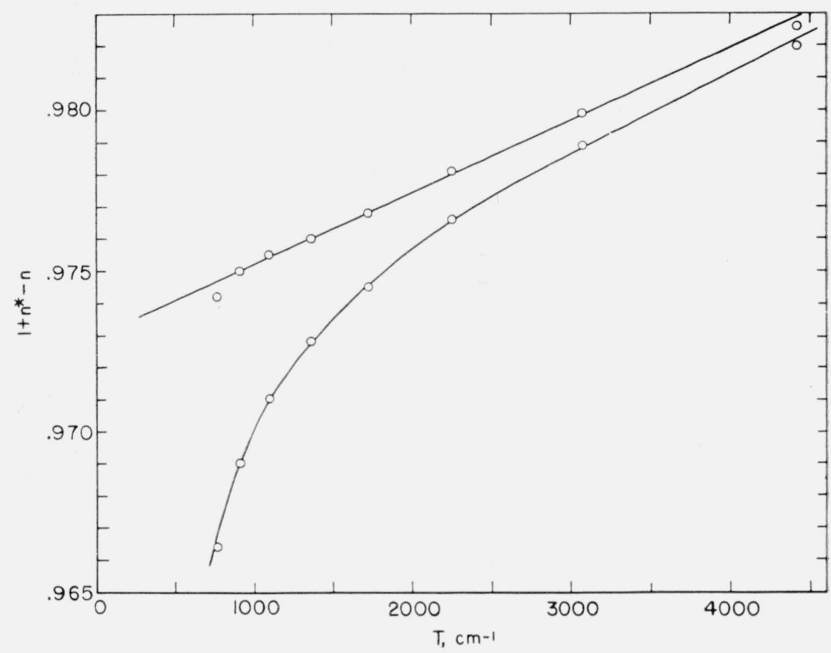

Figure 8. The $\left({ }^{4} \mathrm{~S}^{\circ}\right) \mathrm{ng}{ }^{5} \mathrm{G}^{\circ}{ }_{6}$ series plotted for two different limit values, $154304 \mathrm{~cm}^{-1}$ (straight line) and $154308 \mathrm{~cm}^{-1}$ (curved line).

The series runs from $n=5$, at the right, through $n=12$.

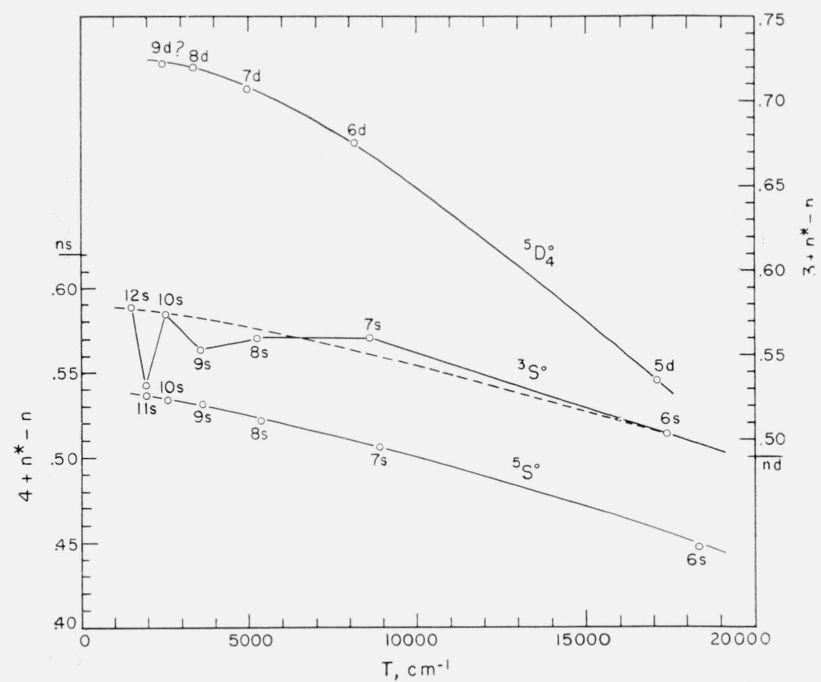

Figure 9. Three series in I II based on the I III $5 \mathrm{p}^{3}{ }^{4} \mathrm{~S}^{\circ}$ lumit at $154304 \mathrm{~cm}^{-1}$ above the ground level of III. 
series. The behavior of the latter series is certainly too irregular to be caused by a single perturbing level. $\mathrm{By}$ analogy with the ${ }^{5} \mathrm{~S}^{\circ}$ series, one might guess that the dashed line shown in figure 9 approximates a hypothesized "unperturbed" behavior of the " $\mathrm{S}^{\circ}$ series. The fact that $9 s^{3} \mathrm{~S}_{1}^{\circ}$ combines strongly with $5 p^{4}{ }^{1} \mathrm{D}_{2}$, whereas the analogous transition for the other $n s{ }^{3} \mathrm{~S}^{\circ}$ levels does not occur or is quite weak, suggests that the level $6 d^{\prime} 15_{1}^{\circ}$ is mainly responsible for the depression of $9 s^{3} \mathrm{~S}_{1}^{\circ}$. This $15_{1}^{\circ}$ level, only 375 $\mathrm{cm}^{-1}$ above $9 s^{3} \mathrm{~S}_{1}^{\circ}$, combines with $5 p^{4}{ }^{1} \mathrm{D}_{2}$ in a transition just twice as strong as the $5 p^{4}{ }^{1} \mathrm{D}_{2}-9 s^{3} \mathrm{~S}_{1}^{\circ}$ line. Similarly, an interaction probably exists between $11 s^{3} \mathrm{~S}_{1}^{\circ}$ and either or both of the slightly higher levels $25_{1}^{\circ}$ and $29_{1}^{\circ}$. The perturbations of the ${ }^{3} \mathrm{~S}^{\circ}$ series are actually not very large. For example, the perturbation required to remove the point for $11 s^{3} \mathrm{~S}^{\circ}$ from the dashed line to the position shown is only $90 \mathrm{~cm}^{-1}$ (a change of $22 \mathrm{~cm}^{-1}$ in the reduced term value).

The $n d{ }^{5} \mathrm{D}_{4}^{\circ}$ series is shown in figure 9 as an example of an apparently regular series which nevertheless fails to obey the simple Ritz formula. It is clear that a limit position determined by assuming such a series to be Ritzian will be too low. A previous value reported [29] by us for the principal ionization energy of I II, $19.12 \mathrm{ev}$, corresponds to a limt of $154260 \mathrm{~cm}^{-1}$ derived from the $n s^{5} \mathrm{~S}_{2}^{\circ}$ and $n d^{5} \mathrm{D}_{4}^{\circ}$ series.

On the basis of the $n g{ }^{5} \mathrm{G}_{6}^{\circ}$ series in figure 8 , it seems reasonable to take the position of I III $5 p^{3}{ }^{4} \mathrm{~S}^{\circ}$ as $154304 \pm 1 \mathrm{~cm}^{-1}$ above the ground level of I II. By combining this result with a recent value [30] for the conversion factor, (wavenumber)/(energy in electronvolts $)=8066.03 \pm 0.14 \mathrm{~cm}^{-1} \mathrm{ev}^{-1}$, we obtain 19.1301 $\pm 0.0004 \mathrm{ev}$ for the principal ionization energy of I II. If the conversion factor adopted in the AEL volumes is applied to our new limit, the resulting energy is $19.126 \mathrm{ev}$.

\section{Conclusion}

The earlier analyses of the I II spectrum, which yielded 43 even and 55 odd levels, have been revised and extended to include 124 even and 190 odd levels. The revisions include changed designations for over 40 levels, improved values for all previously known levels, and new Landé $g_{\mathrm{J}}$ factors for 46 levels. All previously known series have been extended and new ones found. The ionization potential of I II is well determined by one of the new series, $\left({ }^{4} \mathrm{~S}^{\circ}\right) n g{ }^{5} \mathrm{G}_{6}^{\circ}$. Wherever feasible, the results of the analysis have been compared with theory and with experimental findings for homologous and isoelectronic atoms.

This improved analysis was made possible by the observation of almost 2400 I II lines excited in an electrodeless lamp. We have measured the Zeeman patterns of 83 lines. About 1800 lines are now classified, as compared to approximately 500 lines classified in previous analyses. None of the remaining unclassified lines is very strong. The present list includes approximately 300 lines in the vacuum ultraviolet region, 655 to $2000 \mathrm{~A}$, and extends to $11085 \mathrm{~A}$ in the infrared. The measurement of the vacuum ultraviolet spectrum has yielded an accurate value for the connection between the higher levels and those of the ground configuration.

We have observed two magnetic dipole transitions among levels of the $5 p^{4}$ ground configuration and verified their nature by the Zeeman effect.

This work was begun at the suggestion of Dr. C. C. Kiess, who measured most of the Zeeman patterns in connection with the investigation of the first spectrum of iodine. Charlotte Moore compiled most of the new $g_{J}$ values and prepared a preliminary line list for the region above $2000 \mathrm{~A}$. Mrs. Ruth Peterson has very accurately carried out the hand calculations needed for a new I II square array. She also punched the input cards used in calculations made at the Bureau IBM 704 installation.

The observed wavelengths in air were reduced to vacuum wavenumbers on the 704 with a code devised by Charles DeW. Coleman and William R. Bozman. In addition, an energy level search program written by Coleman and Bozman for the computer can be credited with finding a good number of the higher levels. Mr. Bozman has generously devoted many hours to assisting us with the computer work.

The numerical computations involved in an intermediate-coupling calculation for the $5 p^{3} 6 s$ configuration were carried out on the 704 by Dr. Richard E. Trees, using a code written by him. Dr. Trees has also been of help in some of the other theoretical calculations.

Together with Mrs. Agnes Rhodes, who typed and proofread the manuscript, each of these colleagues deserves our sincere thanks for assisting in this work.

\section{References}

[1] C. E. Moore, Atomic energy levels, NBS Cir. 467, Vol. I (1949), Vol. II (1952), Vol. III (1958).

[2] C. H. Corliss, W. R. Bozman, and F. O. Westfall, J. Opt. Soc. Am. 43, 398 (1953).

[3] P. Lacroute, Ann. Phys. (11) 3, 5 (1935); Ann. Astrophys. 2, 318 (1939). References to Lacroute's earlier work and to the previous observations of others are given in these papers.

[4] K. Murakawa, Z. Phys. 109, 162 (1938). Contains references to previous work.

[5] K. Murakawa, Z. Phys. 112, 234 (1939).

[6] L. Bloch and E. Bloch, Ann. Phys. (10) 11, 141 (1929).

[7] L. Bloch, E. Bloch, and N. Felici, J. Phys. Radium 8, 355 (1937).

[8] C. C. Kiess and C. H. Corliss, J. Research NBS 63A, 1 (1959).

[9] K. T. Compton and J. C. Boyce, Rev. Sci. Instr. 5, 218 (1934).

[10] H. A. Robinson and G. H. Shortley, Phys. Rev. 52, 713 (1937).

[11] E. U. Condon and G. H. Shortley, Theory of atomic spectra (Cambridge University Press, Cambridge, England, 1951).

[12] J. E. Ruedy and R. C. Gibbs, Phys. Rev. 46, 880 (1934).

[13] H. Niewodniczanski and F. Lipinski, Nature 142, 1160 (1938).

[14] Bengt Edlén, Phys. Rev. 65, 248 (1944).

[15] S. Mrozowski, J. Opt. Soc. Am. 46, 663 (1956).

[16] G. H. Shortley, L. H. Aller, J. G. Baker, and D. H. Menzel, Ap. J. 93, 178 (1941). 
[17] H. Niewodniczanski, Acta Phys. Polon. 3, 285 (1934).

[18] K. Murakawa, J. Phys. Soc. Japan 13, 484 (1958).

[19] S. Goudsmit, Phys. Rev. 37, 663 (1931).

[20] H. B. G. Casimir, Verhandel, Teyler's Tweede Genootschap, Haarlem (1936).

[21] R. E. Trees, Phys. Rev. 92, 308 (1953).

[22] S. Mrozowski, Phys. Rev. 58, 1086 (1940).

[23] E. Gerjuoy, Phys. Rev. 60, 233 (1941).

[24] H. E. White, Introduction to Atomic Spectra. ch. 18, sec. 10 (McGraw-Hill Book Co., Inc., New York, N.Y., 1934).

[25] F. A. Jenkins and S. Mrozowski, Phys. Rev. 60, 225 (1941).
[26] C. J. Humphreys, J. Research NBS 16, 639 (1936) RP 898.

[27] G. Racah, Phys. Rev. 61, 537 (L) (1942).

[28] Rydberg interpolation table (published by Depts. of Physies and Astronomy, Princeton University, Princeton, N. J., 1934).

[29] W. C. Martin and C. H. Corliss, J. Opt. Soc. Am. 48, 865 (A) (1958).

[30] J. W. M. DuMond and E. R. Cohen, Handbook of Physies, pt. 7, ch. 10, p. 170 (ed. by E. ¡U. Condon and H. Odishaw, MeGraw-Hill Book Co., Ine. New York, N.Y., 1958).

\section{Appendix}

TABLE 10.1. Observed lines of I II

\begin{tabular}{|c|c|c|c|c|}
\hline $\begin{array}{c}\lambda(\text { vac }) \\
\text { observed }\end{array}$ & $\begin{array}{c}\lambda(\mathrm{vac}) \\
\text { calculated }\end{array}$ & Intensity & $\begin{array}{c}\text { Observed } \\
\text { wavenumber, } \\
\mathrm{cm}^{-1}\end{array}$ & Classification \\
\hline $\begin{array}{l}\text { 655. } 804 \\
657.029 \\
659.004 \\
661.412 \\
663.977\end{array}$ & & $\begin{array}{l}2 \\
1 \\
6 \\
1 \\
8\end{array}$ & $\begin{array}{l}152484.6 \\
152200.3 \\
151744.1 \\
151191.7 \\
150607.6\end{array}$ & $\begin{array}{lll}5 p^{4}{ }^{3} \mathrm{P}_{2}- & 51_{1}^{\circ},{ }_{2}, \\
5 p^{4} & { }^{3} \mathrm{P}_{2} & 49_{1}^{\circ}, 2 \\
5 p^{4} & { }^{3} \mathrm{P}_{2}-14 d^{3} \mathrm{D}_{3}^{\circ} \\
5 p^{4}{ }^{3} \mathrm{P}_{2}-13 d^{3} \mathrm{D}_{3}^{\circ}\end{array}$ \\
\hline $\begin{array}{ll}664 . & 031 \\
664 . & 520 \\
665 . & 055 \\
665 . & 135 \\
665 . & 699\end{array}$ & $\begin{array}{l}.512 \\
.041 \\
.132 \\
.695\end{array}$ & $\begin{array}{r}3 \\
8 \\
8 \\
5 \\
150\end{array}$ & $\begin{array}{l}150595.4 \\
150484.6 \\
150363.5 \\
150345.4 \\
150218.0\end{array}$ & $\begin{array}{lll}5 p^{4}{ }^{3} \mathrm{P}_{2} & 48_{1}^{\circ},{ }_{2} \\
5 p^{4} & { }^{3} \mathrm{P}_{2} & 47_{1},{ }_{2} \\
5 p^{4} & { }^{3} \mathrm{P}_{2} & 46_{2}^{\circ} \\
5 p^{4} & { }^{3} \mathrm{P}_{2} & 45_{1}^{\circ},{ }_{2} \\
5 p^{4} & { }^{3} \mathrm{P}_{2} & 43_{1}^{\circ},{ }_{2}\end{array}$ \\
\hline $\begin{array}{l}\text { 666. } 660 \\
667.270 \\
668.264 \\
668.976 \\
672.505\end{array}$ & $\begin{array}{l}653 \\
250 \\
981 \\
491\end{array}$ & $\begin{array}{r}150 \\
100 \\
15 \\
25 \\
40\end{array}$ & $\begin{array}{l}\text { 150001. } 5 \\
149864.4 \\
149641.4 \\
149482.2 \\
148697.8\end{array}$ & 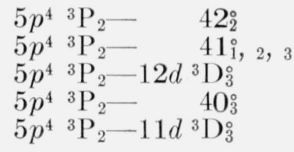 \\
\hline $\begin{array}{l}\text { 674. } 063 \\
675.748 \\
676.493 \\
678.856 \\
679.155\end{array}$ & $\begin{array}{l}.732 \\
.480 \\
.853 \\
.152\end{array}$ & $\begin{array}{r}4 \\
1 \\
80 \\
200 \\
5\end{array}$ & $\begin{array}{l}\text { 148354. } 1 \\
\text { 147984. } 2 \\
147821.2 \\
147306.6 \\
147241.8\end{array}$ & 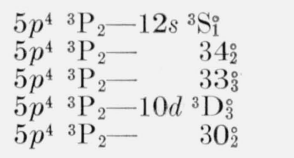 \\
\hline $\begin{array}{l}\text { 679. } 618 \\
680.971 \\
681.266 \\
682.180\end{array}$ & $\begin{array}{l}616 \\
967 \\
.269 \\
.179\end{array}$ & $\begin{array}{r}50 \\
15 \\
6 \\
25\end{array}$ & $\begin{array}{l}147141.5 \\
146849.2 \\
146785.5 \\
146588.9\end{array}$ & $\begin{array}{lll}5 p^{4} & { }^{3} \mathrm{P}_{2}-10 d{ }^{3} \mathrm{D}_{2}^{\circ} \\
5 p^{4} & { }^{3} \mathrm{P}_{2}- & 26_{3}^{\circ} \\
5 p^{4} & { }^{3} \mathrm{P}_{2}- & 25_{1}^{\circ},{ }_{2} \\
5 p^{4} & { }^{3} \mathrm{P}_{2}-11 s & { }^{3} \mathrm{~S}_{1}^{\circ}\end{array}$ \\
\hline $\begin{array}{ll}\text { 682. } & 685 \\
683 . & 414 \\
683 . & 569 \\
685 . & 685 \\
689 . & 294\end{array}$ & $\begin{array}{l}682 \\
.565 \\
.694\end{array}$ & $\begin{array}{r}40 \\
1 \\
80 \\
1 \\
15\end{array}$ & $\begin{array}{l}146480.4 \\
146324.2 \\
146291.0 \\
145839.6 \\
145076.0\end{array}$ & $\begin{array}{l}5 p^{4}{ }^{3} \mathrm{P}_{2}- \\
5 p^{4}{ }^{3} \mathrm{P}_{2}- \\
5 p^{4}{ }^{3} \mathrm{P}_{2}-\end{array}$ \\
\hline $\begin{array}{ll}689 . & 817 \\
690 . & 082 \\
690 . & 272 \\
690 . & 453 \\
691 . & 194\end{array}$ & $\begin{array}{l}.822 \\
\\
.455 \\
.193\end{array}$ & $\begin{array}{r}250 \\
5 \\
3 \\
80 \\
15\end{array}$ & $\begin{array}{l}\text { 144966. } 0 \\
144910.3 \\
144870.4 \\
144832.4 \\
144677.2\end{array}$ & $\begin{array}{l}5 p^{4}{ }^{3} \mathrm{P}_{2}-9 d^{3} \mathrm{D}_{3}^{\circ} \\
5 p^{4}{ }^{3} \mathrm{P}_{2}-9 d^{3} \mathrm{D}_{2}^{\circ} \\
5 p^{4}{ }^{3} \mathrm{P}_{2}-8 s^{\prime}{ }^{3} \mathrm{D}_{2}^{\circ}\end{array}$ \\
\hline $\begin{array}{l}\text { 691. } 295 \\
693.567 \\
696.630 \\
696.840 \\
697.358\end{array}$ & .566 & $\begin{array}{r}5 \\
40 \\
1 \\
1 \\
1 h\end{array}$ & $\begin{array}{l}\text { 144656. } 0 \\
144182.2 \\
143548.2 \\
143505.0 \\
143398.4\end{array}$ & $\begin{array}{lll}5 p^{4} & { }^{3} \mathrm{P}_{1}- & 49_{1}^{\circ}, 2 \\
5 p^{4} & { }^{3} \mathrm{P}_{2}-10 s & { }^{3} \mathrm{~S}_{\mathrm{i}} \\
& & \\
5 p^{4} & { }^{3} \mathrm{P}_{1}- & 48_{1}^{\circ}, 2 \\
5 p^{4} & { }^{3} \mathrm{P}_{1}- & 47_{1}^{\circ}, 2\end{array}$ \\
\hline $\begin{array}{l}\text { 697. } 606 \\
697.940 \\
698.032 \\
698.650 \\
699.697\end{array}$ & $\begin{array}{l}936 \\
.036 \\
.656 \\
.712\end{array}$ & $\begin{array}{r}10 \\
5 \\
3 \\
8 \\
1\end{array}$ & $\begin{array}{l}\text { 143347. } 4 \\
143278.8 \\
143259.9 \\
143133.2 \\
142919.0\end{array}$ & $\begin{array}{ll}5 p^{4} & { }^{3} \mathrm{P}_{1}- \\
5 p^{4} & { }^{3} \mathrm{P}_{1} \\
5 p^{4} & { }^{3} \mathrm{P}_{1}- \\
5 p^{4} & { }^{3} \mathrm{P}_{1}-\end{array}$ \\
\hline
\end{tabular}


TABLE 10.1. Observed lines of I II-Continued

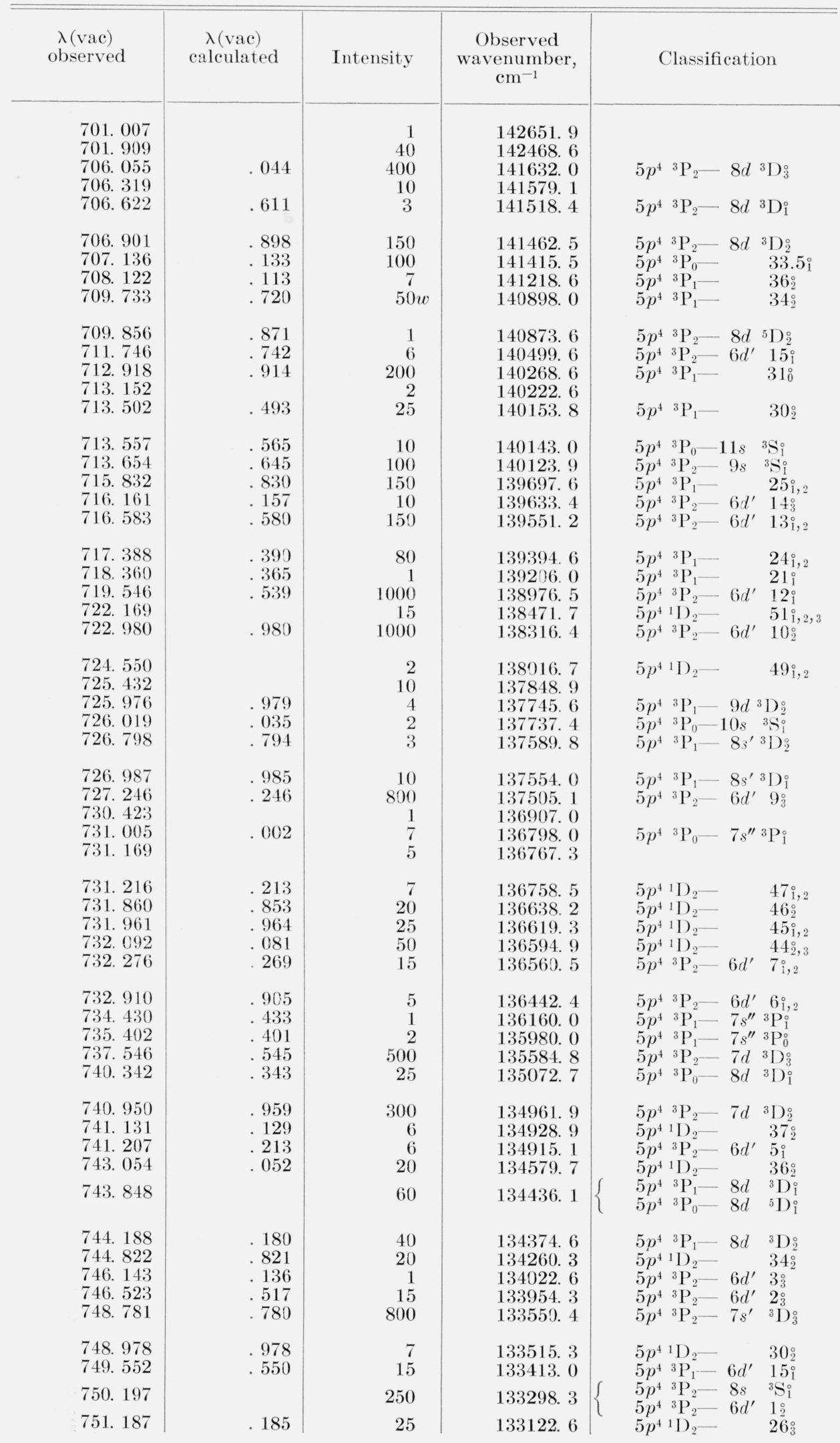


TABLE 10.1. Observed lines of I II-Continued

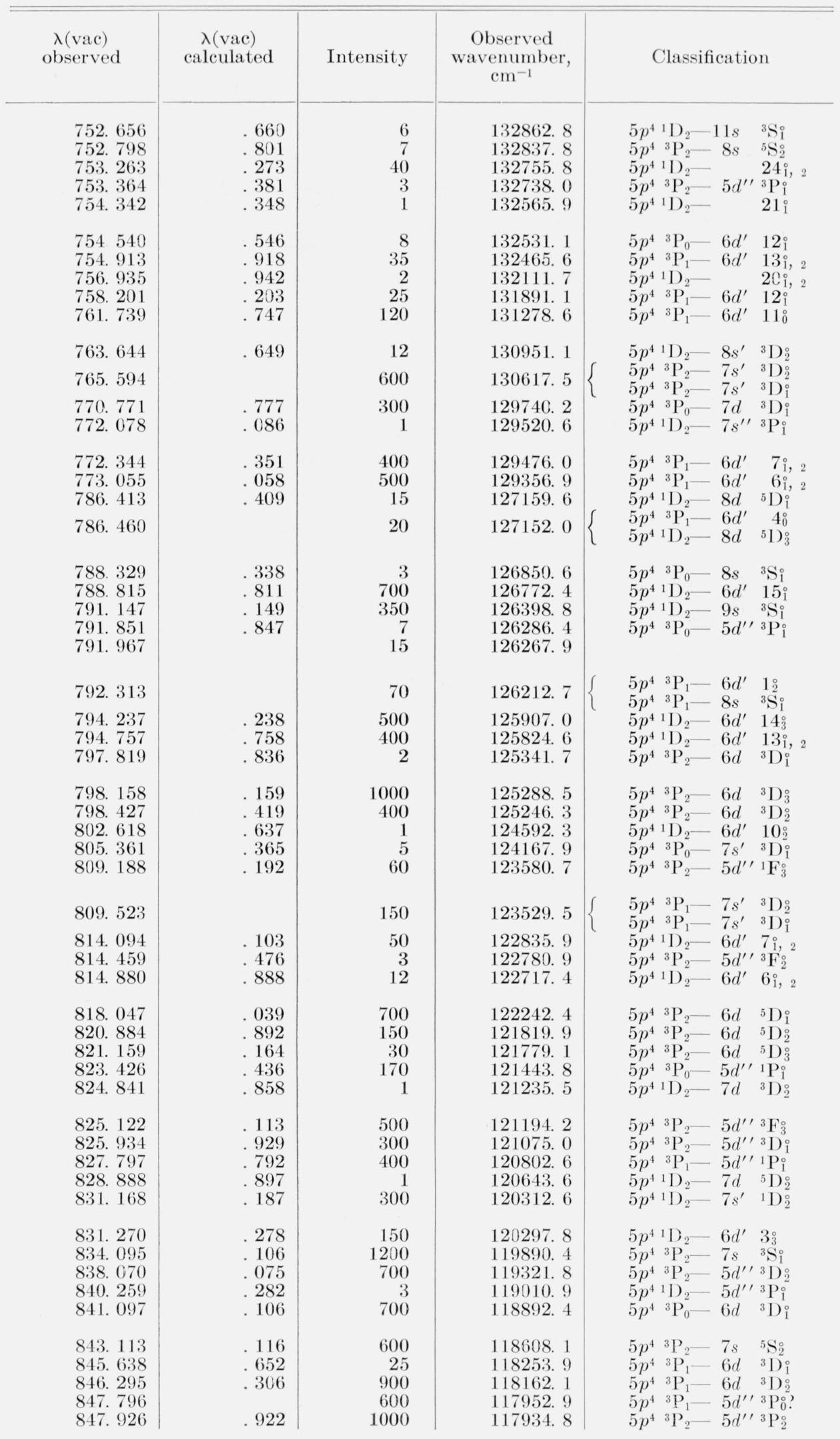


TABLE 10.1. Observed lines of I II-Continued

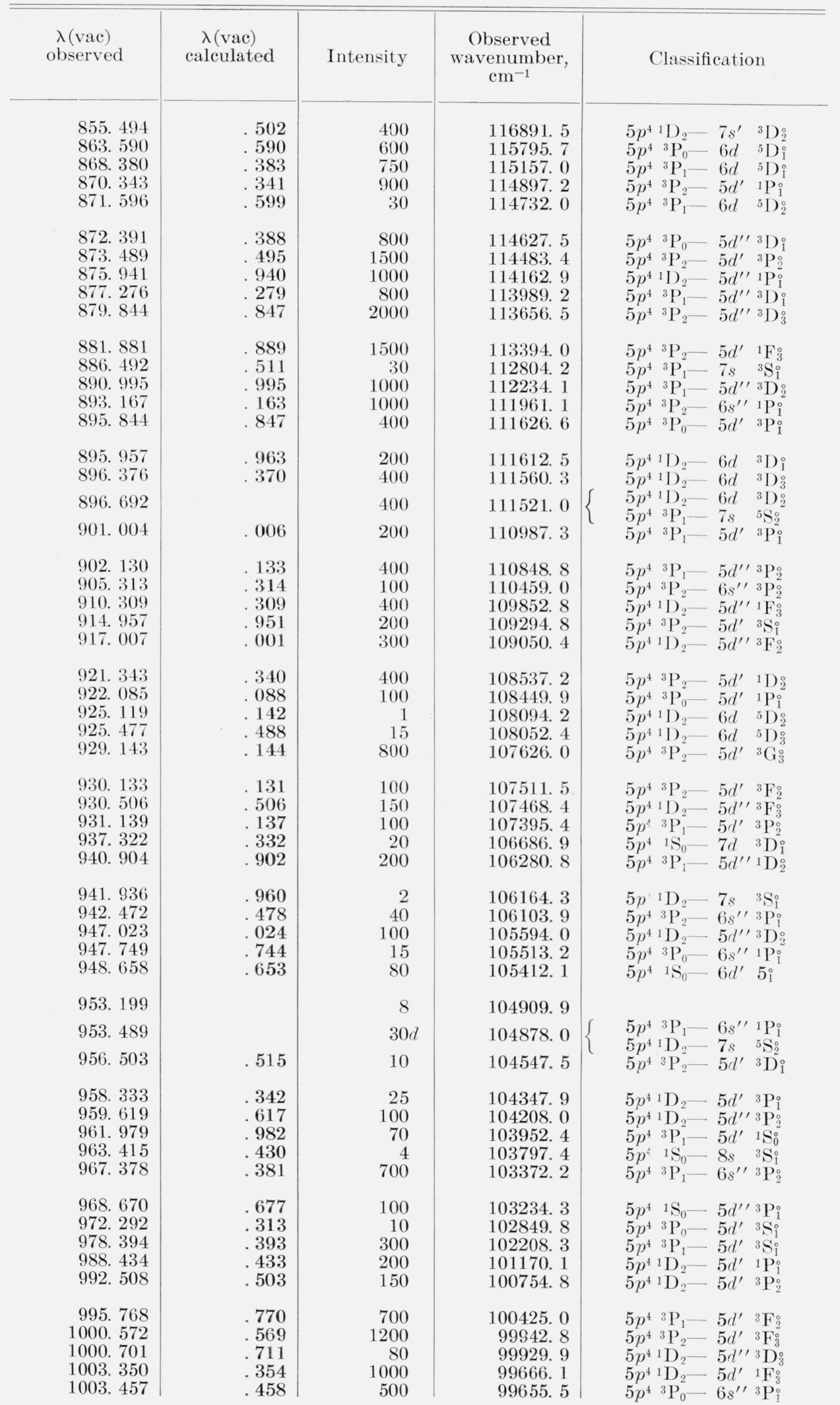


TABLE 10.1. Observed lines of $\mathrm{I}_{\mathrm{II}}$-Continued

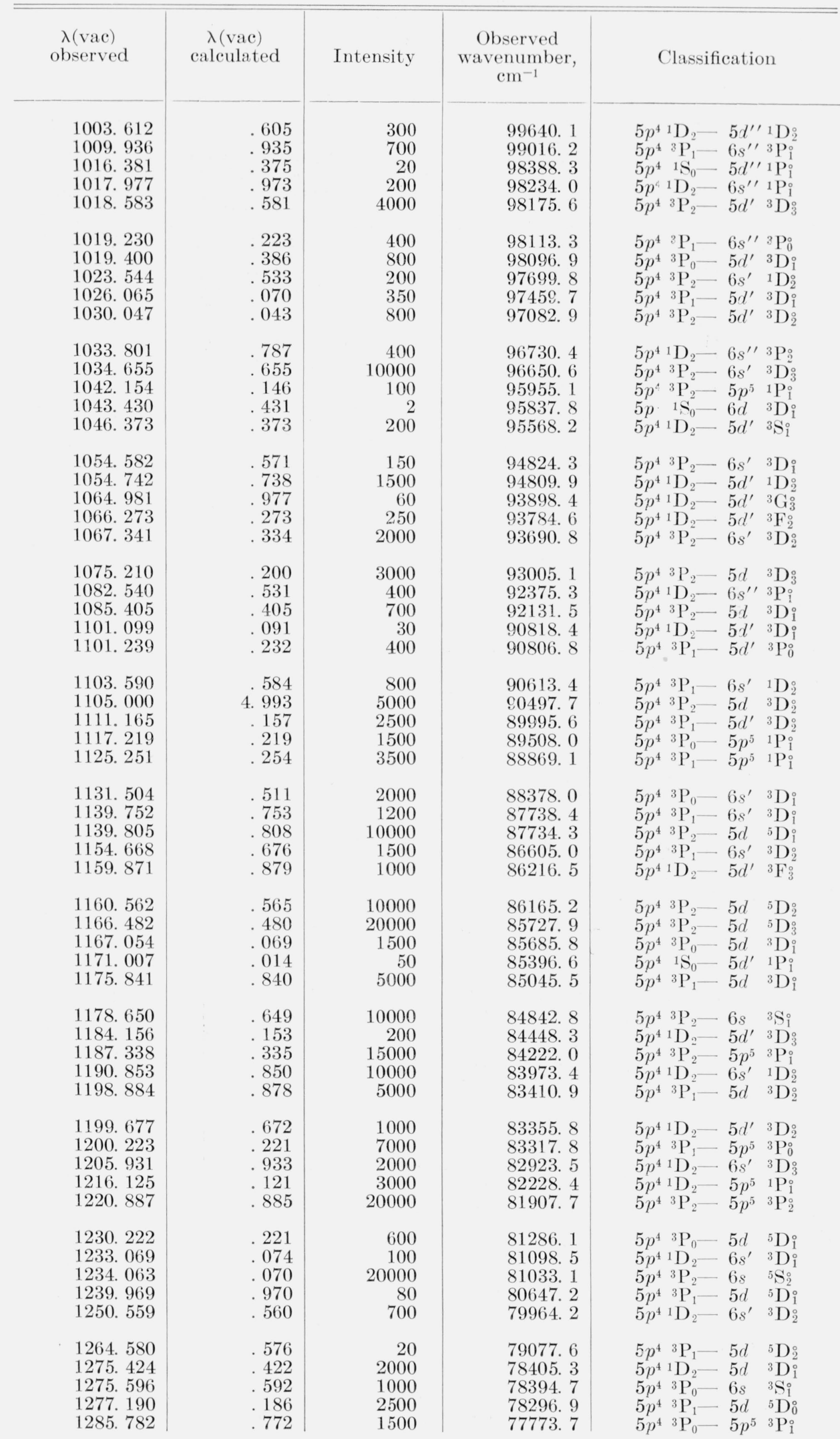


TABLE 10.1. Observed lines of I II-Continued

\begin{tabular}{|c|c|c|c|c|}
\hline $\begin{array}{c}\lambda(\text { vac }) \\
\text { observed }\end{array}$ & $\begin{array}{c}\lambda(\mathrm{vac}) \\
\text { calculated }\end{array}$ & Intensity & $\begin{array}{c}\text { Observed } \\
\text { wavenumber, } \\
\mathrm{cm}^{-1}\end{array}$ & Classification \\
\hline $\begin{array}{l}1286.084 \\
1296.416 \\
1302.580 \\
1332.533 \\
1336.517\end{array}$ & $\begin{array}{l}.076 \\
425 \\
.573 \\
536 \\
.527\end{array}$ & $\begin{array}{r}4000 \\
3000 \\
150 \\
12 \\
20000\end{array}$ & $\begin{array}{l}77755.4 \\
77135.7 \\
76770.7 \\
75045.0 \\
74821.3\end{array}$ & $\begin{array}{lll}5 p^{4}{ }^{3} \mathrm{P}_{1}-6 s & { }^{3} \mathrm{~S}_{1} \\
5 p^{4} & { }^{3} \mathrm{P}_{1}-5 p^{5} & { }^{3} \mathrm{P}_{1} \\
5 p^{4}{ }^{1} \mathrm{D}_{2}-5 d & { }^{3} \mathrm{D}_{2}^{\circ} \\
5 p^{4} & { }_{1} \mathrm{~S}_{0}-5 d^{\prime} & { }^{3} \mathrm{D}_{1}^{\circ} \\
5 p^{4} & { }^{3} \mathrm{P}_{1}-5 p^{5} & { }^{3} \mathrm{P}_{2}^{0}\end{array}$ \\
\hline $\begin{array}{l}1351.219 \\
1380.501 \\
1406.138 \\
1418.539 \\
1466.673\end{array}$ & $\begin{array}{l}225 \\
497 \\
.159 \\
540 \\
.693\end{array}$ & $\begin{array}{r}20 \\
500 \\
10 \\
25 \\
1000\end{array}$ & $\begin{array}{l}\text { 74007. } 2 \\
72437.5 \\
71116.8 \\
70495.1 \\
68181.5\end{array}$ & $\begin{array}{lll}5 p^{4}{ }^{1} \mathrm{D}_{2}-5 d & { }^{5} \mathrm{D}_{1} \\
5 p^{4} & { }^{1} \mathrm{D}_{2}-5 d & { }^{5} \mathrm{D}_{2}^{\circ} \\
5 p^{4}{ }^{1} \mathrm{D}_{2}-6 s & { }^{3} \mathrm{~S}_{1}^{\circ} \\
5 p^{4}{ }^{1} \mathrm{D}_{2}-5 p^{5} & { }^{3} \mathrm{P}_{1} \\
5 p^{4}{ }^{1} \mathrm{D}_{2}-5 p^{5} & { }^{3} \mathrm{P}_{2}^{0}\end{array}$ \\
\hline $\begin{array}{l}1485.734 \\
1504.761 \\
1521.068 \\
1700.529 \\
1825.049\end{array}$ & $\begin{array}{l}.763 \\
.788\end{array}$ & $\begin{array}{r}30 \\
10 \\
15 \\
2 \\
2\end{array}$ & $\begin{array}{l}67306.8 \\
66455.7 \\
65743.3 \\
58805.2 \\
54793.0\end{array}$ & 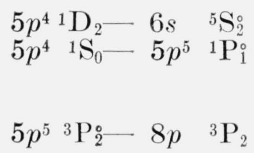 \\
\hline $\begin{array}{l}1826.705 \\
1828.550 \\
1828.729 \\
1859.466\end{array}$ & & $\begin{array}{r}10 \\
3 \\
3 \\
3\end{array}$ & $\begin{array}{l}54743.4 \\
54688.1 \\
54682.8 \\
53778.9\end{array}$ & \\
\hline $\begin{array}{l}1961.837 \\
1964.631 \\
1978.816 \\
1981.360 \\
1990.944\end{array}$ & $\begin{array}{l}.839 \\
.636 \\
.799\end{array}$ & $\begin{array}{l}2 \\
3 \\
2 \\
3 \\
3\end{array}$ & $\begin{array}{l}50972.6 \\
50900.1 \\
50535.3 \\
50470.4 \\
50227.4\end{array}$ & $\begin{array}{llll}5 d & { }^{5} \mathrm{D}_{3}^{\circ}-8 p & { }^{3} \mathrm{P}_{2} \\
5 d & { }^{3} \mathrm{D}_{2}^{\circ}-6 f & { }^{3} \mathrm{~F}_{3} \\
5 d & { }^{5} \mathrm{D}_{2}^{\circ}-8 p & { }^{3} \mathrm{P}_{2}\end{array}$ \\
\hline
\end{tabular}

TABLE 10.1. Observed lines of $\mathrm{I}_{\mathrm{II}}$-Continued

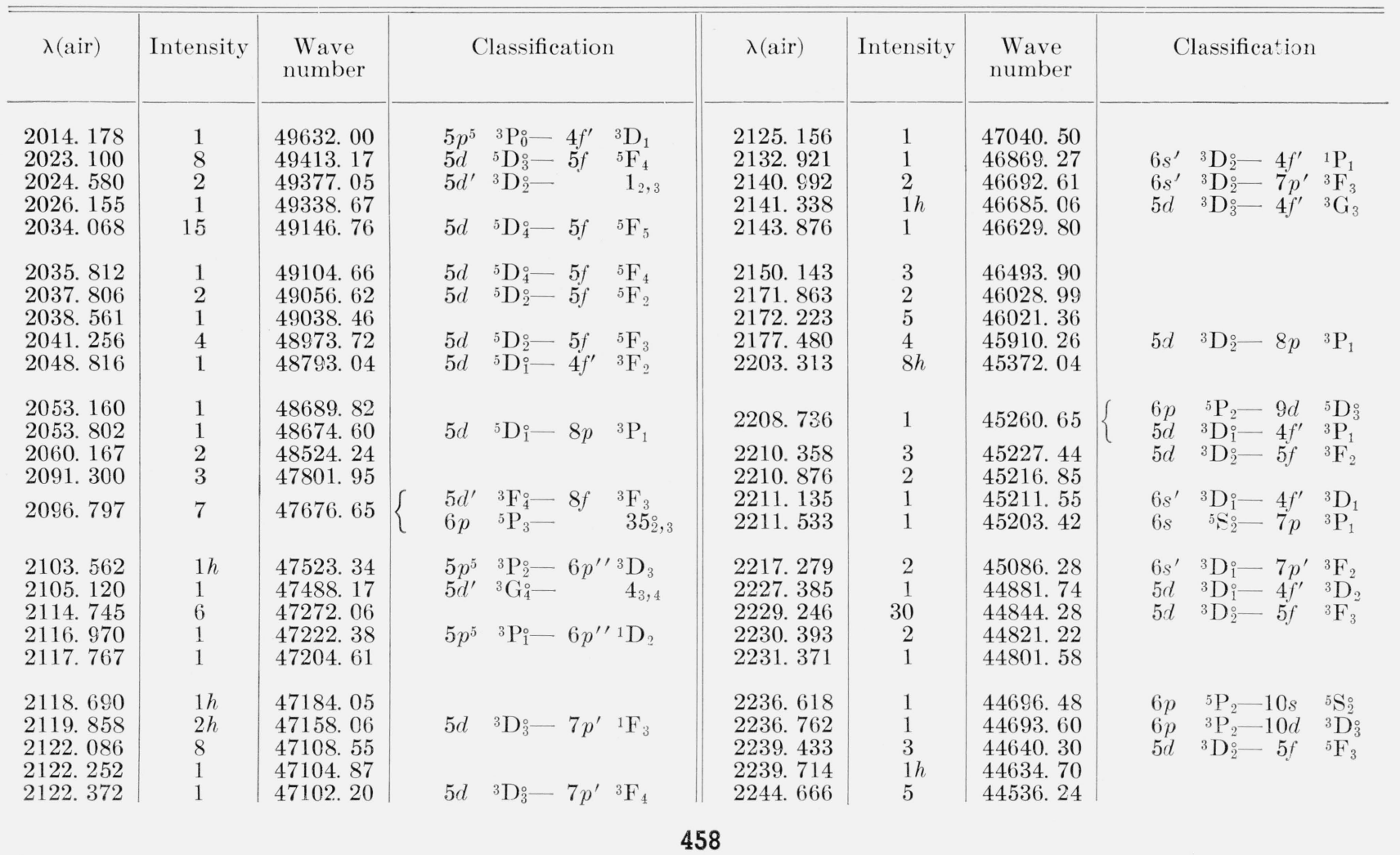


Table 10.1. Observed lines of I II-Continued

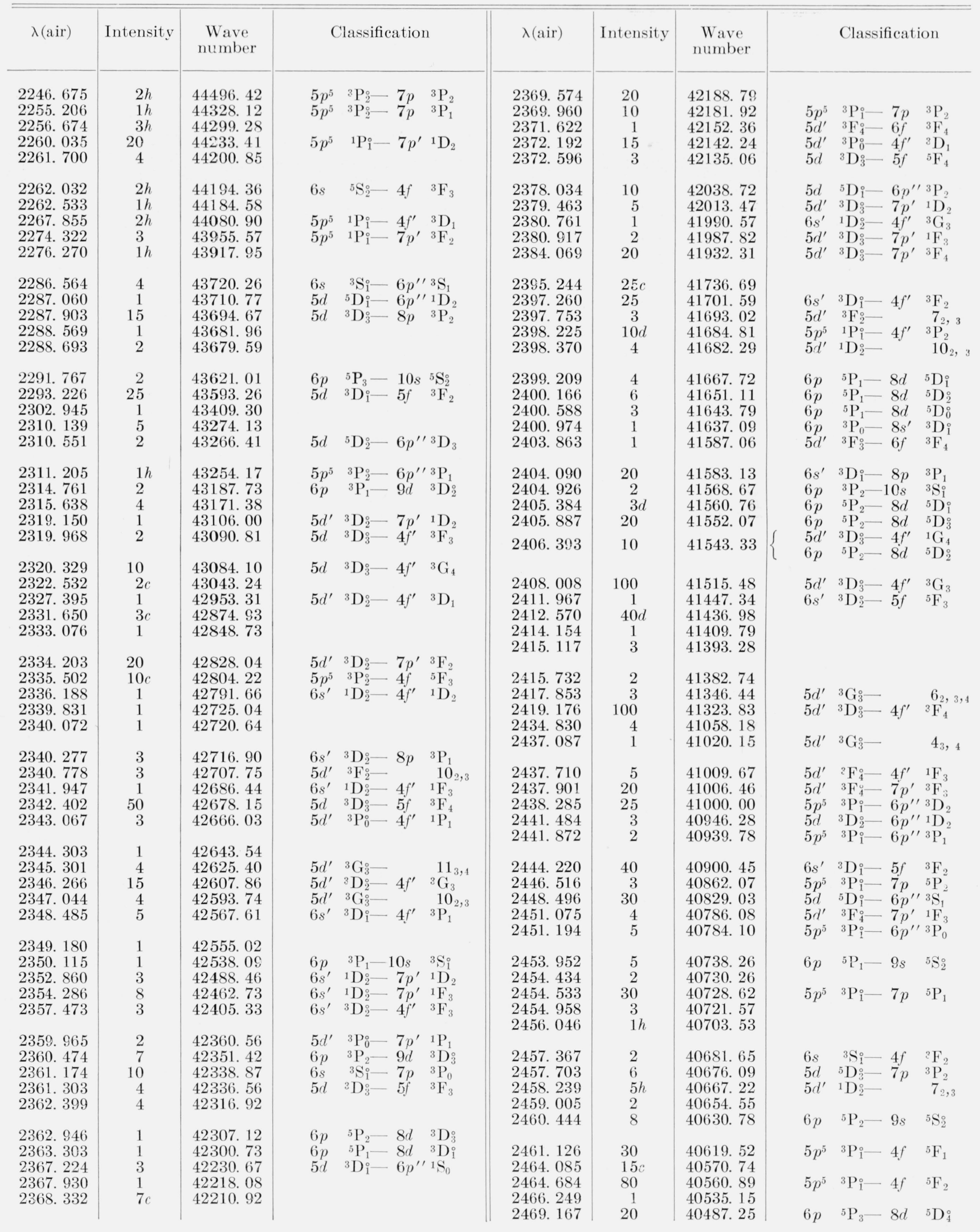


Table 10.1. Observed lines of I II-Continued

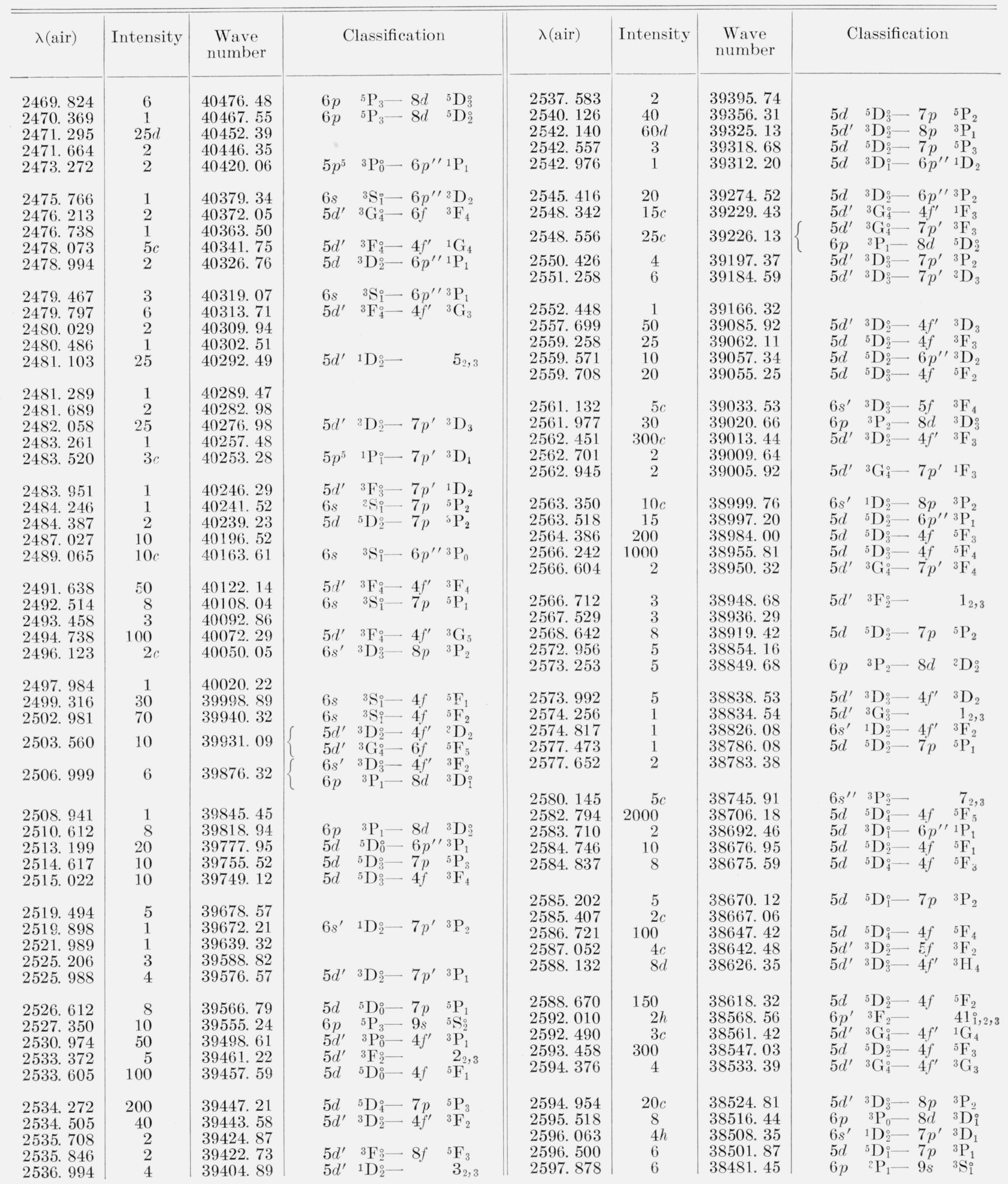


TABLE 10.1. Observed lines of $\mathrm{I}$ II - Continued

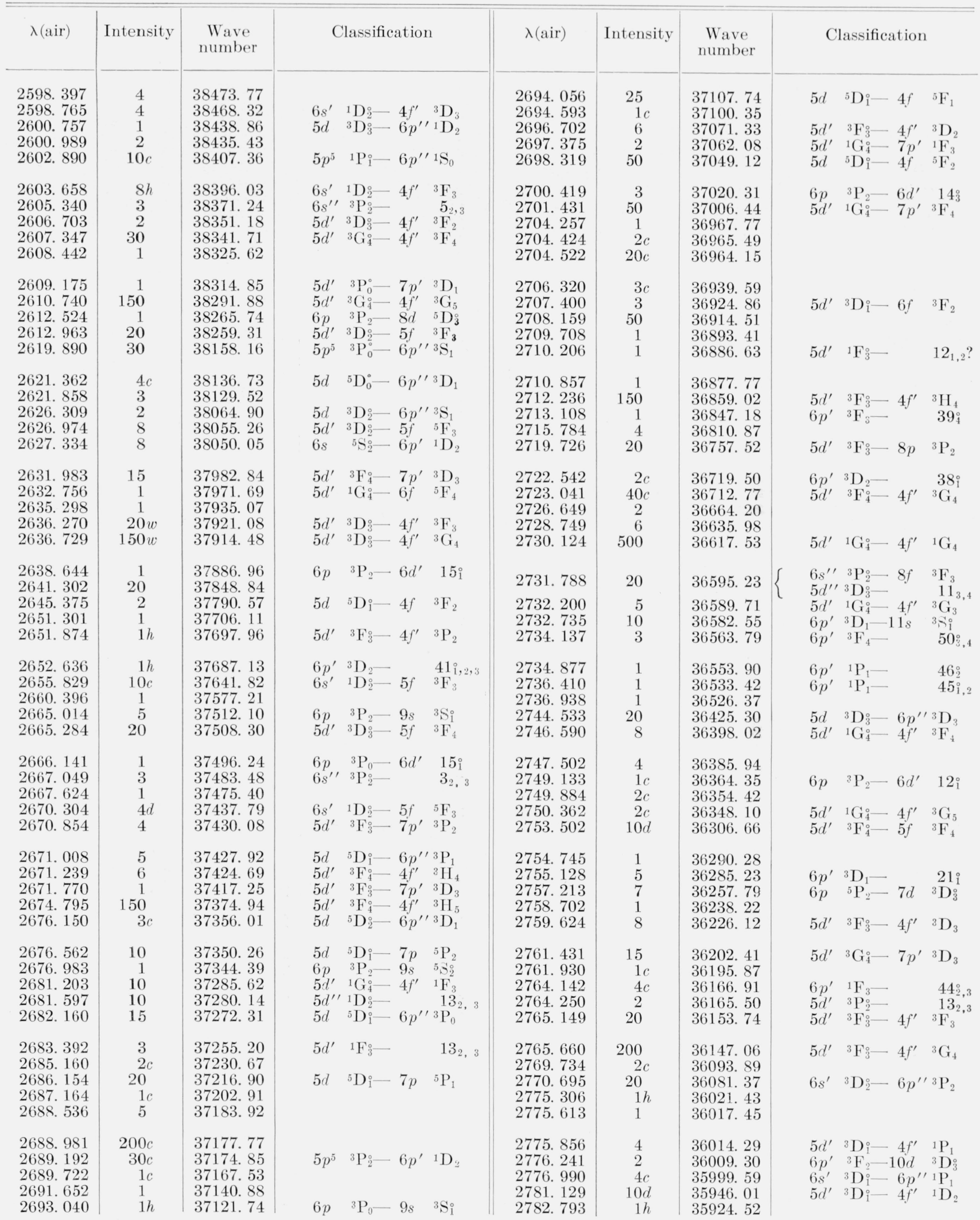


TABLE 10.1. Observed lines of I II-Continued

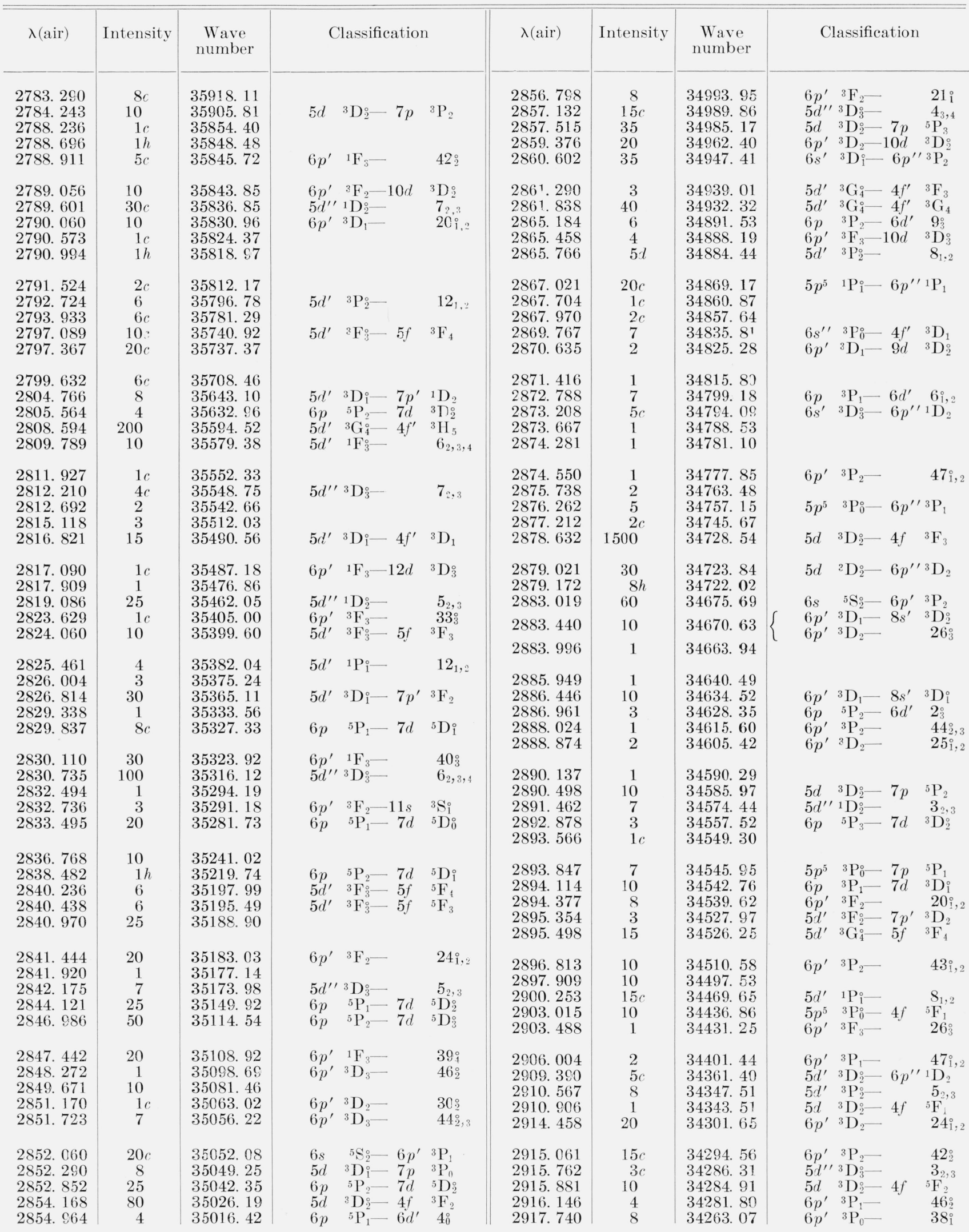


TABle 10.1. Observed lines of I II-Continued

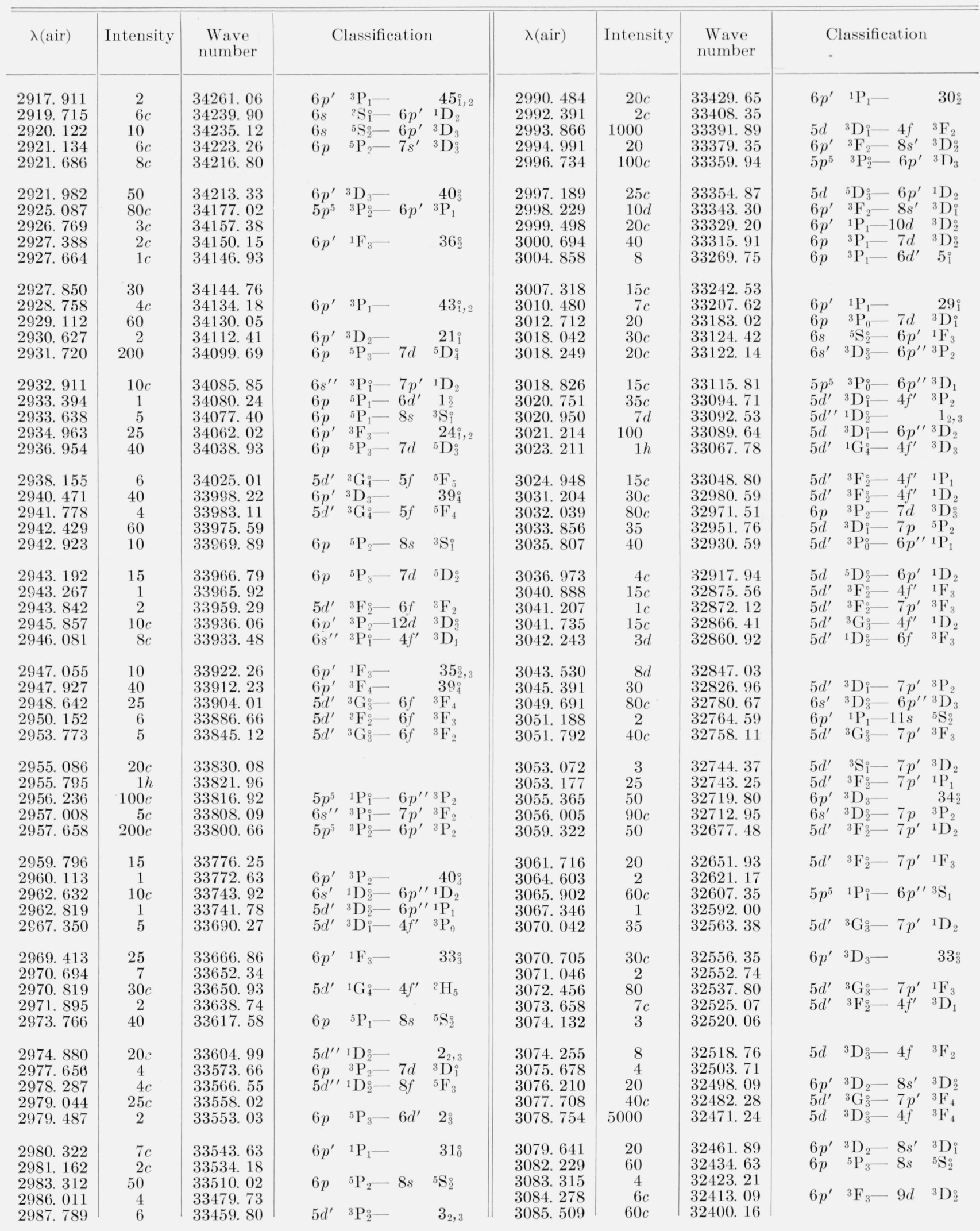


TABLE 10.1. Observed lines of I II-Continued

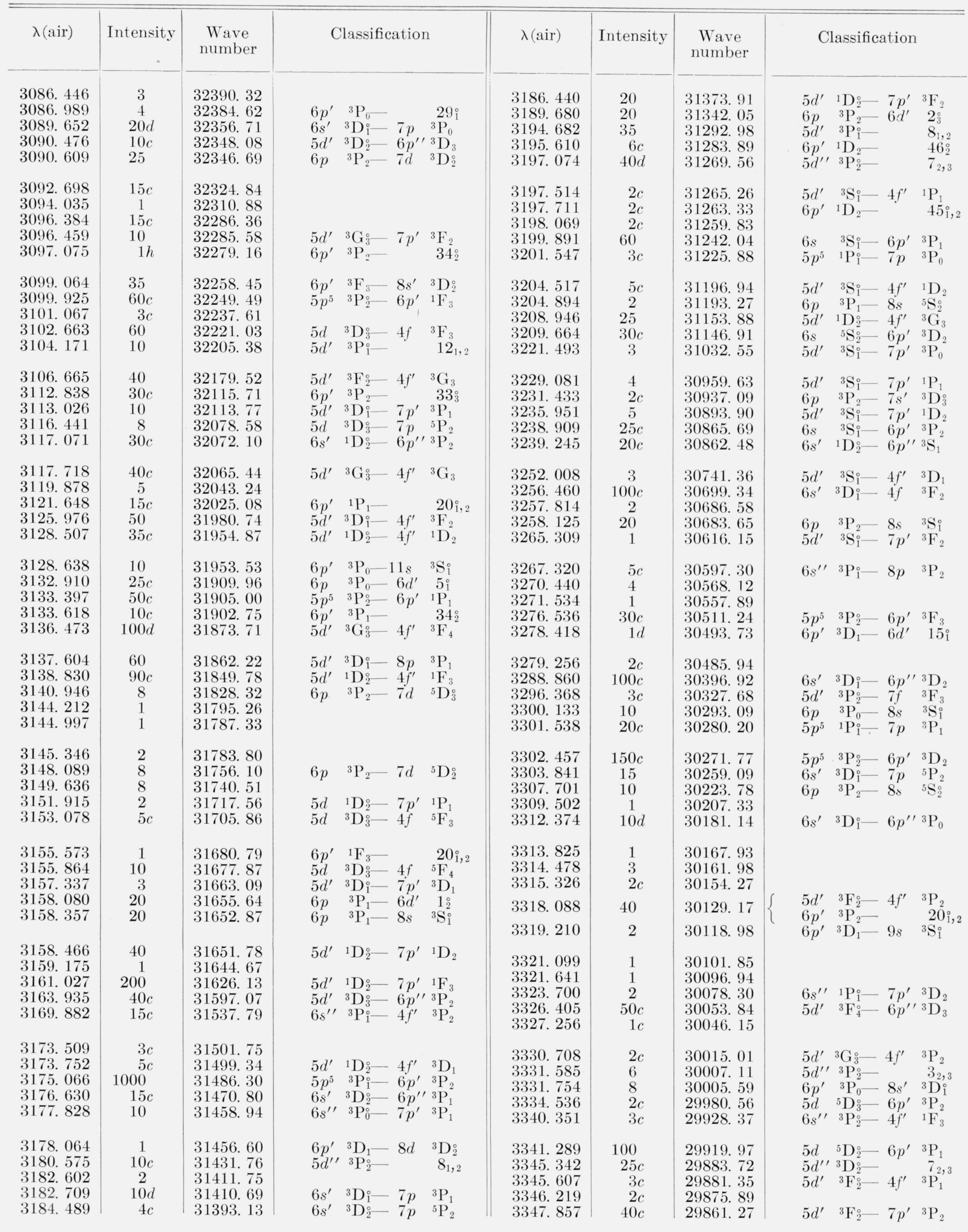


Table 10.1. Observed lines of I II-Continued

\begin{tabular}{|c|c|c|c|c|c|c|c|}
\hline$\lambda($ air $)$ & Intensity & $\begin{array}{l}\text { Wave } \\
\text { number }\end{array}$ & Classification & $\lambda$ (air) & Intensity & $\begin{array}{l}\text { Wave } \\
\text { number }\end{array}$ & Classification \\
\hline $\begin{array}{l}\text { 3349. } 286 \\
3351.394 \\
3352.823 \\
3352.928 \\
3355.531\end{array}$ & $\begin{array}{c}20 \\
30 \\
10 c \\
2 \\
300\end{array}$ & $\begin{array}{l}\text { 29848. } 53 \\
\text { 29829. } 76 \\
\text { 29817. } 04 \\
\text { 29816. } 11 \\
\text { 29792. } 98\end{array}$ & $\begin{array}{lccc}5 d^{\prime} & { }^{3} \mathrm{~F}_{2}- & 7 p^{\prime} & { }^{3} \mathrm{D}_{3} \\
5 d^{\prime} & { }^{3} \mathrm{~F}_{3}-6 p^{\prime \prime} & { }^{3} \mathrm{P}_{2} \\
5 d^{\prime} & { }^{3} \mathrm{D}_{1}^{\circ}-6 p^{\prime \prime} & { }^{1} \mathrm{~S}_{0} \\
6 p^{\prime} & { }^{1} \mathrm{D}_{2}- & & { }^{3} 8_{i}^{\circ} \\
6 s & { }^{3} \mathrm{~S}_{1}-6 p^{\prime} & { }^{3} \mathrm{P}_{0}\end{array}$ & $\begin{array}{l}3464.540 \\
3466.953 \\
3467.261 \\
3468.046 \\
3468.486\end{array}$ & $\begin{array}{l}4 c \\
10 \\
5 c \\
30 c \\
20\end{array}$ & $\begin{array}{l}\text { 28855. } 60 \\
28835.51 \\
28832.95 \\
28826.43 \\
28822.77\end{array}$ & $\begin{array}{lll}5 d^{\prime} & { }^{1} \mathrm{D}_{2}-4 f^{\prime} & { }^{3} \mathrm{P}_{1} \\
5 d^{\prime} & { }^{1} \mathrm{D}_{2}^{\circ}-7 p^{\prime} & { }^{3} \mathrm{P}_{2} \\
6 s^{\prime} & { }^{3} \mathrm{D}_{3}^{\circ}-7 p & { }^{5} \mathrm{P}_{3} \\
6 s^{\prime} & { }^{3} \mathrm{D}_{3}^{\circ}-4 f & { }^{3} \mathrm{~F}_{4} \\
5 d^{\prime} & { }^{1} \mathrm{D}_{2}^{\circ}-7 p^{\prime} & { }^{3} \mathrm{D}_{3}\end{array}$ \\
\hline $\begin{array}{l}\text { 3359. } 961 \\
\text { 3360. } 699 \\
\text { 3362. } 137 \\
\text { 3362. } 598 \\
\text { 3363. } 367\end{array}$ & $\begin{array}{c}150 c \\
8 c \\
7 \\
20 c \\
2\end{array}$ & $\begin{array}{l}29753.70 \\
29747.17 \\
29734.44 \\
29730.37 \\
29723.57\end{array}$ & $\begin{array}{lll}6 s^{\prime} & { }^{3} \mathrm{D}_{3}^{\circ}-7 p & { }^{3} \mathrm{P}_{2} \\
5 d^{\prime} & { }^{3} \mathrm{G}_{3}^{\circ}-7 p^{\prime} & { }^{3} \mathrm{P}_{2} \\
5 d^{\prime} & { }^{3} \mathrm{G}_{3}^{\circ}-7 p^{\prime} & { }^{3} \mathrm{D}_{3} \\
6 s^{\prime \prime} & { }^{3} \mathrm{P}_{2}^{\circ}-7 p^{\prime} & { }^{1} \mathrm{D}_{2}\end{array}$ & $\begin{array}{l}3469.342 \\
3470.131 \\
3478.279 \\
3481.569 \\
3482.917\end{array}$ & $\begin{array}{l}1 \\
6 \\
3 c \\
1 \\
1\end{array}$ & $\begin{array}{l}\text { 28815. } 66 \\
28809.11 \\
28741.62 \\
28714.46 \\
28703.35\end{array}$ & $6 s^{\prime} \quad{ }^{1} \mathrm{D}_{2}^{\circ}-7 p \quad{ }^{3} \mathrm{P}_{2}$ \\
\hline $\begin{array}{l}3365.500 \\
3366.575 \\
3374.457 \\
3378.475 \\
3380.983\end{array}$ & $\begin{array}{r}20 c \\
7 d \\
100 c \\
6 c \\
30 c\end{array}$ & $\begin{array}{l}29704.73 \\
29695.25 \\
29625.89 \\
29590.66 \\
29568.71\end{array}$ & $\begin{array}{llll}6 s^{\prime \prime} & { }^{3} \mathrm{P}_{2}-7 p^{\prime} & { }^{1} \mathrm{~F}_{3} \\
& & & \\
5 d & { }^{5} \mathrm{D}_{3}^{\circ}-6 p^{\prime} & { }^{3} \mathrm{~F}_{4} \\
5 p^{5} & { }^{3} \mathrm{P}_{1}-6 p^{\prime} & { }^{1} \mathrm{P}_{1} \\
5 p^{5} & { }^{1} \mathrm{P}_{1}^{\circ}-4 f & { }^{3} \mathrm{~F}_{2}\end{array}$ & $\begin{array}{l}\text { 3483. } 706 \\
3483.894 \\
3488.509 \\
3489.100 \\
3489.561\end{array}$ & $\begin{array}{c}5 \\
60 c \\
15 \\
2 \\
4\end{array}$ & $\begin{array}{l}\text { 28696. } 85 \\
28695.30 \\
28657.34 \\
28652.49 \\
28648.70\end{array}$ & $\begin{array}{llll}6 s^{\prime} & { }^{3} \mathrm{D}_{1}-6 & 6 p^{\prime \prime} & { }^{3} \mathrm{D}_{1} \\
5 d^{\prime} & { }^{3} \mathrm{~F}_{2}^{\circ}- & 4 f^{\prime} & { }^{3} \mathrm{D}_{3}\end{array}$ \\
\hline $\begin{array}{l}\text { 3382. } 711 \\
3383.858 \\
3386.377 \\
3390.214 \\
3391.360\end{array}$ & $\begin{array}{r}2 \\
80 c \\
4 c \\
15 c \\
7 c\end{array}$ & $\begin{array}{l}29553.60 \\
29543.58 \\
29521.61 \\
29488.20 \\
29478.23\end{array}$ & 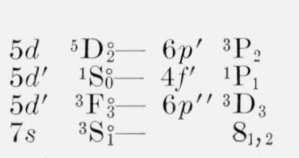 & $\begin{array}{l}\text { 3490. } 488 \\
\text { 3491. } 273 \\
\text { 3492. } 916 \\
\text { 3495. } 624 \\
\text { 3496. } 408\end{array}$ & $\begin{array}{l}1 \\
1 \\
4 \\
1 c \\
5\end{array}$ & $\begin{array}{l}\text { 28641. } 09 \\
28634.65 \\
28621.18 \\
28599.01 \\
28592.60\end{array}$ & $\begin{array}{lll}5 d^{\prime \prime} & 3 \mathrm{D}_{2}^{\circ}- & 3_{2,3} \\
6 s^{\prime \prime} & { }^{1} \mathrm{P}_{1}^{\circ}-4 f^{\prime} & { }^{1} \mathrm{P}_{1} \\
6 p^{\prime} & { }^{3} \mathrm{P}_{1}-8 s^{\prime} & { }^{3} \mathrm{D}_{2}^{\circ}\end{array}$ \\
\hline $\begin{array}{l}3394.192 \\
3399.537 \\
3400.316 \\
3401.500 \\
3402.587\end{array}$ & $\begin{array}{l}7 c \\
8 \\
5 \\
50 c \\
4 c\end{array}$ & $\begin{array}{l}29453.64 \\
29407.33 \\
29400.59 \\
29390.36 \\
29380.97\end{array}$ & $5 p^{5} \quad{ }^{3} \mathrm{P}_{2}^{\circ}-6 p^{\prime} \quad{ }^{3} \mathrm{~F}_{2}$ & $\begin{array}{l}\text { 3497. } 406 \\
3498.372 \\
3498.500 \\
3498.985 \\
3500.824\end{array}$ & $\begin{array}{l}300 c \\
2 \\
1 \\
25 c \\
2\end{array}$ & $\begin{array}{l}28584.44 \\
28576.55 \\
28575.50 \\
28571.54 \\
28556.53\end{array}$ & 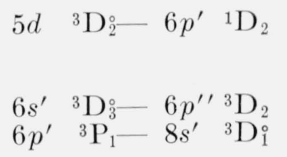 \\
\hline $\begin{array}{l}\text { 3409. } 138 \\
3409.692 \\
3409.938 \\
3411.173 \\
3415.911\end{array}$ & $\begin{array}{c}2 c \\
7 c \\
30 c \\
1 \\
30 c\end{array}$ & $\begin{array}{l}29324.52 \\
29319.75 \\
29317.64 \\
29307.02 \\
29266.37\end{array}$ & $\begin{array}{l}5 d \quad{ }^{5} \mathrm{D}_{4}^{\circ}-6 p^{\prime}{ }^{3} \mathrm{~F}_{4} \\
5 p^{5} \quad{ }^{1} \mathrm{P}_{1}-6 p^{\prime \prime}{ }^{3} \mathrm{D}_{2}\end{array}$ & $\begin{array}{l}\text { 3502. } 457 \\
\text { 3503. } 459 \\
\text { 3503. } 996 \\
3504.729 \\
\text { 3510. } 630\end{array}$ & $\begin{array}{c}2 \\
35 c \\
30 c \\
1 c \\
10\end{array}$ & $\begin{array}{l}28543.22 \\
28535.06 \\
28530.68 \\
28524.72 \\
28476.77\end{array}$ & $\begin{array}{llll}5 d^{\prime} & { }^{3} \mathrm{G}_{3}^{\circ}-4 f^{\prime} & { }^{3} \mathrm{D}_{3} \\
6 s^{\prime} & { }^{1} \mathrm{D}_{2}^{\circ}-7 p & { }^{3} \mathrm{P}_{1} \\
6 s^{\prime \prime} & { }^{1} \mathrm{P}_{1}^{\circ}-4 f^{\prime} & { }^{1} \mathrm{D}_{2} \\
5 d^{\prime} & { }^{1} \mathrm{D}_{2}^{\circ}-4 f^{\prime} & { }^{3} \mathrm{D}_{2}\end{array}$ \\
\hline $\begin{array}{l}3416.759 \\
3417.606 \\
3421.805 \\
3421.987 \\
3422.948\end{array}$ & $\begin{array}{c}5 \\
5 \\
7 \\
3 \\
20 c\end{array}$ & $\begin{array}{l}\text { 29259. } 11 \\
29251.86 \\
29215.96 \\
29214.41 \\
29206.21\end{array}$ & $\begin{array}{ll}5 d^{\prime} & { }^{1} \mathrm{~S}_{0}-7 p^{\prime}{ }^{1} \mathrm{P}_{1} \\
5 p^{5} & { }^{1} \mathrm{P}_{1}-6 p^{\prime \prime}{ }^{3} \mathrm{P}_{1}\end{array}$ & $\begin{array}{l}\text { 3511. } 357 \\
3512.177 \\
3513.304 \\
\text { 3513. } 971 \\
\text { 3514. } 319\end{array}$ & $\begin{array}{r}20 \\
100 \\
2 \\
2 \\
1\end{array}$ & $\begin{array}{l}28470.88 \\
28464.23 \\
28455.10 \\
28449.70 \\
28446.88\end{array}$ & $\begin{array}{llll}5 d^{\prime} & { }^{3} \mathrm{G}_{3}^{\circ}-4 f^{\prime} & { }^{3} \mathrm{~F}_{3} \\
5 d^{\prime} & { }^{3} \mathrm{G}_{3}^{\circ}- & 4 f^{\prime} & { }^{3} \mathrm{G}_{4}\end{array}$ \\
\hline $\begin{array}{l}\text { 3424. } 993 \\
3426.461 \\
3429.784 \\
3432.080 \\
3433.277\end{array}$ & $\begin{array}{c}250 c \\
20 \\
7 d \\
25 c \\
4 c\end{array}$ & $\begin{array}{l}29188.77 \\
29176.26 \\
29148.00 \\
29128.50 \\
29118.34\end{array}$ & $\begin{array}{lll}5 d^{\prime} & { }^{3} \mathrm{~F}_{2}^{\circ}-8 p & { }^{3} \mathrm{P}_{2} \\
5 d^{\prime} & { }^{3} \mathrm{G}_{3}^{\circ}-4 f^{\prime} & { }^{3} \mathrm{H}_{4} \\
5 d^{\prime} & { }^{3} \mathrm{~F}_{2}^{\circ}-7 p^{\prime} & { }^{3} \mathrm{P}_{1} \\
5 p^{5} & { }^{1} \mathrm{P}_{1}^{\circ}-7 p & { }^{5} \mathrm{P}_{2} \\
6 s^{\prime \prime} & { }^{3} \mathrm{P}_{1}^{\circ}-5 f & { }^{5} \mathrm{~F}_{2}\end{array}$ & $\begin{array}{l}3514.757 \\
3515.021 \\
3515.661 \\
3516.504 \\
3517.822\end{array}$ & $\begin{array}{r}2 \\
15 \\
3 \\
50 c \\
3 h\end{array}$ & $\begin{array}{l}\text { 28443. } 34 \\
28441.20 \\
28436.02 \\
28429.20 \\
28418.55\end{array}$ & $\begin{array}{llll}5 d^{\prime} & { }^{3} \mathrm{D}_{2}^{\circ}-4 f & { }^{3} \mathrm{~F}_{2} \\
5 d & { }^{5} \mathrm{D}_{3}^{\circ}-6 p^{\prime} & { }^{1} \mathrm{~F}_{3} \\
5 d^{\prime} & { }^{3} \mathrm{G}_{3}^{\circ}-8 p & { }^{5} \mathrm{P}_{2} ?\end{array}$ \\
\hline $\begin{array}{l}3435.093 \\
3436.712 \\
3438.434 \\
3438.792 \\
3440.510\end{array}$ & $\begin{array}{l}80 c \\
3 \\
20 w \\
3 \\
2\end{array}$ & $\begin{array}{l}29102.95 \\
29089.24 \\
29074.67 \\
29071.65 \\
29057.13\end{array}$ & $\begin{array}{lll}5 d & { }^{5} \mathrm{D}_{2}^{\circ}-6 p^{\prime} & { }^{3} \mathrm{D}_{3} \\
5 d^{\prime} & { }^{3} \mathrm{G}_{3}^{\circ}-8 p & { }^{3} \mathrm{P}_{2}\end{array}$ & $\begin{array}{l}3518.688 \\
3519.105 \\
3520.089 \\
3522.007 \\
3523.646\end{array}$ & $\begin{array}{l}1 \\
3 \\
5 c \\
2 \\
2\end{array}$ & $\begin{array}{l}28411.56 \\
28408.19 \\
28400.25 \\
28384.79 \\
28371.58\end{array}$ & $5 d^{\prime} \quad{ }^{3} \mathrm{D}_{2}^{\circ}-7 p$ \\
\hline $\begin{array}{l}3441.290 \\
3442.819 \\
3444.433 \\
3446.365 \\
3447.683\end{array}$ & $\begin{array}{c}25 c \\
7 \\
1 \\
1 \\
35 c\end{array}$ & $\begin{array}{l}29050.54 \\
29037.64 \\
29024.04 \\
29007.77 \\
28996.68\end{array}$ & $\begin{array}{lll}5 p^{5} & { }^{1} \mathrm{P}_{1}^{\circ}-6 p^{\prime \prime}{ }^{3} \mathrm{P}_{0} \\
5 d^{\prime \prime}{ }^{3} \mathrm{P}_{2}^{\circ}- & 2_{2,3} \\
5 d^{\prime \prime} & { }^{3} \mathrm{~F}_{3}^{\circ}- & 10_{2,3}^{\circ} \\
& & \\
6 p^{\prime} & { }^{1} \mathrm{D}_{2}- & 35_{2,3}^{\circ}\end{array}$ & $\begin{array}{l}3523.886 \\
3524.095 \\
3524.292 \\
3525.403 \\
3525.798\end{array}$ & $\begin{array}{r}1 \\
2 \\
15 \\
2 \\
1\end{array}$ & $\begin{array}{l}\text { 28369. } 65 \\
28367.97 \\
28366.38 \\
28357.44 \\
28354.27\end{array}$ & $\begin{array}{lll}6 s^{\prime \prime} & { }^{1} \mathrm{P}_{1}^{\circ}-7 p^{\prime} & { }^{3} \mathrm{P}_{0} \\
6 p^{\prime} & { }^{3} \mathrm{D}_{1}-6 d^{\prime} & 11_{0}^{\circ} \\
& & \end{array}$ \\
\hline $\begin{array}{l}3447.872 \\
3450.764 \\
3454.191 \\
3455.886 \\
3458.654\end{array}$ & $\begin{array}{r}10 c \\
8 c \\
4 \\
1 \\
20\end{array}$ & $\begin{array}{l}28995.09 \\
28970.79 \\
28942.05 \\
28927.85 \\
28904.70\end{array}$ & $5 p^{5} \quad{ }^{1} \mathrm{P}_{1}^{\circ}-7 p \quad{ }^{5} \mathrm{P}_{1}$ & $\begin{array}{l}3526.223 \\
3526.904 \\
3527.385 \\
3528.062 \\
3528.574\end{array}$ & $\begin{array}{c}60 d \\
500 \\
4 \\
2 \\
2\end{array}$ & $\begin{array}{l}28350.85 \\
28345.38 \\
28341.51 \\
28336.07 \\
28331.96\end{array}$ & $\begin{array}{lcc}5 d & { }^{5} \mathrm{D}_{1}^{\circ}-6 p^{\prime} & { }^{3} \mathrm{P}_{1} \\
5 d^{\prime} & { }^{3} \mathrm{~S}_{1}^{\circ}-4 f^{\prime} & { }^{3} \mathrm{P}_{2} \\
5 d^{\prime} & { }^{3} \mathrm{P}_{0}^{\circ}-7 p & 7{ }^{3} \mathrm{P}_{1} \\
6 p^{\prime} & { }^{3} \mathrm{~F}_{2}-6 d^{\prime} & 14_{3}^{\circ}\end{array}$ \\
\hline $\begin{array}{l}3459.108 \\
3459.626 \\
3461.812 \\
3462.097 \\
3462.332\end{array}$ & $\begin{array}{r}10 \\
3 \\
1 \\
1 \\
2 c\end{array}$ & $\begin{array}{l}28900.91 \\
28896.58 \\
28878.34 \\
28875.96 \\
28874.00\end{array}$ & $\begin{array}{llll}5 d^{\prime} & { }^{3} \mathrm{G}_{3}^{\circ}-4 f^{\prime} & { }^{3} \mathrm{~F}_{2} \\
5 d^{\prime} & { }^{3} \mathrm{~F}_{2}^{\circ}-8 p & { }^{3} \mathrm{P}_{1}\end{array}$ & $\begin{array}{l}3528.810 \\
3529.316 \\
3529.540 \\
3531.331 \\
3533.379\end{array}$ & $\begin{array}{l}1 \\
2 h \\
1 \\
5 h \\
60\end{array}$ & $\begin{array}{l}\text { 28330. } 07 \\
28326.00 \\
28324.21 \\
28309.84 \\
28293.43\end{array}$ & $\begin{array}{lll}6 p^{\prime} & 3 \mathrm{D}_{1}-6 d^{\prime} & { }^{1} 0_{2}^{\circ} \\
6 s^{\prime \prime} & { }^{1} \mathrm{P}_{1}^{\circ}-7 p^{\prime} & { }^{1} \mathrm{P}_{1}\end{array}$ \\
\hline
\end{tabular}


TABLE 10.1. Observed lines of I II-Continued

\begin{tabular}{|c|c|c|c|c|c|c|c|}
\hline$\lambda($ air $)$ & Intensity & $\begin{array}{l}\text { Wave } \\
\text { number }\end{array}$ & Classification & $\lambda($ air $)$ & Intensity & $\begin{array}{l}\text { Wave } \\
\text { number }\end{array}$ & Classification \\
\hline $\begin{array}{l}\text { 3533. } 648 \\
3535.876 \\
3537.561 \\
3538.334 \\
3539.628\end{array}$ & $\begin{array}{c}10 \\
70 \\
10 c \\
1 h \\
1\end{array}$ & $\begin{array}{l}\text { 28291. } 28 \\
28273.45 \\
28259.99 \\
28253.81 \\
28243.48\end{array}$ & $\begin{array}{lll}5 d^{\prime \prime} & { }^{3} \mathrm{D}_{1}^{\circ}- & 8_{1,2} \\
5 d^{\prime} & { }^{3} \mathrm{G}_{4}-6 p^{\prime \prime}{ }^{3} \mathrm{D}_{3} \\
6 s^{\prime \prime} & { }^{3} \mathrm{P}_{1}-6 p^{\prime \prime}{ }^{1} \mathrm{~S}_{9} \\
6 p^{\prime} & { }^{3} \mathrm{~F}_{2}-6 d^{\prime} \quad{ }^{3} 13_{1,2}\end{array}$ & $\begin{array}{l}3649.144 \\
3650.800 \\
3652.299 \\
3653.355 \\
3655.423\end{array}$ & $\begin{array}{c}3 h \\
20 c \\
4 \\
15 \\
5 h\end{array}$ & $\begin{array}{l}27395.88 \\
27383.46 \\
27372.22 \\
27364.30 \\
27348.82\end{array}$ & $\begin{array}{llll}6 s^{\prime} & { }^{1} \mathrm{D}_{2}^{\circ}-7 p & { }^{5} \mathrm{P}_{2} \\
6 p^{\prime} & { }^{3} \mathrm{D}_{2}-6 d^{\prime} & 13_{1,2}{ }^{\circ}, \\
5 d^{\prime} & { }^{3} \mathrm{~S}_{1}^{\circ}-7 p^{\prime} & { }^{3} \mathrm{P}_{1} \\
5 d^{\prime} & { }^{3} \mathrm{D}_{3}^{\circ}-4 f & { }^{3} \mathrm{~F}_{2}\end{array}$ \\
\hline $\begin{array}{l}3541.605 \\
3543.319 \\
3547.170 \\
3549.734 \\
3552.196\end{array}$ & $\begin{array}{r}100 \\
1 \\
1 \\
2 \\
100 c\end{array}$ & $\begin{array}{l}28227.72 \\
28214.06 \\
28183.44 \\
28163.08 \\
28143.56\end{array}$ & $\begin{array}{llll}6 s^{\prime \prime} & { }^{1} \mathrm{P}_{1}-7 p^{\prime} & { }^{1} \mathrm{D}_{2} \\
5 d^{\prime} & { }^{3} \mathrm{~F}_{2}^{\circ}-5 f & { }^{3} \mathrm{~F}_{2} \\
& & & \\
5 d^{\prime} & { }^{1} \mathrm{D}_{2}^{\circ}-8 p & { }^{3} \mathrm{P}_{2} \\
5 d^{\prime} & { }^{3} \mathrm{D}_{2}^{\circ}-4 f & { }^{3} \mathrm{~F}_{3}\end{array}$ & $\begin{array}{l}3657.060 \\
3661.792 \\
3662.816 \\
3671.889 \\
3677.874\end{array}$ & $\begin{array}{c}100 \\
50 c \\
2 \\
1 \\
3 c\end{array}$ & $\begin{array}{l}27336.58 \\
27301.26 \\
27293.62 \\
27226.19 \\
27181.88\end{array}$ & $\begin{array}{lrl}6 s & { }^{3} \mathrm{~S}_{1}-6 p^{\prime} & { }^{3} \mathrm{D}_{2} \\
5 d^{\prime} & { }^{3} \mathrm{D}_{3}^{\circ}-4 f & { }^{3} \mathrm{~F}_{4}\end{array}$ \\
\hline $\begin{array}{l}3552.782 \\
3553.034 \\
3553.843 \\
3554.873 \\
3555.039\end{array}$ & $\begin{array}{l}20 \\
8 c \\
1 \\
5 \\
2 c\end{array}$ & $\begin{array}{l}28138.92 \\
28136.92 \\
28130.52 \\
28122.37 \\
28121.05\end{array}$ & $\begin{array}{llll}5 d^{\prime} & { }^{3} \mathrm{D}_{2}^{\circ}-6 p^{\prime \prime} & { }^{3} \mathrm{D}_{2} \\
5 d^{\prime} & { }^{1} \mathrm{~F}_{3}^{\circ}-6 f & { }^{3} \mathrm{~F}_{4} \\
& & & \\
5 d^{\prime} & { }^{1} \mathrm{D}_{2}^{\circ}-7 p^{\prime} & { }^{3} \mathrm{P}_{1} \\
5 d & { }^{5} \mathrm{D}_{4}^{\circ}-6 p^{\prime} & { }^{1} \mathrm{~F}_{3}\end{array}$ & $\begin{array}{l}3685.694 \\
3692.266 \\
3695.633 \\
3696.292 \\
3700.027\end{array}$ & $\begin{array}{r}3 c \\
5 c \\
1 c \\
15 c \\
1\end{array}$ & $\begin{array}{l}27124.21 \\
27075.93 \\
27051.26 \\
27046.44 \\
27019.14\end{array}$ & $\begin{array}{lll}5 d^{\prime \prime} & { }^{1} \mathrm{D}_{2}^{\circ}-4 f^{\prime} & { }^{1} \mathrm{D}_{2} \\
5 p^{5} & { }^{3} \mathrm{P}_{1}-6 p^{\prime} & { }^{3} \mathrm{~F}_{2} \\
5 d^{\prime} & { }^{3} \mathrm{D}_{3}^{\circ}-4 f & 4{ }^{3} \mathrm{~F}_{3} \\
5 d^{\prime} & { }^{3} \mathrm{D}_{3}^{\circ}-6 p^{\prime \prime} & { }^{3} \mathrm{D}_{2} \\
5 d^{\prime \prime} & { }^{1} \mathrm{D}_{2}^{\circ}-4 f^{\prime} & { }^{1} \mathrm{~F}_{3}\end{array}$ \\
\hline $\begin{array}{l}3555.576 \\
3558.008 \\
3560.542 \\
3563.001 \\
3566.158\end{array}$ & $\begin{array}{r}2 \\
50 \\
200 \\
5 \\
2\end{array}$ & $\begin{array}{l}28116.81 \\
28097.59 \\
28077.59 \\
28058.22 \\
28033.38\end{array}$ & $\begin{array}{lccc}5 d^{\prime} & { }^{3} \mathrm{~S}_{1}-4 f^{\prime} & { }^{3} \mathrm{P}_{1} \\
5 d^{\prime} & { }^{3} \mathrm{~S}_{1}^{\circ}-7 p^{\prime} & { }^{3} \mathrm{P}_{2} \\
5 d^{\prime} & { }^{3} \mathrm{G}_{3}^{\circ}-5 f & { }^{3} \mathrm{~F}_{4} \\
6 s^{\prime} & { }^{3} \mathrm{D}_{3}^{\circ}-4 f & { }^{5} \mathrm{~F}_{4}\end{array}$ & $\begin{array}{l}3700.703 \\
3703.426 \\
3709.498 \\
3714.466 \\
3715.233\end{array}$ & $\begin{array}{r}1 \\
5 c \\
40 c \\
1 c \\
5 c\end{array}$ & $\begin{array}{l}\text { 27014. } 21 \\
\text { 26994. } 34 \\
26950.16 \\
\text { 26914. } 11 \\
\text { 26908. } 56\end{array}$ & $\begin{array}{llll}5 d^{\prime} & { }^{1} \mathrm{~F}_{3}^{\circ}-4 f^{\prime} & { }^{1} \mathrm{~F}_{3} \\
5 d & { }^{3} \mathrm{D}_{1}^{\circ}-6 p^{\prime} & { }^{1} \mathrm{D}_{2} \\
6 s^{\prime \prime} & { }^{3} \mathrm{P}_{2}^{\circ}-7 p^{\prime} & { }^{3} \mathrm{P}_{2} \\
5 d^{\prime} & { }^{3} \mathrm{D}_{3}^{\circ}-7 p & { }^{5} \mathrm{P}_{2}\end{array}$ \\
\hline $\begin{array}{l}3569.696 \\
3569.888 \\
3570.278 \\
3571.386 \\
3571.769\end{array}$ & $\begin{array}{c}1 \\
6 \\
10 c \\
10 c \\
10 d\end{array}$ & $\begin{array}{l}28005.59 \\
28004.09 \\
28001.03 \\
27992.34 \\
27989.34\end{array}$ & 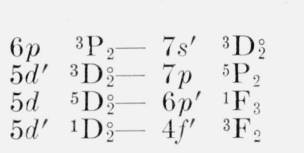 & $\begin{array}{l}3716.170 \\
3725.274 \\
3727.200 \\
3727.330 \\
3729.580\end{array}$ & $\begin{array}{r}50 \\
1 \\
2 \\
10 \\
1\end{array}$ & $\begin{array}{l}\text { 26901. } 77 \\
26836.03 \\
26822.16 \\
\text { 26821. } 23 \\
\text { 26805. } 05\end{array}$ & $\begin{array}{llll}5 d & { }^{5} \mathrm{D}_{1}-6 p^{\prime} & { }^{3} \mathrm{P}_{0} \\
5 d^{\prime \prime} & { }^{3} \mathrm{D}_{3}^{\circ}-4 f^{\prime} & { }^{1} \mathrm{D}_{2} \\
5 d^{\prime} & { }^{3} \mathrm{P}_{1}-7 f & 7 f & { }^{3} \mathrm{~F}_{2} \\
5 d^{\prime \prime} & { }^{1} \mathrm{D}_{2}^{\circ}-7 p^{\prime} & { }^{1} \mathrm{D}_{2} \\
5 d^{\prime} & { }^{1} \mathrm{D}_{2}^{\circ}-5 f & { }^{3} \mathrm{~F}_{3}\end{array}$ \\
\hline $\begin{array}{l}3573.680 \\
3575.861 \\
3576.826 \\
3579.477 \\
3586.568\end{array}$ & $\begin{array}{c}200 c \\
70 \\
1 \\
1 \\
3 c\end{array}$ & $\begin{array}{l}27974.37 \\
27957.31 \\
27949.77 \\
27929.07 \\
27873.85\end{array}$ & $\begin{array}{lll}5 d & { }^{5} \mathrm{D}_{1}^{\circ}-6 p^{\prime} & { }^{3} \mathrm{P}_{2} \\
5 p^{5} & { }^{3} \mathrm{P}_{\mathrm{i}}-6 p^{\prime} & { }^{3} \mathrm{D}_{2} \\
6 s^{\prime \prime} & { }^{1} \mathrm{P}_{1}^{\circ}-7 p^{\prime} & { }^{3} \mathrm{~F}_{2} \\
5 d^{\prime \prime} & { }^{3} \mathrm{D}_{3}^{\circ}-6 f & { }^{3} \mathrm{~F}_{4}\end{array}$ & $\begin{array}{l}3730.890 \\
3734.366 \\
3739.327 \\
3740.358 \\
3740.900\end{array}$ & $\begin{array}{l}25 \\
60 c \\
2 \\
4 c \\
2\end{array}$ & $\begin{array}{l}26795.64 \\
26770.70 \\
26735.18 \\
26727.81 \\
26723.94\end{array}$ & 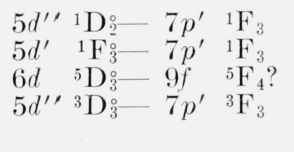 \\
\hline $\begin{array}{l}3586.946 \\
3587.105 \\
3587.363 \\
3588.505 \\
3592.110\end{array}$ & $\begin{array}{c}10 \\
1 \\
3 c \\
4 \\
15\end{array}$ & $\begin{array}{l}27870.92 \\
27869.68 \\
27867.68 \\
27858.81 \\
27830.85\end{array}$ & $\begin{array}{llll}5 d^{\prime} & { }^{1} \mathrm{D}_{2}^{\circ}-8 p & { }^{3} \mathrm{P}_{1} \\
5 d^{\prime \prime} & { }^{3} \mathrm{~F}_{2}^{\circ}- & 13_{2,3}^{\circ} \\
5 d^{\prime} & { }^{3} \mathrm{D}_{2}^{2}-7 p & { }^{5} \mathrm{P}_{1} \\
& & & \\
5 d^{\prime} & { }^{3} \mathrm{~F}_{2}^{\circ}-5 f & { }^{3} \mathrm{~F}_{3}\end{array}$ & $\begin{array}{l}3742.138 \\
3744.138 \\
3745.553\end{array}$ & $\begin{array}{r}200 \\
1 \\
6 c\end{array}$ & $\begin{array}{l}26715.10 \\
26700.83 \\
26690.74\end{array}$ & $\begin{array}{llll}5 d^{\prime} & { }^{1} \mathrm{~F}_{3}^{\circ} & 7 p^{\prime} & { }^{3} \mathrm{~F}_{4} \\
6 d & { }^{5} \mathrm{D}_{2}^{\circ}-9 f & { }^{5} \mathrm{~F}_{3} ? \\
4 f & { }^{3} \mathrm{~F}_{3} & & 50_{3}^{\circ}, 4 \\
6 d & { }^{5} \mathrm{D}_{4}^{\circ}-9 f & { }^{5} \mathrm{~F}_{5} ? \\
6 p^{\prime} & { }^{1} \mathrm{P}_{1}-6 d^{\prime} & 15_{1}^{\circ} \\
6 d & { }^{5} \mathrm{D}_{4}^{\circ}-9 f & { }^{5} \mathrm{~F}_{4} ?\end{array}$ \\
\hline $\begin{array}{l}3593.030 \\
3594.691 \\
3596.204 \\
3597.133\end{array}$ & $\begin{array}{l}1 h \\
2 \\
1 \\
4\end{array}$ & $\begin{array}{l}27823.72 \\
27810.87 \\
27799.17 \\
27791.99\end{array}$ & $6 s^{\prime} \quad{ }^{1} \mathrm{D}_{2}^{\circ}-4 f$ & $\begin{array}{l}3748.299 \\
3764.694 \\
3766.364 \\
3767.804 \\
3769.287\end{array}$ & $\begin{array}{l}4 c \\
2 \\
3 \\
4 c \\
1\end{array}$ & $\begin{array}{l}26671.19 \\
26555.04 \\
26543.26 \\
26533.12 \\
26522.68\end{array}$ & $\begin{array}{lll}5 d^{\prime \prime} & { }^{1} \mathrm{~F}_{3}^{\circ}- & 11_{3,4} \\
6 p^{\prime}{ }^{3} \mathrm{D}_{1}-6 d^{\prime} & 7_{1,2}^{\circ} \\
5 d^{\prime \prime} & { }^{1} \mathrm{D}_{2}^{\circ}-7 p^{\prime} & { }^{3} \mathrm{~F}_{2} \\
5 d^{\prime \prime} & { }^{3} \mathrm{D}_{3}^{\circ}-7 p^{\prime} & { }^{1} \mathrm{D}_{2}\end{array}$ \\
\hline $\begin{array}{l}3598.012 \\
3606.902 \\
3611.680 \\
3612.769 \\
3615.372\end{array}$ & $\begin{array}{l}3 \\
1 \\
8 h \\
2 \\
3\end{array}$ & $\begin{array}{l}\text { 27785. } 20 \\
27716.72 \\
27680.05 \\
27671.71 \\
27651.78\end{array}$ & $\begin{array}{llll}5 d^{\prime} & { }^{3} \mathrm{G}_{3}^{\circ}- & 5 f & { }^{3} \mathrm{~F}_{3} \\
5 d^{\prime} & { }^{1} \mathrm{~F}_{3}^{\circ} & 6 f & { }^{5} \mathrm{~F}_{4} \\
5 d^{\prime} & { }^{1} \mathrm{D}_{2}^{\circ}-7 p^{\prime} & { }^{3} \mathrm{D}_{1} \\
5 d^{\prime \prime}{ }^{3} \mathrm{D}_{2}^{\circ}- & & 2_{2,3}\end{array}$ & $\begin{array}{l}3769.891 \\
3771.453 \\
3772.506 \\
3778.068 \\
3778.913\end{array}$ & $\begin{array}{r}5 \\
10 \\
1 \\
2 \\
10 c\end{array}$ & $\begin{array}{l}26518.43 \\
26507.45 \\
26500.05 \\
26461.04 \\
26455.12\end{array}$ & $\begin{array}{lll}5 d^{\prime} & { }^{1} \mathrm{~F}_{3}^{\circ}-7 p^{\prime} & { }^{3} \mathrm{~F}_{2} \\
5 d^{\prime \prime} & { }^{3} \mathrm{D}_{3}-7 p^{\prime} & { }^{1} \mathrm{~F}_{3} \\
4 f & { }^{5} \mathrm{~F}_{5}-12 g & { }^{5} \mathrm{G}_{6}^{\circ} \\
5 d^{\prime} & { }^{3} \mathrm{~F}_{3}^{\circ}-7 p & { }^{3} \mathrm{P}_{2} \\
6 s & { }^{3} \mathrm{~S}_{3}-6 p^{\prime} & { }^{3} \mathrm{~F}_{2}\end{array}$ \\
\hline $\begin{array}{l}3615.868 \\
3617.136 \\
3618.014 \\
3618.652 \\
3620.408\end{array}$ & $\begin{array}{c}20 d \\
1 \\
6 \\
6 \\
1\end{array}$ & $\begin{array}{l}27647.99 \\
27638.30 \\
27631.59 \\
27626.72 \\
27613.32\end{array}$ & $\begin{array}{lll}5 d & { }^{5} \mathrm{D}_{2}^{\circ}-6 p^{\prime} & { }^{1} \mathrm{P}_{1} \\
5 d^{\prime} & { }^{1} \mathrm{D}_{2}^{\circ}-4 f^{\prime} & { }^{3} \mathrm{D}_{3} \\
5 d^{\prime} & { }^{3} \mathrm{~F}_{2}^{\circ}-5 f & { }^{5} \mathrm{~F}_{3} \\
5 d^{\prime \prime} & { }^{3} \mathrm{D}_{2}^{\circ}-8 f & { }^{5} \mathrm{~F}_{3}\end{array}$ & $\begin{array}{l}3779.374 \\
3781.442 \\
3787.772 \\
3789.289 \\
3792.147\end{array}$ & $\begin{array}{l}25 \\
20 c \\
1 \\
5 \\
1\end{array}$ & $\begin{array}{l}26451.90 \\
26437.43 \\
26393.25 \\
26382.68 \\
26362.80\end{array}$ & $\begin{array}{llll}5 d^{\prime \prime} & { }^{3} \mathrm{D}_{3}^{\circ}-7 p^{\prime} & { }^{3} \mathrm{~F}_{4} \\
5 d^{\prime} & { }^{3} \mathrm{D}_{2}^{\circ}-6 p^{\prime \prime} & { }^{3} \mathrm{D}_{1} \\
4 f & { }^{3} \mathrm{~F}_{2}- & & 50_{3,4}^{\circ} \\
5 d & { }^{5} \mathrm{D}_{4}^{\circ}-6 p^{\prime} & { }^{3} \mathrm{~F}_{3}\end{array}$ \\
\hline $\begin{array}{l}3620.691 \\
3626.755 \\
3627.507 \\
3627.785 \\
3631.880\end{array}$ & $\begin{array}{c}1 \\
20 c \\
15 \\
3 \\
6 c\end{array}$ & $\begin{array}{l}27611.16 \\
27565.00 \\
27559.28 \\
27557.17 \\
27526.10\end{array}$ & $\begin{array}{llll}6 p & { }^{3} \mathrm{P}_{0}-7 s^{\prime} & { }^{3} \mathrm{D}_{1}^{\circ} \\
5 p^{5} & { }^{1} \mathrm{P}_{1}-6 p^{\prime \prime} & { }^{3} \mathrm{D}_{1} \\
5 d^{\prime} & { }^{1} \mathrm{D}_{2}^{\circ}-4 f^{\prime} & { }^{3} \mathrm{~F}_{3} \\
5 d^{\prime} & { }^{3} \mathrm{P}_{2}^{\circ}-7 p^{\prime} & { }^{3} \mathrm{D}_{2} \\
6 s^{\prime} & { }^{1} \mathrm{D}_{2}^{\circ}-4 f & { }^{3} \mathrm{~F}_{3}\end{array}$ & $\begin{array}{l}3793.419 \\
3800.176 \\
3801.073 \\
3801.453 \\
3804.274\end{array}$ & $\begin{array}{l}10 \\
2 \\
2 \\
5 d ? \\
1\end{array}$ & $\begin{array}{l}26353.96 \\
26307.10 \\
26300.89 \\
26298.26 \\
26278.76\end{array}$ & $\begin{array}{llll}5 d^{\prime} & { }^{1} \mathrm{~F}_{3}^{\circ}-4 f^{\prime} & { }^{3} \mathrm{G}_{3} \\
5 d^{\prime} & { }^{3} \mathrm{D}_{1}^{\circ}-6 p^{\prime \prime} & { }^{1} \mathrm{P}_{1}\end{array}$ \\
\hline $\begin{array}{l}3632.500 \\
3633.665 \\
3640.432 \\
3641.130 \\
3648.812\end{array}$ & $\begin{array}{c}10 \\
1 \\
1 c \\
1 \\
2 h\end{array}$ & $\begin{array}{l}27521.40 \\
27512.58 \\
27461.44 \\
27456.18 \\
27398.37\end{array}$ & 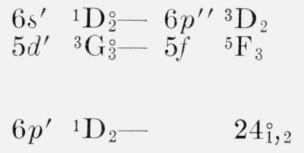 & $\begin{array}{l}3804.720 \\
3804.843 \\
3807.840 \\
3809.651 \\
3815.519\end{array}$ & $\begin{array}{r}1 \\
6 \\
10 \\
5 c \\
1 c\end{array}$ & $\begin{array}{l}26275.68 \\
26274.83 \\
26254.16 \\
26241.68 \\
26200.82\end{array}$ & $\begin{array}{llll}6 s^{\prime \prime} & { }^{1} \mathrm{P}_{1}-4 f^{\prime} & { }^{3} \mathrm{P}_{0} \\
5 d & { }^{5} \mathrm{D}_{2}^{\circ}-6 p^{\prime} & { }^{3} \mathrm{~F}_{3} \\
6 s^{\prime \prime} & { }^{3} \mathrm{P}_{2}^{\circ}-8 p & 8 p & { }^{3} \mathrm{P}_{2} \\
6 s^{\prime \prime} & { }^{3} \mathrm{P}_{2}^{\circ}-7 p^{\prime} & { }^{3} \mathrm{P}_{1}\end{array}$ \\
\hline
\end{tabular}


Table 10.1. Observed lines of I II-Continued

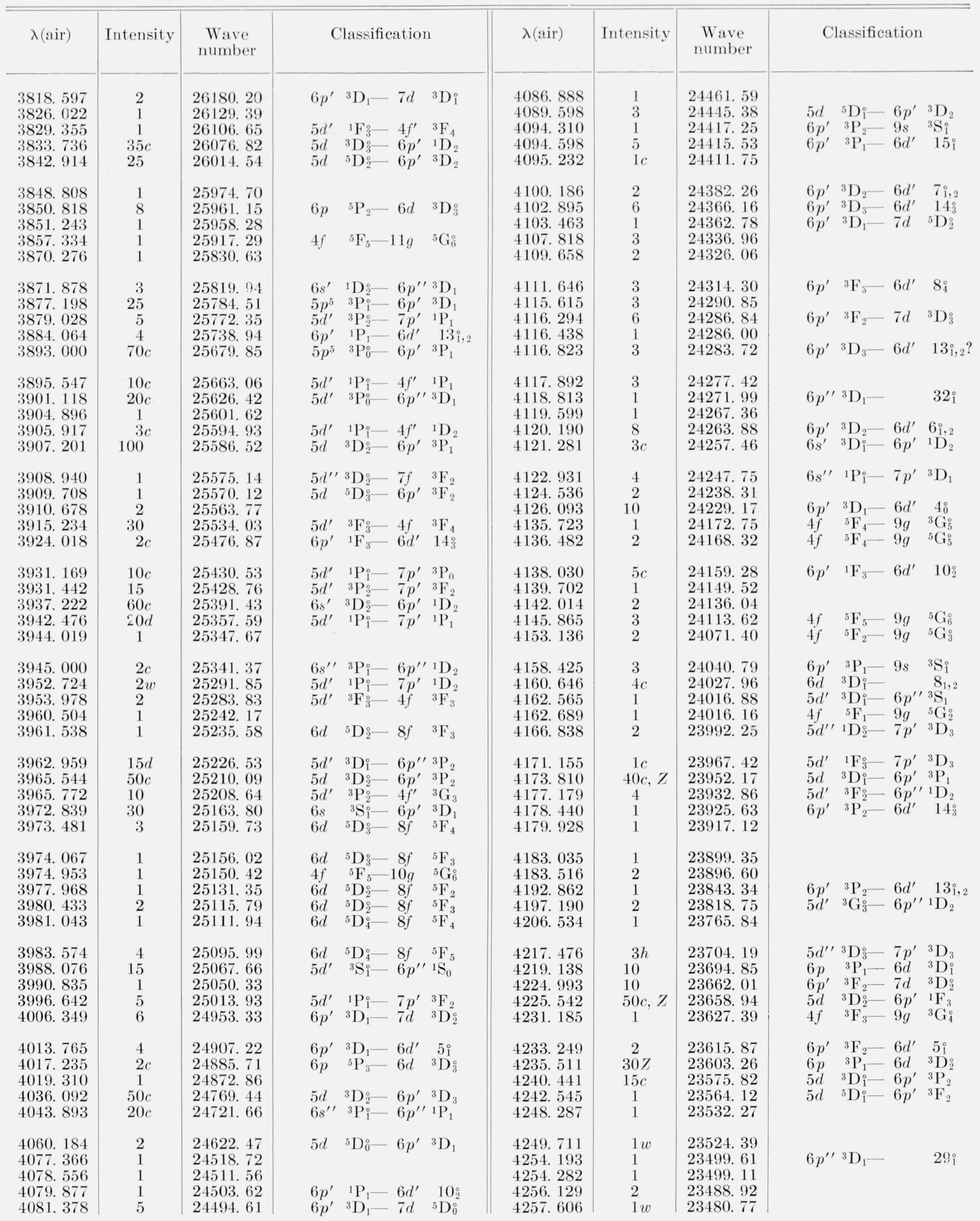


Table 10.1. Observed lines of I II-Continued

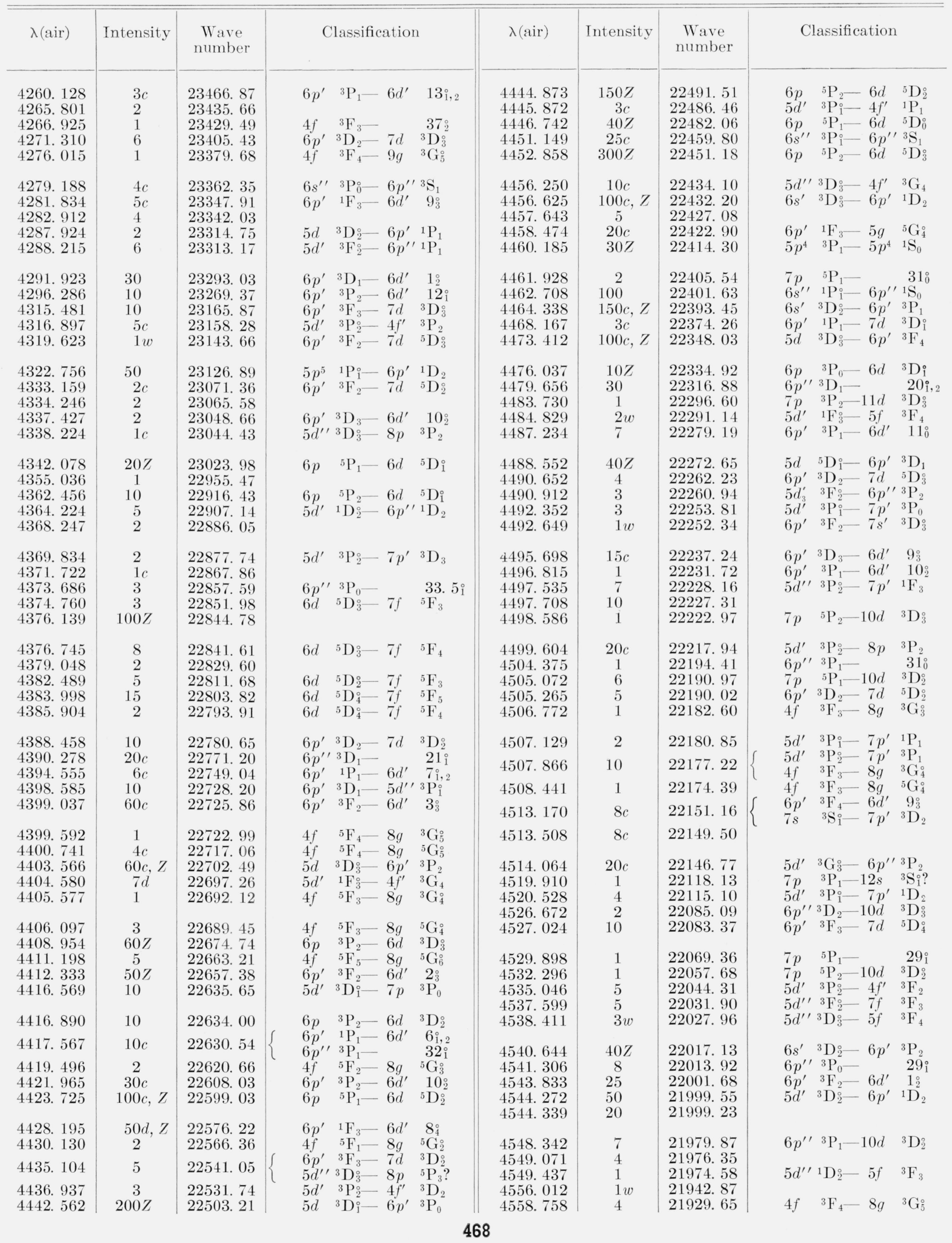


TABle 10.1. Observed lines of I II-Continued

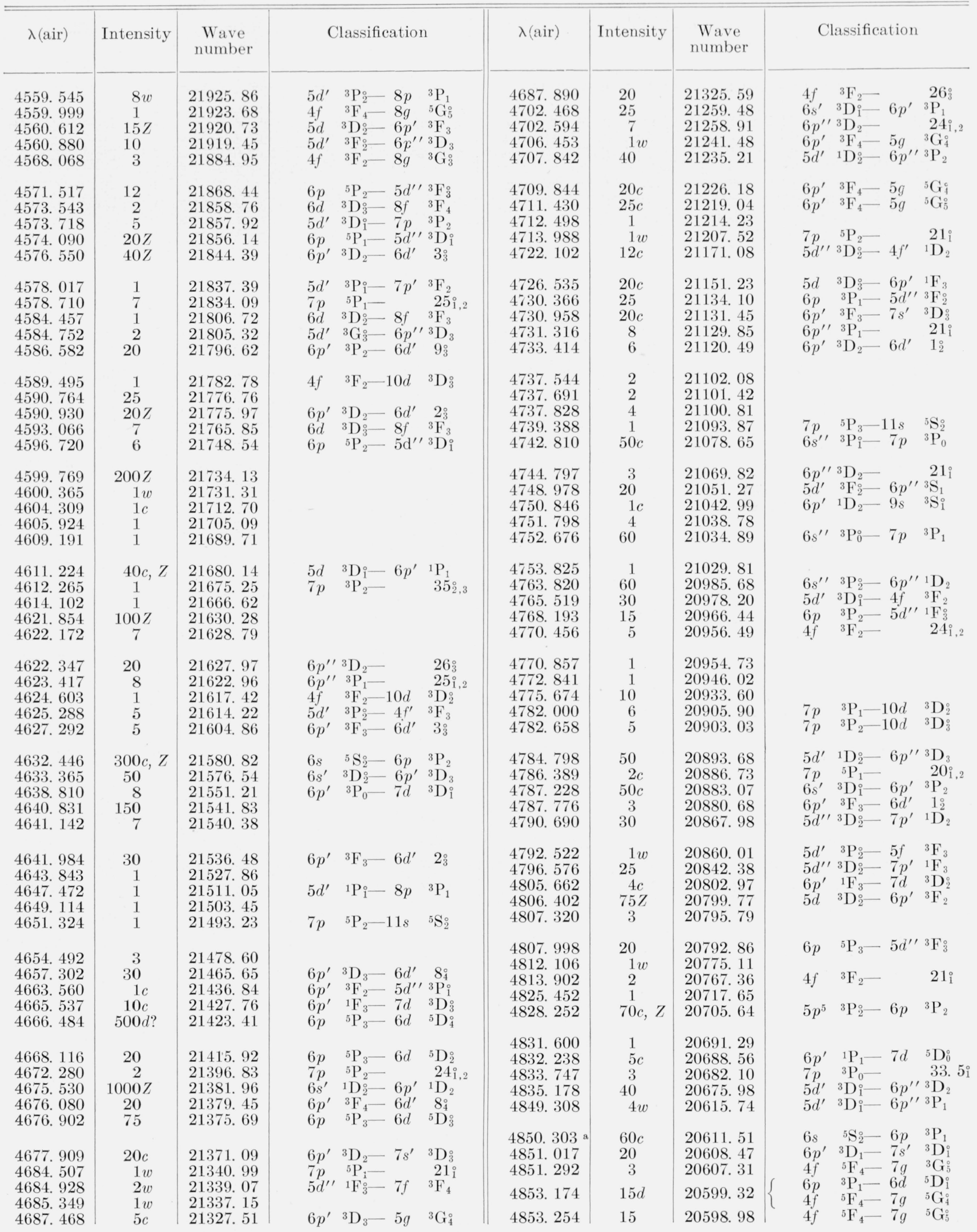


TABLE 10.1. Observed lines of I II-Continued

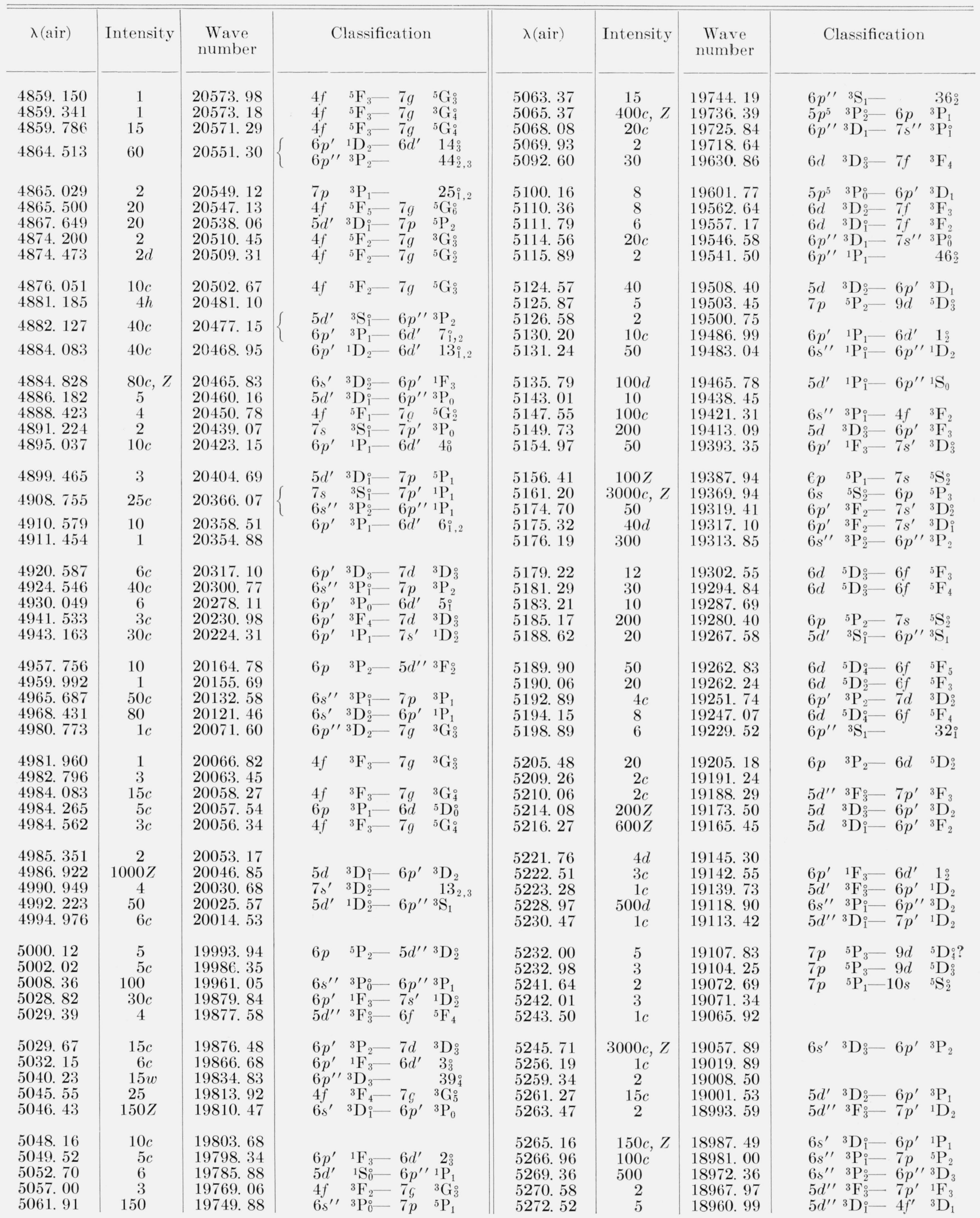


TABle 10.1. Observed lines of I II-Continued

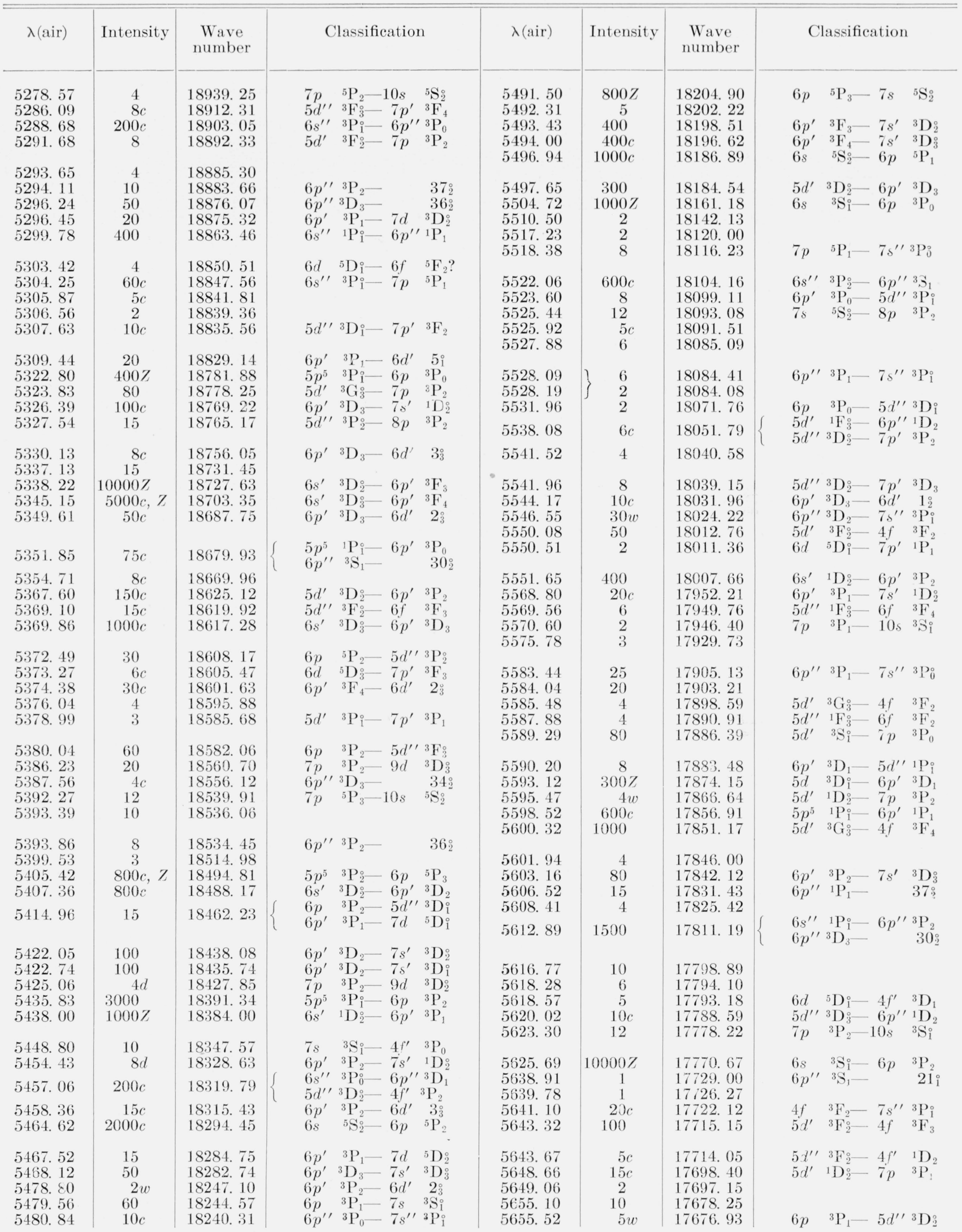


Table 10.1. Observed lines of I II-Continued

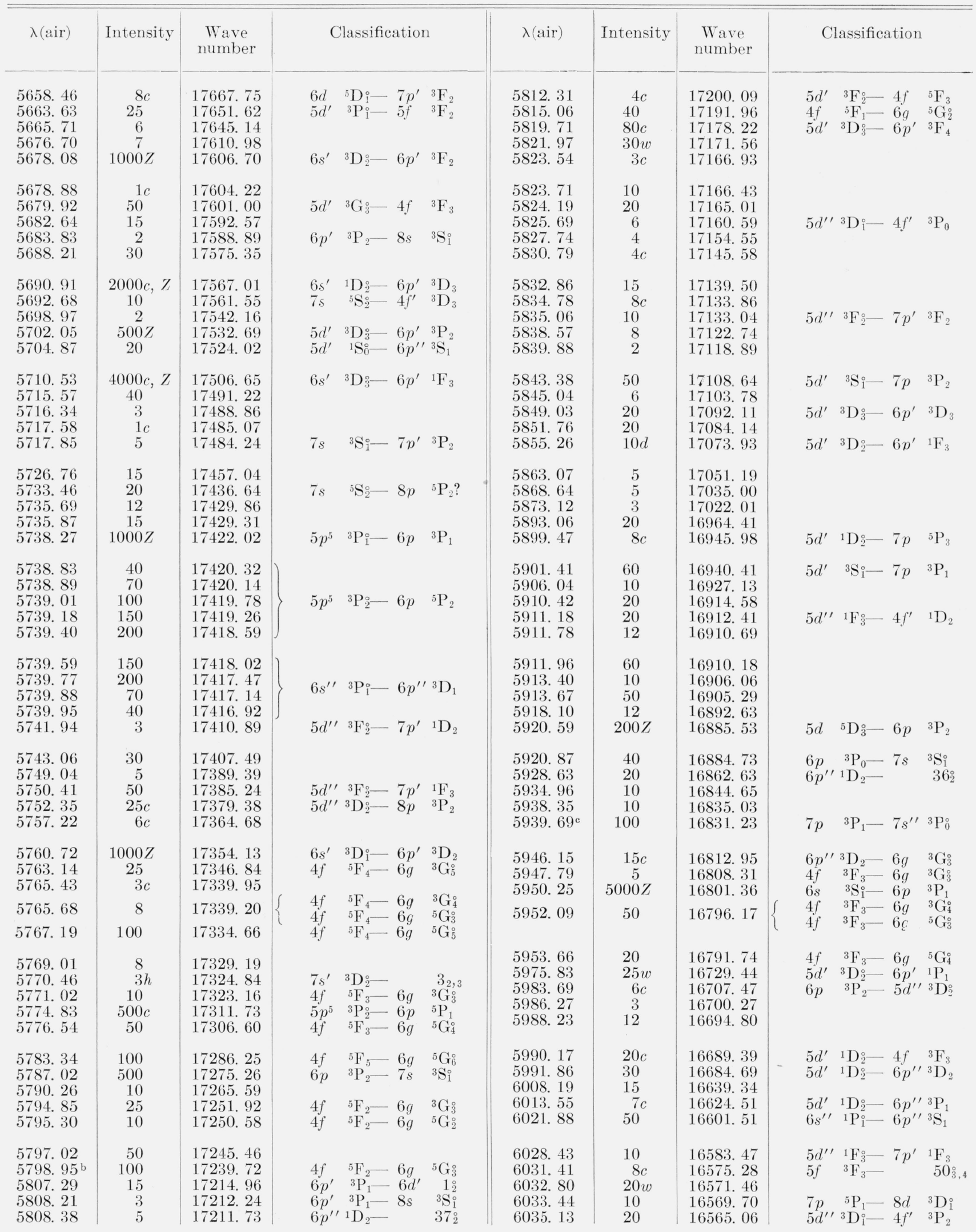


TABLE 10.1. Observed lines of $\mathrm{I} \mathrm{II}$-Continued

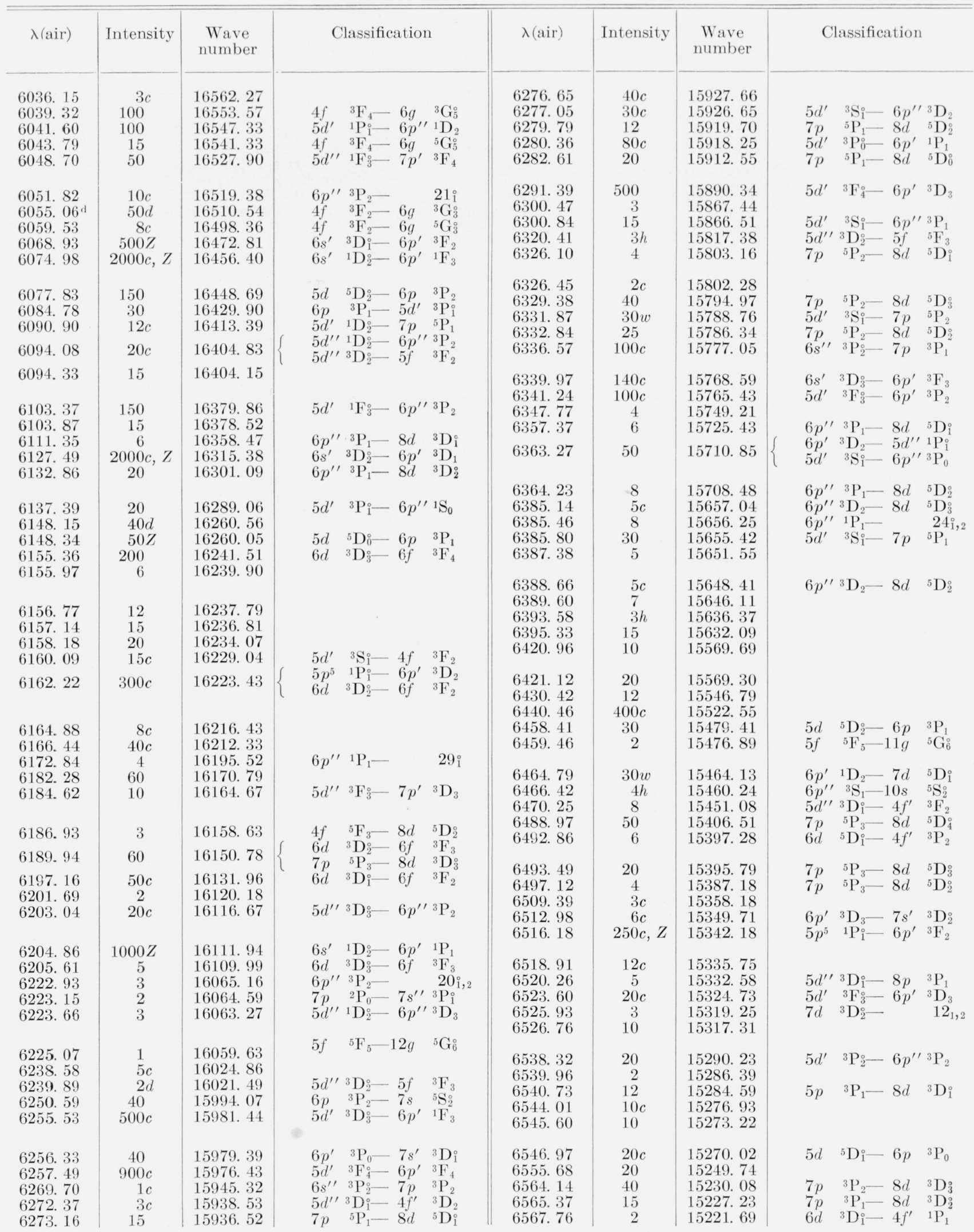


Table 10.1. Observed lines of I II-Continued

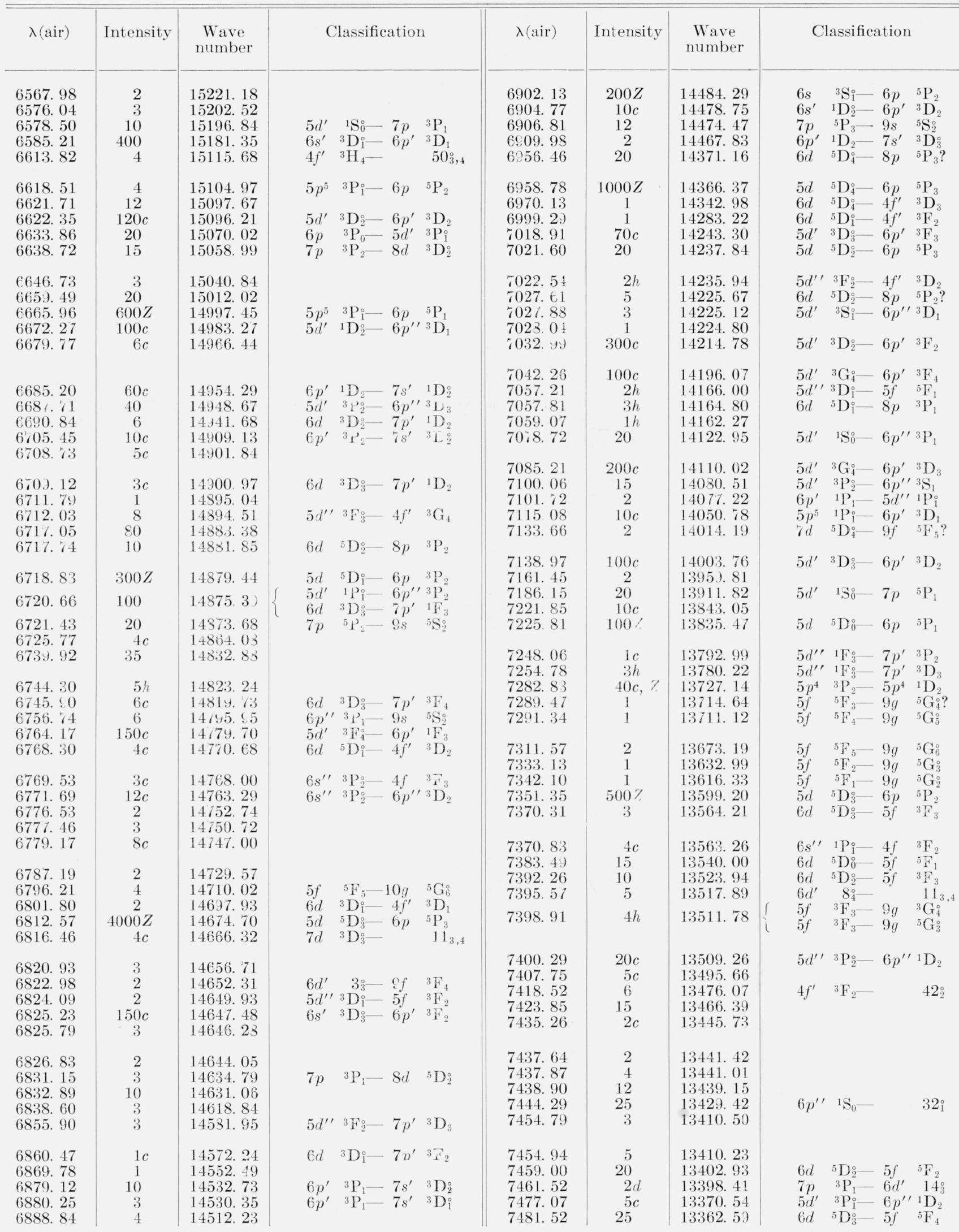


Table 10.1. Observed lines of $\mathrm{I} \mathrm{II}$-Continued

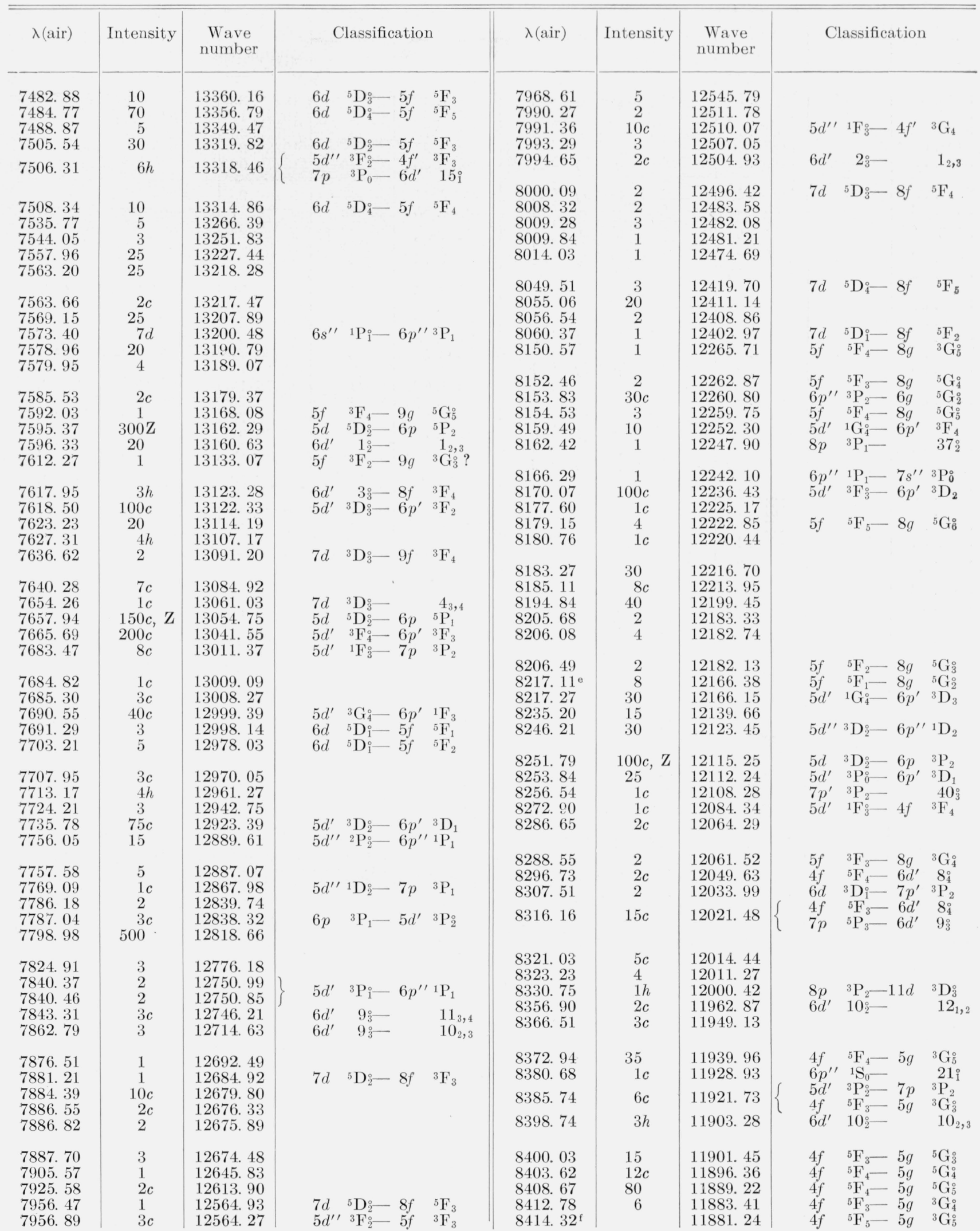


Table 10.1. Observed lines of I II-Continued

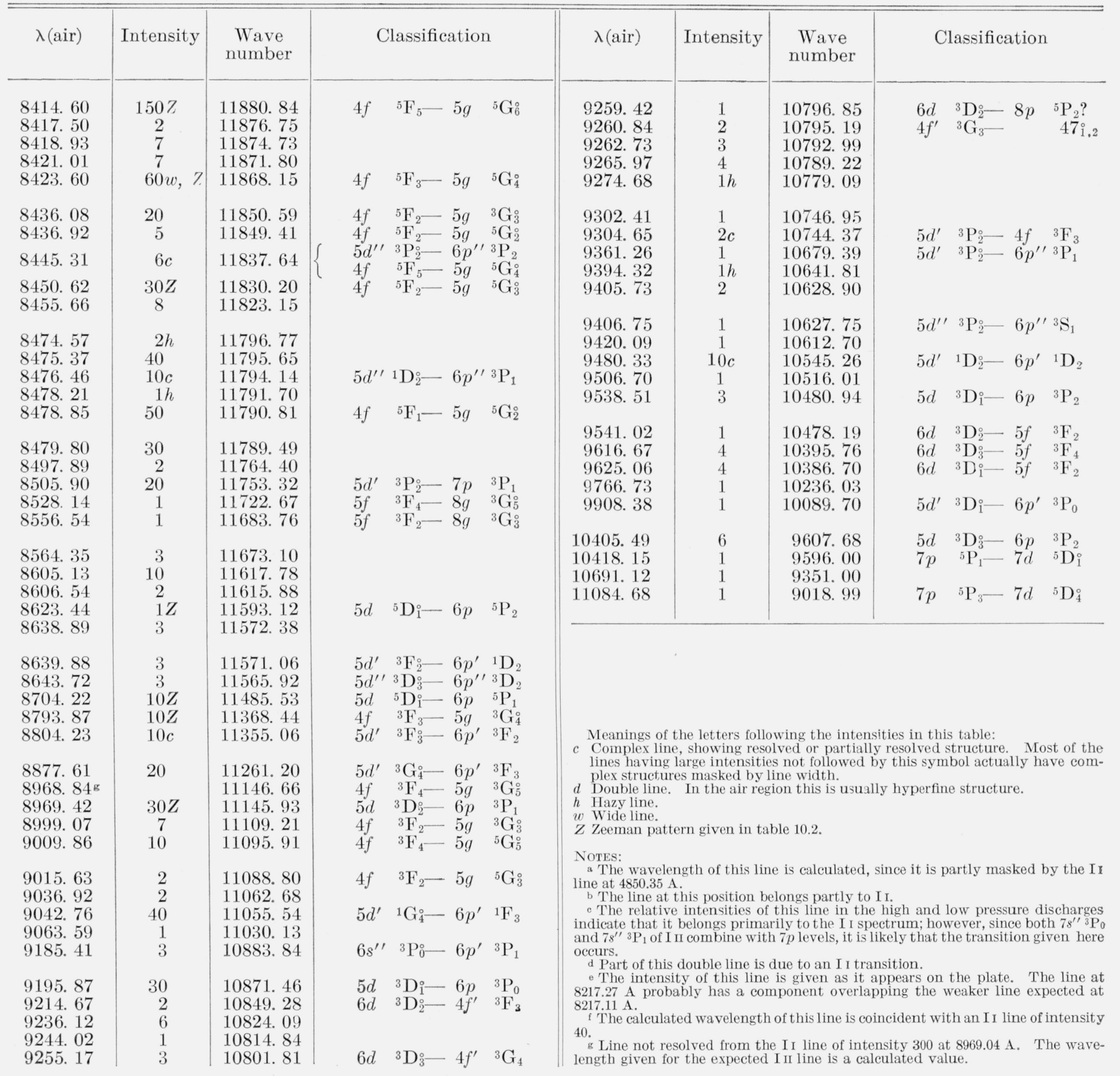


4173. 810 4225. 542 4235. 511 4342. 078 4376. 139

4403. 566 4408. 954 4412. 333 4423. 725 4428. 195

4442. 562 4444. 873 4446. 742 4452. 858 4456. 625

4460. 185 4464. 338

4473. 412

4476. 037

4488. 552

4540. 644 4560. 612 4574. 090 4576.550 4590. 930

4599. 769 4611. 224 4621. 854 4632. 446 4675. 530

4806. 402 4828. 252 4884. 828 4986. 922 5046. 43

5065. 37 5156. 41 5161. 20 5214. 08 5216. 27

5245. 71 5265. 16 5322. 80 5338. 22 5345. 15

The magnetic displacements, in Lorentz units, of the Zeeman components with polation parallel to the field are given in parentheses. The displacements of polarizaridenteses. Bold type indicates strongest components.

(. . .) $0.659,1.434$

$(0.00 w) 1.187 w$

0.719, 1.095

(0.841) $1.467,2.304$

$(0.00 w) 0.795 \mathrm{~A}$

$(0.00 w) 1.238 B$

$(0.00 w) 0.841 A$

(...) 1.747

0.000, 0.873$) \mathbf{0 . 6 0 2}, 1.440,2.301$

$(0.00 w) 1.33 w$

$(0.000) 0.687$

$(0.272$, 0.550) 1.187, 1.452, 1.715, 1.980

$(0.000) 2.308$

(0.000, $0.264,0.548)$ 0.862, 1.108, 1.432, 1.718

(...) $1.388, \mathbf{1 . 8 2 1}$

(1.512) 0.000

$(0.00 w) 1.127 w$

$(0.00 w) 1.252 B$

$(0.000) 0.674$

(0.586) $0.908,1.497$

(. . .) 1.084, 1.425

$(0.00 w) 1.136 w$

$(0.841) 1.438,2.298$

$(0.00 w) 0.465 w$

(0.00w) $1.203 B$

$(0.00 w) 0.561 A$

$(0.330)$ 0.6\%1, 1.083

$(0.00 w) 1.084 w$

$(0.423, \mathbf{0 . 8 1 4}) 1.160, \mathbf{1 . 5 1 4}, \mathbf{1 . 8 9 9}, 2.314$

$(0.168 w) 1.048 w$

$(0.453 w) 0.794, \mathbf{1 . 1 0 5}, \mathbf{1 . 3 1 0} w$

(..) $1.478 w$

$(0.00 w) 1.104 w$

(0.000, 0.484$) 0.686,1.157, \mathbf{1 . 6 2 9}$

$(0.000) \quad 0.656$

$(0.00 w) 1.565 w$

(0.000, 0.406) 1.50\%, 1.891, 2.319

(0.000, $0.267,0.589)$ 1.05\%, $1.343,1.720,2.045$

$(0.00 w) 1.590 \mathrm{~B}$

(0.000, 0.218$) 0.924, \mathbf{1 . 1 4 3}$

$(0.00 w) 1.353 w$

(0.351) $0.643,1.016$

$(0.000) 1.536$

$(0.00 w) 1.025 w$
5405. 42

5438. 00

5491. 50

5504. 72

5593. 12

5625. 69

5678. 08

5690. 91

5702. 05

5710. 53

5738. 27

5760. 72

5920. 59

5950. 25

6068. 93

6074. 98

6127. 49

6148. 34

6204. 86

6516. 18

6665. 96

6718. 83

6812. 57

6902. 13

6958. 78

7225. 81

7282. 83

7351.35

7595. 37

7657. 94

8251. 79

8414. 60

8423. 60

8450. 62

8623. 44

8704. 22

8793. 87

8969. 42
$(0.00 w) 1.622 w$

(0.000, 0.380$)$ 0.629, $1.013,1.397$

$(\mathbf{0 . 0 0 0}, 0.262,0.532) \mathbf{1 . 0 8 4}, 1.353,1.623,1.882$ $(0.000) 1.773$

(0.224) $0.680,0.903$

(0.000, 0.253) $1.232,1.494,1.743$

$(0.329, \mathbf{0 . 6 5 9}) \quad 0.567,0.892,1.242,1.584$

(0.000, $0.208,0.415) 1.196,1.454, \mathbf{1 . 6 3 1}$

$(0.00 w) 1.064 w$

$(0.362, \mathbf{0 . 5 2 9}) 1.275 w$

(0.000) 1.519

(0.000, 0.524$) \quad 0.649,1.170,1.681$

$(0.00 w) 1.402 w$

$(0.240) 1.514,1.760$

(0.000, 0.243) $0.911, \mathbf{1 . 1 4 5}$

(0.000, $0.139,0.286) \ldots .1 .269, \mathbf{1 . 3 9 3}$

(0.000, 0.309$) \quad 0.932,1.219, \mathbf{1 . 5 4 8}$

$(0.000) 1.533$

(0.00w) $1.026 w$

(0.00w) $0.847 w$

(0.785) $1.525,2.316$

(0.00w) $1.518 w$

$(0.168,0.341, \mathbf{0 . 4 9 6}) 1.131,1,303, \mathbf{1 . 4 6 2 , ~ 1 . 6 2 3 ,}$ $1.791,1.949$

$(0.00 w) 1.715 w$

(0.000, $0.151,0.300,0.446) \mathbf{1 . 0 2 8}, 1.173,1.330$ 1.491

(0.000) 2.310

(. . $1.042 w, 1.459,1.860) 0.393, \mathbf{0 . 8 0 8} W$

(0.000, $0.257,0.527) \mathbf{0 . 9 4 3}, 1.199,1.472,1.730$, 1.968

$(0.309, \mathbf{0 . 5 \% 0}) 1.136, \mathbf{1 . 4 3 5}, \mathbf{1 . 7 3 \%}, 2.047$

(0.000, 0.874$)$ 0.561, $1.436,2.316$

$(0.372, \mathbf{0 . 7 5 9}) \quad 0.751, \mathbf{1 . 1 2 3}, \mathbf{1 . 5 0 2}, 1.886$

$(0.00 \mathrm{~W}) 1.05 \mathrm{w}$

$(0.00 \mathrm{~W}) 1.03 \mathrm{w}$

$0.00 \mathrm{~W}) 0.69 \mathrm{u}$

(0.009, 0.304$) 1.728, \mathbf{1 . 9 9 5}$

(0.823) $\mathbf{1 . 4 8 3}, 2.325$

$(0.00 w) 0.97 w$

(0.000, 0.440) $0.713,1.134$

The letters $A$ and $B$ in this table indicate the type of shading displayed by the unresolved patterns:

$A$ indicates $/ \mid>$,

$B$ indicates $>$,

$w$ Wide line, usually several unresolved components,

$W$ Very wide line.

Unresolved or incomplete patterns were treated as "blend" or "strongest line only" patterns in the calculation of $g_{J}$ values. 
TABLE 19.3. Even levels of I II

\begin{tabular}{|c|c|c|c|c|c|c|c|c|}
\hline Designation & Level & $g_{J}$ & Designation & Level & $g_{J}$ & Designation & Level & $g_{J}$ \\
\hline 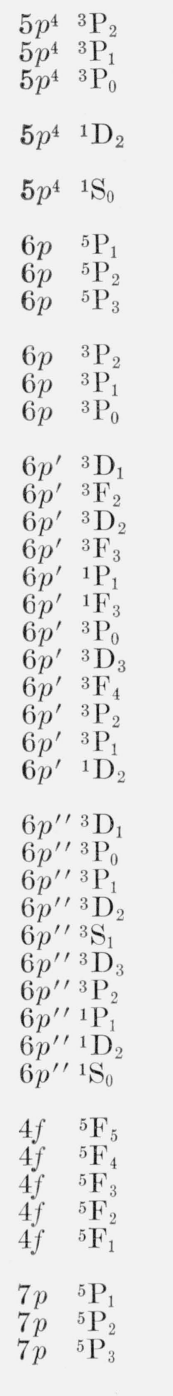 & $\begin{array}{r}99219.61 \\
99327.14 \\
100402.68 \\
102613.52 \\
101644.21 \\
103004.04 \\
\\
110006.71 \\
111298.09 \\
112179.49 \\
112419.04 \\
113812.79 \\
114157.21 \\
114635.82 \\
115267.82 \\
115353.94 \\
115708.45 \\
116084.84 \\
119082.78 \\
123520.74 \\
125006.38 \\
125162.00 \\
125222.20 \\
128563.14 \\
129431.27 \\
129772.76 \\
130824.99 \\
131444.69 \\
134363.21 \\
124742.50 \\
124683.79 \\
124711.93 \\
124783.18 \\
124841.77 \\
124950.92 \\
125084.32 \\
125483.51\end{array}$ & $\begin{array}{l}2.309 \\
1.714 \\
1.638 \\
\\
1.501 \\
1.520 \\
\\
0.915 \\
0.915 \\
1.158 \\
1.12 \\
0.985 \\
1.13 \\
1.212 \\
1.29 \\
1.425 \\
1.39 \\
1.11\end{array}$ & $\begin{array}{cc}4 f & { }^{3} \mathrm{~F}_{4} \\
4 f & { }^{3} \mathrm{~F}_{3} \\
4 f & { }^{3} \mathrm{~F}_{2} \\
7 p & { }^{3} \mathrm{P}_{2} \\
7 p & { }^{3} \mathrm{P}_{1} \\
7 p & { }^{3} \mathrm{P}_{0} \\
& \\
5 f & { }^{5} \mathrm{~F}_{5} \\
5 f & { }^{5} \mathrm{~F}_{4} \\
5 f & { }^{5} \mathrm{~F}_{3} \\
5 f & { }^{5} \mathrm{~F}_{2} \\
5 f & { }^{5} \mathrm{~F}_{1} \\
& \\
5 f & { }^{3} \mathrm{~F}_{4} \\
5 f & { }^{3} \mathrm{~F}_{3} \\
5 f & { }^{3} \mathrm{~F}_{2} \\
& \\
8 p & { }^{5} \mathrm{P}_{2} ? \\
8 p & { }^{5} \mathrm{P}_{3} ? \\
4 f^{\prime} & { }^{3} \mathrm{G}_{4} \\
4 f^{\prime} & { }^{3} \mathrm{~F}_{3} \\
4 f^{\prime} & { }^{3} \mathrm{D}_{3} \\
4 f^{\prime} & { }^{3} \mathrm{~F}_{2} \\
4 f^{\prime} & { }^{3} \mathrm{H}_{5} \\
4 f^{\prime} & { }^{3} \mathrm{H}_{4} \\
4 f^{\prime} & { }^{3} \mathrm{D}_{2} \\
4 f^{\prime} & { }^{3} \mathrm{P}_{1} \\
4 f^{\prime} & { }^{3} \mathrm{P}_{2} \\
4 f^{\prime} & { }^{3} \mathrm{P}_{0} \\
4 f^{\prime} & { }^{3} \mathrm{G}_{5} \\
4 f^{\prime} & { }^{3} \mathrm{~F}_{4} \\
4 f^{\prime} & { }^{3} \mathrm{G}_{3} \\
4 f^{\prime} & { }^{1} \mathrm{G}_{4} \\
4 f^{\prime} & { }^{3} \mathrm{D}_{1} \\
4 f^{\prime} & { }^{1} \mathrm{~F}_{3} \\
4 f^{\prime} & { }^{1} \mathrm{D}_{2} \\
4 f^{\prime} & { }^{1} \mathrm{P}_{1} \\
7 p^{\prime} & { }^{3} \mathrm{D}_{1} \\
7 p^{\prime} & { }^{3} \mathrm{P}_{1} \\
77 p^{\prime} & { }^{3} \mathrm{D}_{3} \\
77 p^{\prime} & { }^{3} \mathrm{P}_{2} \\
77 p^{\prime} & { }^{3} \mathrm{~F}_{2} \\
77 p^{\prime} & { }^{3} \mathrm{~F}_{4} \\
7 p^{\prime} & { }^{1} \mathrm{~F}_{3} \\
77 p^{\prime} & { }^{1} \mathrm{D}_{2} \\
7 p^{\prime} & { }^{1} \mathrm{P}_{1}\end{array}$ & 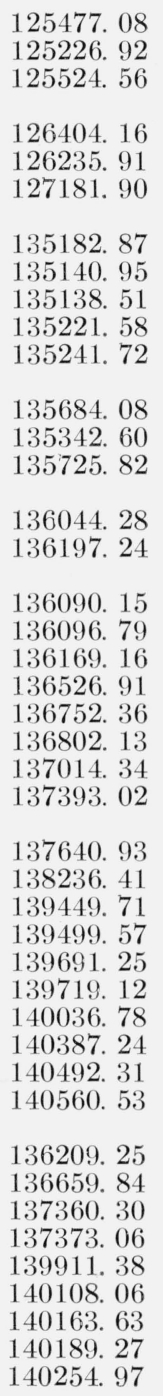 & $0.83 \mathrm{~L}$ & 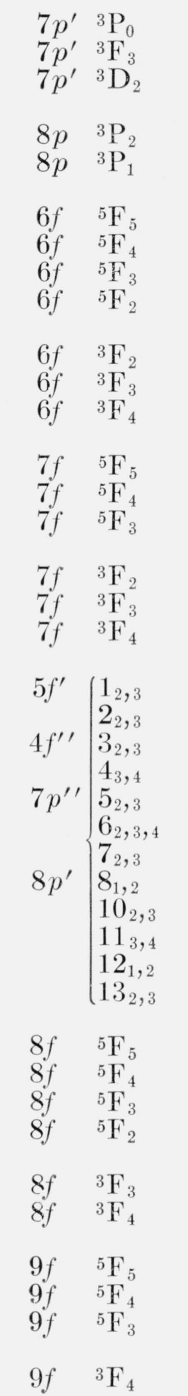 & $\begin{array}{l}140327.95 \\
140383.95 \\
142039.80 \\
136700.57 \\
136408.45 \\
141088.90 \\
141073.17 \\
141080.89 \\
141094.09 \\
141471.00 \\
141398.31 \\
141529.89 \\
144629.91 \\
144619.97 \\
144630.32 \\
144896.23 \\
144810.22 \\
144919.15 \\
146460.44 \\
146973.00 \\
147942.43 \\
148646.01 \\
148830.03 \\
148972.30 \\
149204.87 \\
149367.05 \\
150219.69 \\
150251.30 \\
150279.40 \\
150648.09 \\
146922.08 \\
146938.07 \\
146934.47 \\
146949.97 \\
147054.27 \\
147147.10 \\
148516.58 ? \\
148513.52 ? \\
148519.48 ? \\
148676.16\end{array}$ & \\
\hline
\end{tabular}

a The letter " $L$ " following a $g_{J}$ value indicates that the value is taken from Lacroute [3].

TABLE 10.4. Odd levels of I II

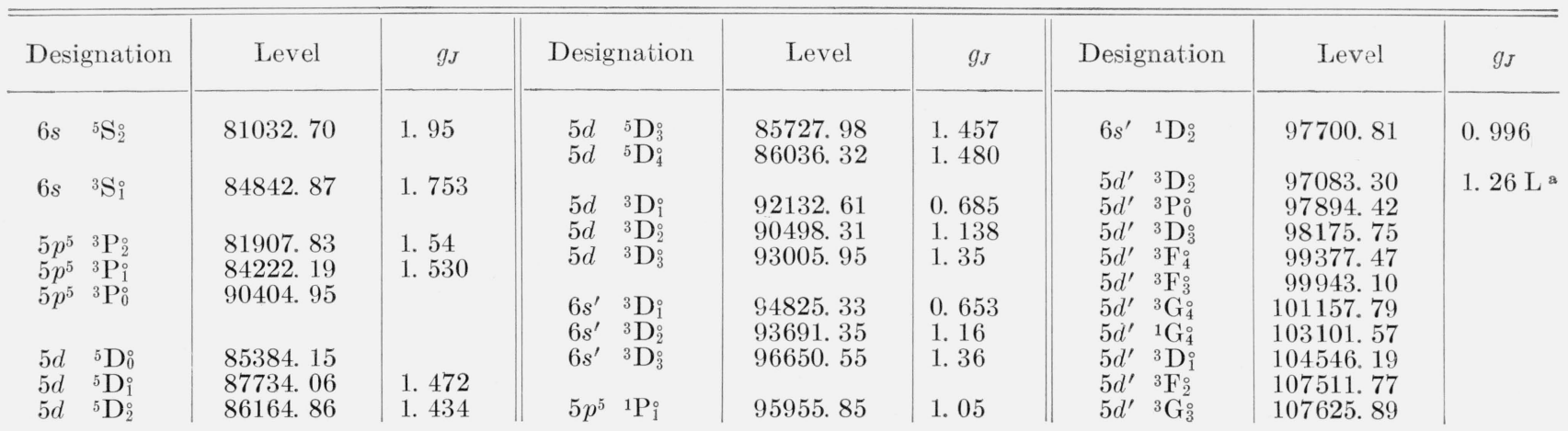


TaBle 10.4. Odd levels of I II-Continued

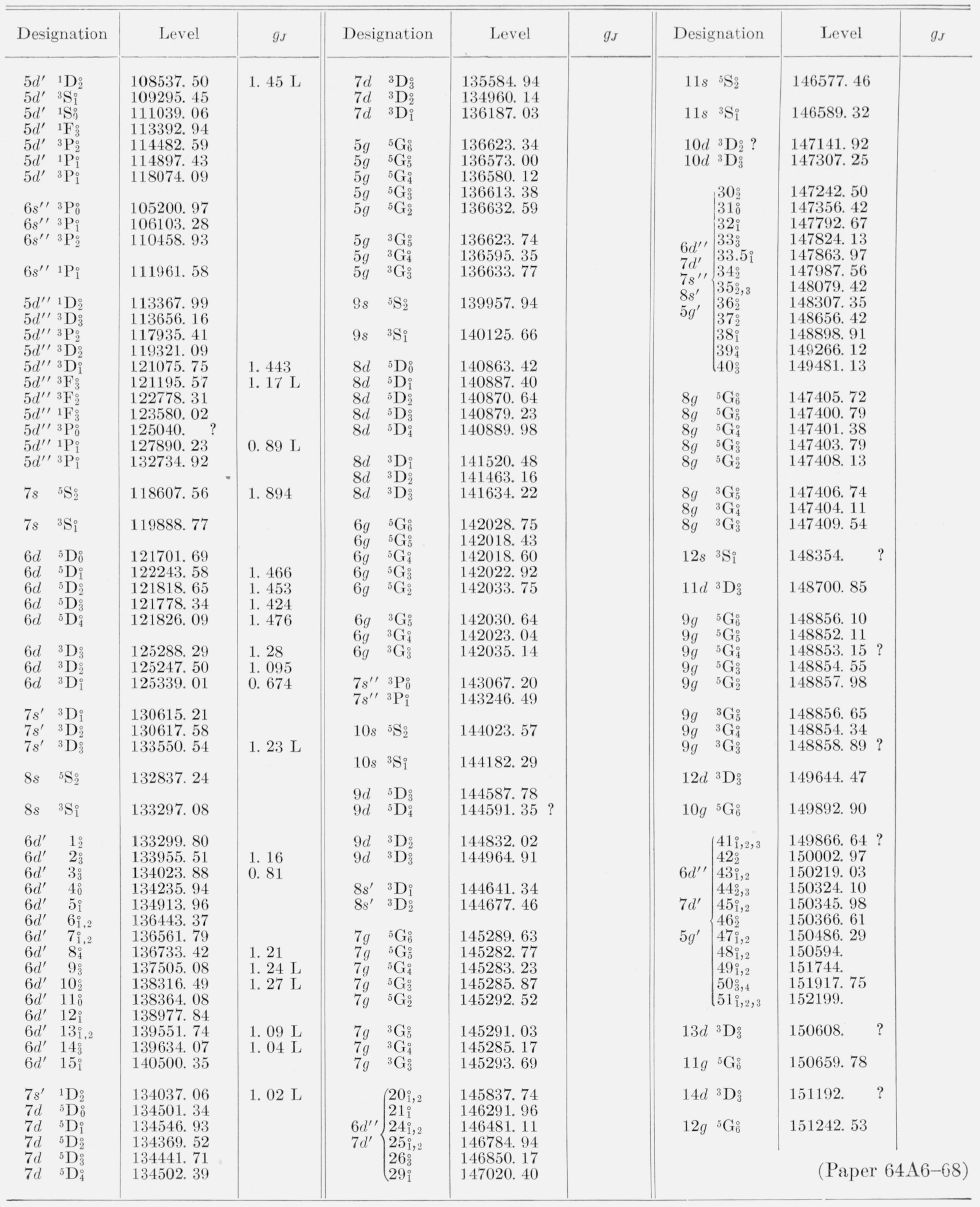

" The letter " $L$ " following a $g_{J}$ value indicates that the value is taken from Lacroute [3]. 